\title{
A proposal to measure absolute environmental sustainability in lifecycle assessment
}

Bjørn, Anders; Margni, Manuele; Roy, Pierre-Olivier; Bulle, Cécile ; Hauschild, Michael Zwicky

Published in:

Ecological Indicators

Link to article, DOI:

10.1016/j.ecolind.2015.11.046

Publication date:

2016

Document Version

Peer reviewed version

Link back to DTU Orbit

Citation (APA):

Bjørn, A., Margni, M., Roy, P-O., Bulle, C., \& Hauschild, M. Z. (2016). A proposal to measure absolute environmental sustainability in lifecycle assessment. Ecological Indicators, 63, 1-13.

https://doi.org/10.1016/j.ecolind.2015.11.046

\section{General rights}

Copyright and moral rights for the publications made accessible in the public portal are retained by the authors and/or other copyright owners and it is a condition of accessing publications that users recognise and abide by the legal requirements associated with these rights.

- Users may download and print one copy of any publication from the public portal for the purpose of private study or research.

- You may not further distribute the material or use it for any profit-making activity or commercial gain

- You may freely distribute the URL identifying the publication in the public portal 


\title{
A proposal to measure absolute environmental sustainability in Life Cycle Assessment
}

\author{
Anders Biørn ${ }^{1}$, Manuele Margni ${ }^{2}$, Pierre-Olivier Roy ${ }^{2}$, Cécile Bulle ${ }^{3}$ and Michael Zwicky \\ Hauschild $^{1}$ \\ ${ }^{1}$ The Technical University of Denmark, Produktionstorvet, Building 424, $2800 \mathrm{Kgs}$. Lyngby, Denmark \\ ${ }^{2}$ CIRAIG, Polytechnique Montréal, 2500, chemin Polytechnique, H3T 1J4, Montréal (QC), Canada \\ ${ }^{3}$ CIRAIG, Ecole des Sciences de la Gestion, Université du Québec à Montréal, 315, rue Sainte-Catherine \\ Est, H2X 3X2, Montréal (QC), Canada \\ E-mail contact : anbjo@dtu.dk
}

\begin{abstract}
Environmental monitoring indicates that progress towards the goal of environmental sustainability in many cases is slow, non-existing or negative. Indicators that use environmental carrying capacity references to evaluate whether anthropogenic systems are, or will potentially be, environmentally sustainable are therefore increasingly important. Such absolute indicators exist, but suffer from shortcomings such as incomplete coverage of environmental interferences, varying data quality and varying or insufficient spatial resolution. The purpose of this article is to demonstrate that Life Cycle Assessment (LCA) can potentially reduce or eliminate these shortcomings.

We developed a generic mathematical framework for the use of carrying capacity as environmental sustainability reference in spatially resolved life cycle impact assessment models and applied this framework to the LCA impact category terrestrial acidification. In this application carrying capacity was expressed as acid deposition (eq. $\mathrm{mol} \mathrm{H}^{+}$.ha $\mathrm{a}^{-1}$.year ${ }^{-1}$ ) and derived from two complementary $\mathrm{pH}$ related thresholds. A geochemical steady-state model was used to calculate a carrying capacity corresponding to these thresholds for 99,515 spatial units worldwide. Carrying capacities were coupled with deposition factors from a global deposition model to calculate characterisation factors (CF), which expresses space integrated occupation of carrying capacity (ha-year) per kg emission. Principles for calculating the entitlement to carrying capacity of anthropogenic systems were then outlined, and the logic of considering a studied system environmentally sustainable if its indicator score (carrying capacity occupation) does not exceed its carrying capacity entitlement was demonstrated. The developed CFs and entitlement calculation principles were applied to a case study evaluating emission scenarios for personal residential electricity consumption supplied by production from 45 US coal fired electricity plant.

Median values of derived CFs are $0.16-0.19$ ha $\cdot$ year $\cdot \mathrm{kg}^{-1}$ for common acidifying compounds. CFs are generally highest in Northern Europe, Canada and Alaska due to the low carrying capacity of soils in these regions. Differences in indicator scores of the case study emission scenarios are to a larger extent driven by variations in pollution intensities of electricity plants than by spatial variations in CFs. None of the 45 emission scenarios could be considered environmentally sustainable when using the relative contribution to GDP or the grandfathering (proportionality to past emissions) valuation principles to calculating carrying capacity entitlements. It is argued that CFs containing carrying capacity references are complementary to existing CFs in supporting decisions aimed at simultaneously reducing environmental interferences efficiently and maintaining or achieving environmental sustainability.
\end{abstract}


We have demonstrated that LCA indicators can be modified from being relative to being absolute indicators of environmental sustainability. Further research should focus on quantifying uncertainties related to choices in indicator design and on reducing uncertainties effectively.

\section{Keywords:}

LCA; Terrestrial acidification; Carrying capacity; characterisation factors; entitlement

\section{Introduction}

During the last decades the number of sustainability indicators and their use in decision-making has greatly increased (Hak et al., 2012; Singh et al., 2012). Many such indicators rank the sustainability of anthropogenic systems. For instance Switzerland ranked highest and Somalia lowest in the 2014 Environmental Performance Index of countries (Hsu et al., 2014). Another example is Greenpeace's Guide to Greener Electronics (2012b;2012a), which ranks 16 large electronics companies. Here we term indicators used for ranking relative environmental sustainability indicators (RESI) because indicator scores of studied anthropogenic systems are relative because they are evaluated by comparison to indicator scores of one or more reference systems, chosen specifically to match the nature or function of the studied system. While RESI can reveal how the sustainability performance of system $X$ compare to that of a chosen reference system, it cannot evaluate whether system $X$ can be considered sustainable on an absolute scale (Moldan et al., 2012). This limitation is very problematic considering that the state of the environment is declining by and large (Steffen et al., 2015; WRI, 2005). Therefore the global economy and its subsystems are in fact drifting further away from the goal of environmental sustainability, originally defined as "seek[ing] to improve human welfare by protecting the sources of raw materials used for human needs and ensuring that the sinks for human wastes are not exceeded, in order to prevent harm to humans" (Goodland 1995).

This shortcoming of RESI may be addressed by supplementing RESI by indicators containing reference values of environmental sustainability (Moldan et al., 2012). We term such indicators absolute environmental sustainability indicators (AESI) because the environmental sustainability references are absolute, since they are based on characteristics of natural systems independent of the study. While ranking of products or systems is also possible in AESI, the environmental sustainability of a system can additionally be evaluated on an absolute scale, i.e. answering the question "is system X environmentally sustainable or not?" Figure 1 illustrates the difference and complementarity between RESI and AESI. 
a)

Reference of choice

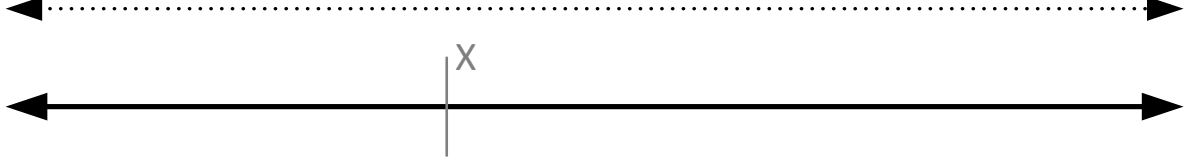

Higher interference

Lower interference

b)

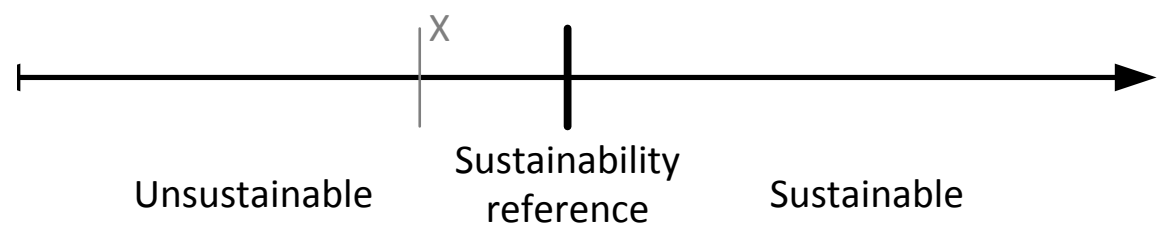

Figure 1: The concepts of relative (a) and absolute (b) environmental sustainability indicators. The ranking of the hypothetical system $X$ depends on the chosen reference(s) (a). System $X$ is environmentally unsustainable because its environmental interference is higher than the sustainability reference (b).

The concept of carrying capacity (Sayre, 2008) can be applied in AESI to operationalize and quantify references for environmental sustainability as defined by Goodland (1995). Following Bjørn and Hauschild (2015) we define carrying capacity as "the maximum sustained environmental interference a natural system can withstand without experiencing negative changes in structure or functioning that are difficult or impossible to revert." Here we use "environmental interference" as a generic term for anthropogenic changes to any point in an impact pathway (from emission or resource use to ultimate damage). It follows that total environmental interferences on natural systems, whether caused by resource uses or emissions, can be considered environmentally sustainable if their level is below the affected eco-system's carrying capacity.

"Footprinting" indicators, that use carrying capacity as sustainability reference value, can be characterized as AESI. The popular ecological footprint indicator expresses demands on nature in units of "global hectares" and compares this to land availability (termed "biocapacity") to facilitate an evaluation of whether demands are environmentally sustainable (Borucke et al., 2013). This has inspired other footprint indicators such as the well-established water footprint (Hoekstra and Mekonnen, 2012) and first generation chemical footprints (Bjørn et al., 2014; Zijp et al., 2014). Existing footprinting indicators, however, have weaknesses such as: 1 ) the incomplete coverage of all environmental interferences that are threatening environmental sustainability, 2) the varying data sources which are generally crude for assessments at the product scale (Huijbregts et al., 2008; Kitzes et al., 2009), 3) the variations in spatial resolution amongst footprints ${ }^{1}$, which can be a source of bias due to the potentially high spatial variability of carrying capacity (Bjørn and Hauschild, 2015), and 4) the inconvenience for users that each indicator is made available by means of a unique software tool. We believe that the life cycle assessment (LCA) method has the potential to overcome these weaknesses of current AESI.

\footnotetext{
${ }^{1}$ The ecological footprint normalises land demands in the unit "global hectares", which means that indicator results are unaffected by spatial differences in yield, while water- and chemical footprints are spatially resolved to varying extents.
} 
LCA aims to cover all relevant environmental interferences over the life cycle (from raw materials to waste management) of a product (or other anthropogenic systems). LCA requires a life cycle inventory (LCI), which compiles the physical inputs and outputs (resource uses and emissions) of a product during its life cycle, and is commonly based on product system specific data supplemented by a common life cycle inventory database of unit processes (e.g. the average electricity generation of a country). LCA uses characterisation factors (CFs), which express the relationship between the resource uses or emissions of a $\mathrm{LCl}$ and measures of resulting environmental interference. CFs are obtained from mathematical representations of cause effect-chains that can be spatially resolved and allow the conversion of a $\mathrm{LCl}$ into indicator scores for a number of mutually exclusive and collectively exhaustive "impact categories" such as climate change, eutrophication and eco-toxicity.

The characteristics of LCA make it potentially suitable for reducing or eliminating the listed weaknesses of current AESI. However LCA indicators can be characterized as RESI: Indicator scores are typically used to rank the environmental performance of functionally comparable product systems or scenarios, based on their potential to, via their emissions or resource uses, create a small change in the level of environmental interferences. This small change is either calculated as a marginal change in the known existing level of environmental interference or as an approximated linear change in interference within the zone between 0 and a chosen level of interference (see S1 for a conceptual figure of the two approaches) (Hauschild and Huijbregts, 2015). LCA indicators therefore generally do not include carrying capacity as sustainability reference values (Castellani and Sala, 2012). To harness the potentials of LCA in AESI, LCA indicators need to be modified to quantifying occupations of carrying capacity instead of quantifying small changes in levels of environmental interferences. The overall purpose of this article is to provide an initial contribution to this development.

This article aims to 1) develop a generic mathematical expression for calculating spatially resolved occupation of carrying capacity for any emissions based LCA impact category, 2) use this method tentatively on the terrestrial acidification LCA impact category, 3) demonstrate the applicability of the method in a case study, , 4) compare the relevance and complementarity of AESI and RESI in decision support.

\section{Methods}

\subsection{Definitions and interpretations}

To support the operationalization of carrying capacity (defined as "the maximum sustained environmental interference a natural system can withstand without experiencing negative changes in structure or functioning that are difficult or impossible to revert") we introduce two definitions: 1 ) control variable: "a numerical indicator of the structure and/or functioning of a natural system."; 2) Threshold: "the maximum value of a control variable a natural system can withstand without experiencing negative changes in structure and/or functioning that are difficult or impossible to revert." The carrying capacity is generally closer to the cause in an impact pathway than the threshold from which it is derived. Carrying capacity is static because it is calculated from a situation where a control variable value equals a threshold value at steady state (Bjørn and Hauschild, 2015). Note that the definitions of threshold and carrying capacity leave room for interpretation (what are negative changes and at what point do these become difficult to revert?). This interpretative flexibility is intentional as it reflects the ambiguity in the definition of environmental 
sustainability of Goodland (1995) with respect to preventing "harm to humans": Humans may be physically harmed by a reduction of material eco-system services (e.g. access to clean water) caused by severe environmental degradation. According to some, humans may also be harmed culturally and spiritually by effects on or disappearance of a single vulnerable species caused by just minor environmental degradation. Environmental sustainability can thus be interpreted anthropocentrically or eco-centrically (or somewhere in between), which can greatly influence the choice of threshold and resulting quantification of carrying capacity. The sensitivity of AESI scores to this interpretation of environmental sustainability and other choices is analysed in Bjørn et al. (2015).

\subsection{Characterisation framework}

In LCA characterisation factors (CF) are multiplied with each inventoried emission or resource use (Q) of pollutants or resource $(x)$ that contribute to a given impact category and the products are summed to calculate the indicator score (IS) for that impact category:

$$
I S=\sum_{x} C F_{x} \cdot Q_{x}
$$

By integrating carrying capacity as sustainable reference value in CFs, indicator scores can be expressed as occupation of carrying capacity. We propose this integration by dividing spatially resolved conventional CF constituents by carrying capacity (CC) for any emissions based indicator (aim 1):

$$
C F_{x, i, k}=\sum_{j} \frac{F F_{x, i, k, j} \cdot X F_{i, j} \cdot E F_{i, j}}{C C_{j}}
$$

Here CF (ha*year* ${ }^{*} g_{\text {emitted }}{ }^{-1}$ ) is the characterisation factor for substance $\mathrm{x}$ emitted within spatial unit $\mathrm{i}$ into environmental compartment $\mathrm{k}$ (air, soil or water). $\mathrm{FF}$ is a fate factor linking an emission of pollutant $\mathrm{x}$ within $\mathrm{i}$ into $\mathrm{k}$ to its fate typically expressed as a change in concentration or mass in the receiving spatial unit $\mathrm{j}$. XF is an exposure factor which accounts for the fraction of pollutant $x$ that species of concern in $j$ are exposed to. $E F$ is an effect factor, which calculates the effect increase on these species in $\mathrm{j}$ from an increased exposure of $\mathrm{x} . \mathrm{CC}$ is the carrying capacity in $\mathrm{j}$. The metric of CC depends on the metrics of FF, XF and EF and differs from one impact category to another. Note that equation 2 applies to indicators of effects on species. If indicator scores are expressed closer to the cause of these effects the denominator should only contain FF or FF.XF. When following equation 1 by multiplying CFs with emissions $(\mathrm{kg})$ the indicator score is expressing the carrying capacity occupation in a unit of ha.year, which indicates an area in which carrying capacity for a given impact category is occupied for a time. If the time frame during which pollutants are emitted is known, the indicator score can be expressed in a unit of ha, which resembles that of the ecological footprint method (Borucke et al., 2013).

Note that our proposed framework is only compatible with indicators for which FF, XF or EF are of a linear nature, i.e. that calculate the approximated linear environmental change from an emission within the zone between 0 and a chosen level of interference (see S1). Our proposed framework is not compatible with marginal CF components because these are derivatives of estimated existing levels of environmental interference, while carrying capacity should be independent of existing levels of environmental interference (Bjørn and Hauschild, 2015). 


\subsection{Application to terrestrial acidification}

We demonstrate the calculation of proposed characterisation factors for the LCA impact category terrestrial acidification, for which no AESI currently exists (aim 2). The spatial derivation was based on the only existing global deposition model of Roy et al. (2012) having a $2.0^{\circ} \times 2.5^{\circ}$ resolution (i.e. composed of 13,104 grid cells).

\subsubsection{Choice of control variable and threshold}

As a basis for carrying capacity two complementary thresholds of the control variable "soil solution pH" were chosen. The first threshold was based on a deviation of natural $\mathrm{pH}$ corresponding to the point where the numerical decrease in $\mathrm{pH}$ starts increasing for every additional quantity of deposition. At this point the functioning of the soil ecosystem starts changing as the carbonate buffering system is weakening and additional depositions will bring the system close to its chemical $\mathrm{pH}$ threshold. ${ }^{2}$ Based on a screening of $\mathrm{pH}$ curves modelled with the geochemical steady-state model PROFILE (Warfvinge and Sverdrup, 1992) we found that a $\mathrm{pH}$ decrease of 0.25 , compared to natural $\mathrm{pH}$, generally corresponded well with this point where $\mathrm{pH}$ starts responding non-linearly to additional depositions (see S2). The second threshold was required to take into account naturally acidic soils for which the critical factor threatening ecosystem structure is not $\mathrm{pH}$ decrease, but rather the mobilisation of toxic aluminium (III) from the buffering of acid depositions through reaction with aluminium oxides and hydroxides from clay particles (Sparks, 2002). This buffering process occurs in the $\mathrm{pH}$ interval 2.8-4.2 and we therefore chose $\mathrm{pH} 4.2$, below which aluminium (III) starts to mobilize, as the second threshold. ${ }^{3}$ In other words, we interpreted environmental sustainability, with regards to the interference of acidifying compounds with natural soils, to correspond to a situation where natural buffer systems are not weakened and aluminium (III) is not mobilized.

\subsubsection{Calculation of carrying capacity}

The carrying capacity was, inspired by the critical loads concept (Spranger et al., 2004), expressed as a critical deposition of acidifying compounds (eq. ha $^{-1} \cdot$ year $^{-1}$, where 1 eq refers to 1 mol H$^{+}$-eq.). The carrying capacity was derived for 99,515 spatial units, covering the global terrestrial area (Roy et al., 2012a), by running PROFILE in 9 steps gradually increasing depositions of $\mathrm{SO}_{\mathrm{x}}$ above natural levels for each spatial unit until a change of $0.25 \mathrm{pH}$ units or an absolute $\mathrm{pH}$ value below 4.2 was reached. Natural depositions were modelled based on Tegen and Fung (1994) and Bey et al. (2001) as described in Roy et al. (2012b). The design of the 9 steps is explained in S2. We found that $10 \%$ of spatial units were for at least one deposition step affected by a non-convergence error in PROFILE. For these cells the carrying capacity was approximated by neighbouring cells using a kriging function, see S4. Area-weighted averages of the carrying capacities of the 99,515 spatial units of PROFILE were used to estimate the carrying capacities of the 13,104 grid cells of the deposition model of Roy et al. (2012). CFs were then calculated according to equation 2

\footnotetext{
${ }^{2}$ We did not choose the steepest point of the chemical $\mathrm{pH}$ threshold as basis for carrying capacity because this point is often $2 \mathrm{pH}$ units or more below natural $\mathrm{pH}$, which represents a $\mathrm{pH}$ decrease that few species can tolerate (Azevedo et al., 2013) and can therefore not be considered as reference for environmental sustainability.

${ }^{3}$ Our choice of an absolute threshold of $4.2 \mathrm{pH}$ units is in good agreement with a proposal within the critical loads framework that a pH of 4 could be used to calculate critical loads for forest soils (Spranger et al., 2004).
} 
using atmospheric fate factors (FF, keq $_{\text {deposited }}{ }^{*} \mathrm{~kg}_{\text {emitted }}{ }^{-1}$ ) of Roy et al. $(2012)^{4}$ and excluding XF and EF in the denominator because $\mathrm{CC}$ is expressed as a critical deposition:

$$
C F_{x, i}=\sum_{j} \frac{F F_{x, i, j}}{C C_{j}}
$$

\subsection{Carrying capacity entitlement}

Our CFs can in principle be used to evaluate whether a society as a whole is environmentally sustainable because the indicator score, expressing the area equivalent of fully occupied carrying capacity, from all activities of the society can be compared to the actual area of the relevant ecosystem. An individual system embedded in society, such as a product, a person or company, can in turn be considered environmentally sustainable if it does not occupy more of the total carrying capacity than it can be considered entitled to. Carrying capacity entitlement is a normative concept because it depends on the perceived value of a studied system relative to those of "competing systems" that rely on occupying carrying capacity in the same area where the studied system occupies carrying capacity. Therefore environmental sustainability references for individual anthropogenic systems embedded in society are inherently normative. Below we outline three steps in deriving and applying these environmental sustainability references

\subsubsection{Identify competing systems}

Ideally competing systems would be identified by combining a source-receptor fate model with a spatially differentiated emission inventory covering all anthropogenic systems of society in a chosen reference year: The fate model would first identify the spatial units affected by emissions of the studied system. The fate model would then identify all the systems of the societal total emission inventory whose emissions affect the spatial units previously identified. These systems would be labeled competing systems because they rely on occupying parts of the same carrying capacity as the studied system for their functioning. Note that the group of competing systems is potentially unique for each affected spatial unit (of which there may be thousands). This is impractical to operate with and therefore three simplifications are introduced: 1) a cutoff criterion is established whereby only spatial units receiving above a specified share of emissions from the studied system (e.g. $0.1 \%$ ) are considered (the territory of these spatial units are termed $T_{\text {affected }}$ and its area is termed $A_{\text {affected }}$, 2) all emissions that occur within $T_{\text {affected }}$ are, in this part of the AESI, assumed to occur in the spatial unit where the emission from the studied system occurs and thus assumed to have the same fate, 3 ) it is assumed that no emissions within $T_{\text {affected }}$ leave $T_{\text {affected }}$ and that no emissions from outside enters. These three simplifications are visually presented in Figure 2.

\footnotetext{
${ }^{4}$ The fate factors of Roy et al. (2012) were expressed in $\mathrm{kg}_{\text {deposited }}{ }^{*} \mathrm{~kg}_{\text {emitted }}{ }^{-1}$. For this study $\mathrm{kg}_{\text {deposited }}$ was converted to $\mathrm{keq}_{\text {deposited }}$ by division by the molecular weight of the emissions and multiplication by the electrical charges of their corresponding ions, following Posch et al. (2008).
} 


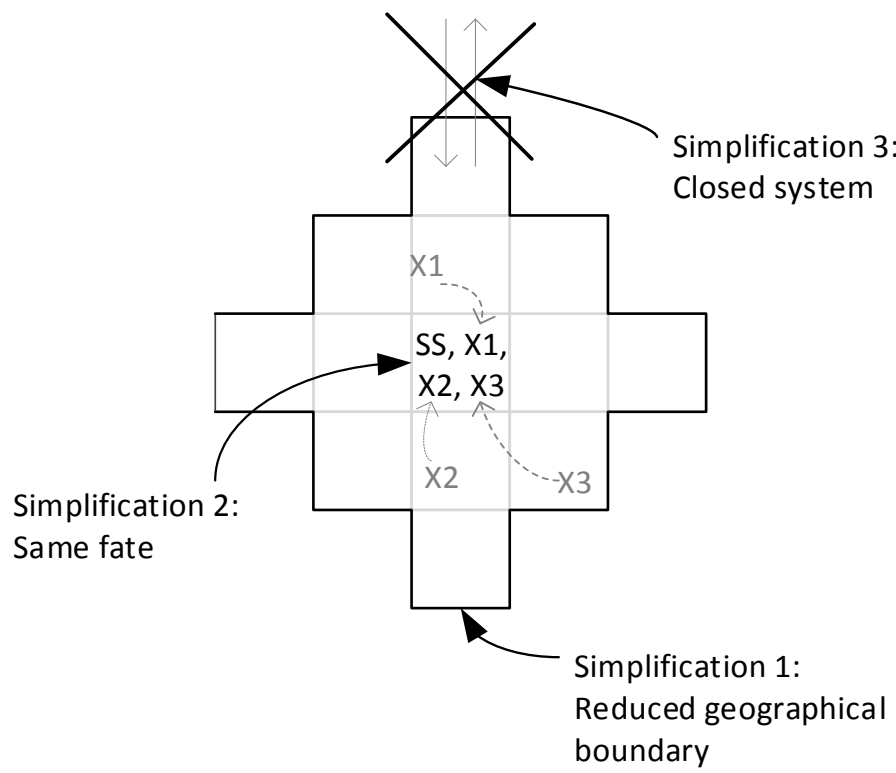

Figure 2: Illustration of three simplifications for identifying competing systems (X1-X3) of a studied system (SS) located in the middle grid cell and affecting 13 grid cells above an arbitrary emission distribution threshold. These 13 grid cells make up $T_{\text {affected }}$ and have the area $A_{\text {affected }}$. The dotted arrows indicate a change in location of X1-X3.

The consequence of the simplifications is that only one carrying capacity entitlement needs to be calculated for each emission location of a studied system and that the group of competing systems is the same for all anthropogenic systems within $T_{\text {affected. }}$. The simplifications can be defended in situations where potential competing systems are rather homogenously distributed in space and have emissions of similar magnitude. When this is not the case it may be more appropriate to follow the ideal approach outlined above to identifying competing systems.

\subsubsection{Quantify relative value of studied system}

The perceived value of a studied system relative to identified systems competing for carrying capacity in the same territory may be quantified using different valuation principles, such as 1) relative contribution to GDP, or 2) "grandfathering" where the relative value of a system is considered proportional to its relative indicator score in a chosen past reference year (i.e. if total carrying capacity was exceeded in the reference year, the indicator scores of all systems in that reference year should be reduced by the percentage that is needed to reduce the total indicator score below the total carrying capacity. The perceived relative value of a studied system may be expressed as a value factor (VF) between 0 and 1 of the total value (i.e. the sum of the perceived value of the studied system and those of competing systems).

\subsubsection{Calculate carrying capacity entitlement and compare to AESI score}

The time-integrated area in which carrying capacity can be entitled to a studied system ( $A_{\text {entitled, }}$ in ha·year) can be calculated by multiplying $A_{\text {affected }}$ for the studied system by the duration of the emissions $(t)$ and the value factor (VF) for each emissions location (i):

$$
A_{\text {entitled } \_i}=A_{\text {affected } \_i} \cdot t_{i} \cdot V F_{i}
$$

If $A_{\text {entitled }}$ exceeds the AESI score of a studied system for one or more emission locations (i) the studied system cannot be considered environmentally sustainable. 


\subsection{Case study}

We applied the derived CFs to emissions caused by the electricity production from one randomly selected coal fired electricity plant in each of 45 states of contiguous United States ${ }^{5}$ in 2010. For each of the electricity plants we calculated an emission inventory corresponding to the residential electricity consumption of an average inhabitant in the concerned state in the year 2010. The case study provided a vehicle for demonstrating the use of the proposed indicator for terrestrial acidification on 45 scenarios of realistic residential electricity consumption in a hypothetical situation where this is entirely fuelled by coal (aim 3). ${ }^{6}$ We use the term "scenario" to stress that we are not attempting to model the actual situation. The case study also allows for discussing the relevance of LCA-supported AESI compared to using LCA to rank environmental performance (aim 4).

State specific per capita annual residential electricity consumption was obtained from the US Department of Energy (DoE, 2015) and used to define the quantities of electricity produced (P) by each of 45 power plants (i) to meet the demand by an average inhabitant. Power plant specific emissions intensities (EI) expressing emissions of $\mathrm{SO}_{\mathrm{x}}$ and $\mathrm{NO}_{\mathrm{x}}(\mathrm{x})$ per $\mathrm{kWh}$ of generated electricity were obtained from the eGRID database of the US EPA (2014), which contains data on a total of 541 US coal fired electricity plants in 45 states. ${ }^{7}$ El was multiplied by $\mathrm{P}$ to obtain the emissions $(\mathrm{Q})$ of $\mathrm{SO}_{\mathrm{x}}$ and $\mathrm{NO}_{\mathrm{x}}$ per power plant (i). Indicator scores (IS) for each power plant were hence, following equation 1 , calculated as:

$$
I S_{i}=\sum_{x} C F_{i, x} \cdot Q_{x}=\sum_{x} C F_{i, x} \cdot P_{i} \cdot E I_{i, x}
$$

Here $\mathrm{CF}_{i, \mathrm{k}}$ is the characterisation factor derived for pollutant $\mathrm{x}\left(\mathrm{SO}_{\mathrm{x}}\right.$ or $\left.\mathrm{NO}_{\mathrm{x}}\right)$ for the grid cell in which power plant $\mathrm{i}$ is located.

Indicator scores were evaluated by comparing them to carrying capacity entitlements calculated following the simplified approach outlined above: We used the fate model of Roy et al. (2012) to identify spatial units receiving depositions caused by emissions of the different power plants. This global model predicts that all its 13,104 grid cells receives a share of an emission from any of the power plants (Roy et al., 2012b). However, most grid cells receive a very small share. For identifying competing systems we therefore used a cut-off value of $0.1 \%$ deposition of an emission. This resulted in an affected territory $\left(T_{\text {affected }}\right)$ for each $i$ in which around $70 \%$ of an emission deposits (depending on the pollutant and i). ${ }^{8} \mathrm{~A}_{\text {affected }}$ (the area of $\mathrm{T}_{\text {affected }}$ ) for all $i$ and both pollutant were found to be approximately equivalent to the area of the entire contiguous United States. Since all power plants are located in contiguous United States there is a great geographical overlap between $T_{\text {affected }}$ of the 45 emission scenario locations. This overlap justified the additional simplification of assigning the terrestrial contiguous United States a common $\mathrm{T}_{\text {affected }}$ and its area, $765,300,400$ ha $\left(\right.$ USCB, 2012), a common $A_{\text {affected }}$ for all i. Competing systems for all $i$ are consequently all systems that emit acidifying compounds to air within the contiguous United States.

\footnotetext{
${ }^{5}$ The contiguous United States consists of the 48 adjoining U.S. states plus Washington, D.C. (federal district).

${ }^{6}$ In reality residential electricity use is supplied by various energy technologies that, due to an integrated federal grid, may be located far away (i.e. in another state) than the location of consumption.

${ }^{7}$ The states of Maine, Rhode Island and Vermont were not covered by the eGRID database of coal fired electricity plants, presumably because they have none.

${ }^{8}$ The remaining share of an emission, on average $30 \%$, deposits on grid cells receiving less than $0.1 \%$ of the emission and accumulates in high altitude, near the stratosphere.
} 
In quantifying the value factors (VF) of the 45 studied emissions scenarios two alternative valuations were applied to explore the sensitivity of case study outcomes to this form of value judgment. The first valuation was based on the relative contribution to GDP, estimated by dividing personal or household expenditure on a studied product or service by pre-tax income. In 2009 (no data for 2010) an average US household spent $2.0 \%$ of its pre-tax income on residential electricity (ACCCE, 2014). The relative contribution to GDP valuation principle thus grants residential electricity consumption a value of 0.02 relative to all anthropogenic systems within $\mathrm{T}_{\text {affected }}$. The alternative valuation was based on the grandfathering principle, according to which US residential electricity consumption is entitled to maintain its past share of total environmental interferences. In 2010 38\% of US total electricity consumption was consumed by the residential sector (IEA, 2012), meaning that $38 \%$ of environmental interferences from total electricity consumption could be attributed to the residential sector. We could not obtain the share of environmental interference taken up by total electricity consumption of the total US environmental interference with respect to terrestrial acidification. We therefore approximated this share by the corresponding share in EU27, where in $201023 \%$ of total environmental interferences was presumably taken up by electricity production. ${ }^{9}$ Our use of the grandfathering valuation principle thus grants residential electricity consumption in the US a tentative value of $9 \%$ (38\% of $23 \%$ ) relative to all anthropogenic systems within $T_{\text {affected. }}$.

Since both valuation principles were applied to average residential electricity consumption in the US, the value factors for the 45 scenarios are the same (i.e. not calculated specifically for each emissions scenario, although this is in theory possible) and can be calculated by dividing the nationwide relative values with the population of contiguous United States (306,675,006 in 2010 (USCB, 2015)). A entitled was subsequently calculated for the alternative valuation principles following equation 4 :

Relative contribution to GDP:

$A_{\text {entitled }}=A_{\text {affected }} \cdot t \cdot V F=765,300,400 \mathrm{ha} \cdot 1$ year $\cdot \frac{0.02}{306,675,006}=0.050 \mathrm{ha} \cdot$ year

Grandfathering:

$A_{\text {entitled }}=A_{\text {affected }} \cdot t \cdot V F=765,300,400 \mathrm{ha} \cdot 1$ year $\cdot \frac{0.09}{306,675,006}=0.22 \mathrm{ha} \cdot$ year

The two alternative $A_{\text {entitted }}$ were compared to the indicator scores of the 45 scenarios to evaluate which of them could be considered environmentally sustainable. We then compared the spatial variation in each of the components of equation 5 , including the CF components of equation 3 , to analyse the sensitivity of indicator scores of the 45 scenarios to each of these components. As a basis for discussing the relevance of AESI compared to RESI we furthermore compared the CFs of the 45 power plant locations with corresponding CFs of Roy et al. (2014).

\footnotetext{
${ }^{9}$ Environmental interferences were calculated using the tentative CFs for terrestrial acidification developed in this study (average of the 45 emission locations) on the emission inventory for EU27 of EMEP (2015). The sector "Combustion in energy and transformation industries (stationary sources)" of the EMEP inventory was assumed to cover electricity production only.
} 


\section{Results}

\subsection{Carrying capacities and characterisation factors}

Estimated carrying capacities (CC) ranged from less than 100 eq. $\cdot \mathrm{ha}^{-1} \cdot \mathrm{year}^{-1}$ to more than $4000 \mathrm{eq} \cdot \mathrm{ha}^{-1} \cdot \mathrm{year}^{-}$ ${ }^{1}$ with a median value around $500 \mathrm{eq} \cdot \mathrm{ha}^{-1} \cdot \mathrm{year}^{-1}$. The global distribution is shown in S5. Numerical CFs for all 13,104 grid cells for $\mathrm{NO}_{\mathrm{x}}, \mathrm{SO}_{\mathrm{x}}$ and $\mathrm{NH}_{\mathrm{x}}$ are available in a spreadsheet in $\mathrm{S} 6$, from which they may be exported to LCA software such as GaBi (Thinkstep, 2015) or Simapro (PRé, 2015) and thereby linked to LCI databases such as Ecolnvent (2015). CFs for $\mathrm{SO}_{x}$ ranged from less than 0.0054 ha $\cdot y e a r \cdot \mathrm{kg}^{-1}\left(10^{\text {th }}\right.$ percentile) to more than $0.41 \mathrm{ha} \cdot \mathrm{year} \cdot \mathrm{kg}^{-1}\left(90^{\text {th }}\right.$ percentile) with a median value of $0.16 \mathrm{ha} \cdot \mathrm{year} \cdot \mathrm{kg}^{-1}$ (when excluding CFs for locations in the open sea, which are generally close to 0 ). In absolute terms the median $\mathrm{CF}_{\text {for }} \mathrm{SO}_{x}$ can be interpreted as $1 \mathrm{~kg} \mathrm{SO}$ emitted occupying the carrying capacity of 0.048 hectares (corresponding to a square with $22 \mathrm{~m}$ sides) for 1 year. Figure 3 shows the distribution of $\mathrm{CFs}$ for all global locations of $\mathrm{NO}_{\mathrm{x}}$, $\mathrm{SO}_{\mathrm{x}}$ and $\mathrm{NH}_{\mathrm{x}}$.

\section{a) NOx}

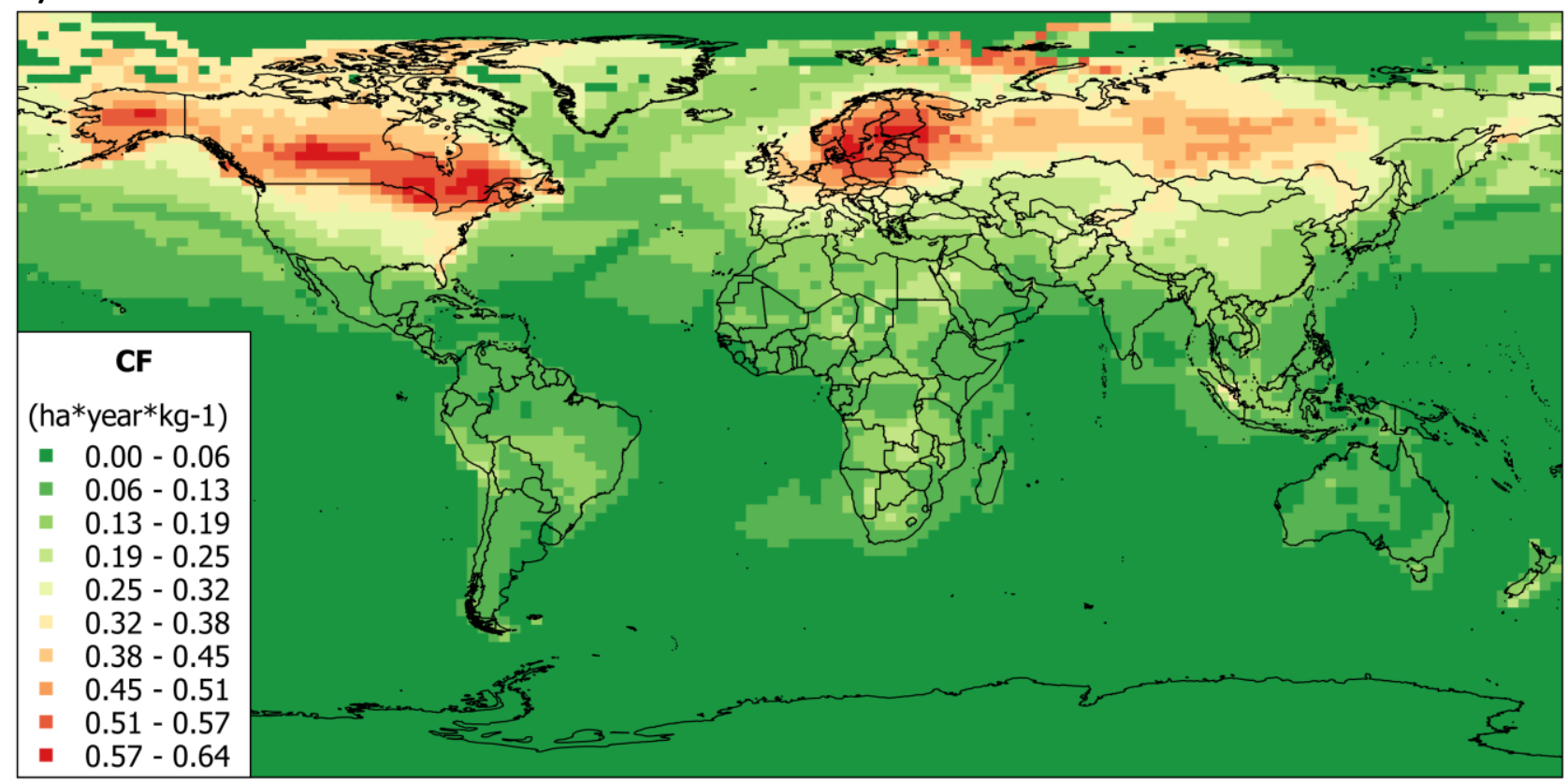




\section{c) $\mathrm{NHx}$}

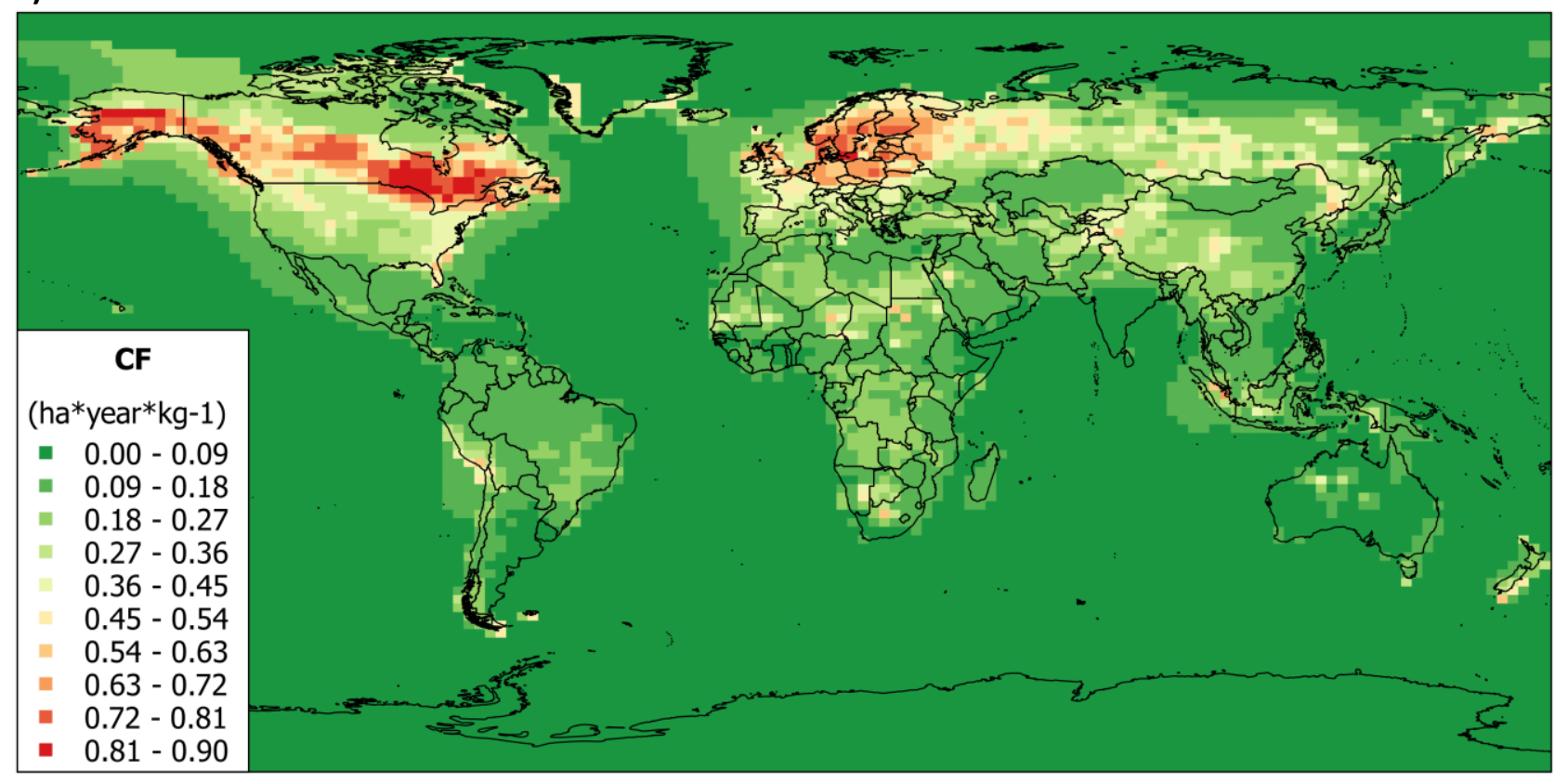

Figure 3: Global distribution of CFs for $\mathrm{NO}_{\mathrm{x}}(\mathrm{a}), \mathrm{SO}_{\mathrm{x}}(\mathrm{b})$ and $\mathrm{NH}_{\mathrm{x}}(\mathrm{c})$

It can be seen that CFs are generally highest in Northern Europe, Canada and Alaska, which is caused by the relatively low carrying capacity of soils in these regions (see S5). The highest CFs for $\mathrm{NO}_{\mathrm{x}}, \mathrm{SO}_{\mathrm{x}}$ and $\mathrm{NH}_{\mathrm{x}}$ corresponds to emission locations in Canada (latitude $55^{\circ}$; longitude $-112.5^{\circ}$ ), Denmark/Sweden (latitude $55^{\circ}$, longitude $12.5^{\circ}$ ) and Alaska (latitude $65^{\circ}$, longitude $-157.5^{\circ}$ ) respectively. It can also be seen that local differences in CFs (e.g. between neighbouring cells) are lowest for $\mathrm{NO}_{\mathrm{x}}$, higher for $\mathrm{SO}_{\mathrm{x}}$ and highest for $\mathrm{NH}_{\mathrm{x}}$. This is because the share of an emission that deposits in or close to the emission cell is largest for $\mathrm{NH}_{\mathrm{X}}$, 
smaller for $\mathrm{SO}_{\mathrm{x}}$ and smallest for $\mathrm{NO}_{\mathrm{x}} \cdot{ }^{10}$ In other words, local differences in carrying capacity have a much larger influence on $\mathrm{CFs}$ for $\mathrm{NH}_{\mathrm{x}}$ than for $\mathrm{NO}_{\mathrm{x}}$. This observation was also made by Huijbregts et al. (2000) for the spatial pattern of European CFs based on the critical loads concept (Spranger et al., 2004).

\subsection{Case study}

Table 1 shows the input parameters for equation 5 and indicator scores for the 45 emission scenarios.

Table 1: Input parameters for equation 5, indicator scores and comparison to two carrying capacity entitlements for 45 scenarios in the reference year 2010.

\begin{tabular}{|c|c|c|c|c|c|c|c|c|c|c|c|c|c|}
\hline 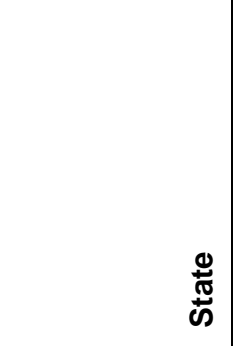 & 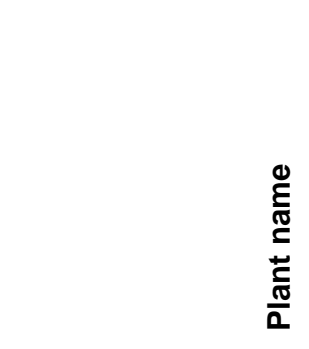 & 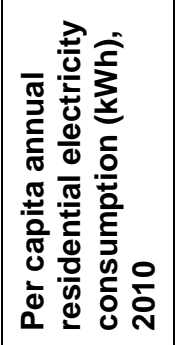 & 姜 & 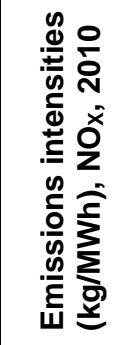 & 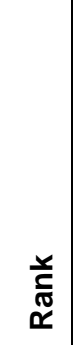 & 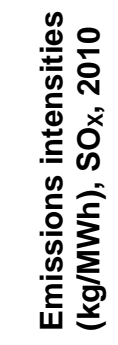 & 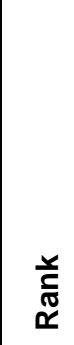 & 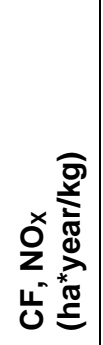 & 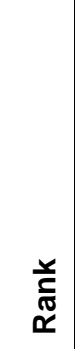 & 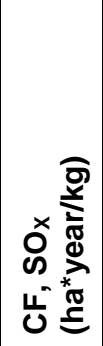 & 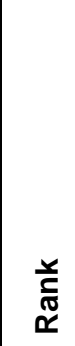 & 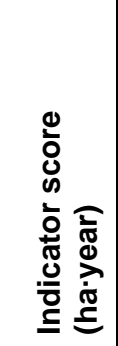 & 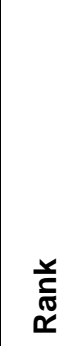 \\
\hline Alabama & Barry & 7425 & 1 & 0.50 & 37 & 1.11 & 26 & 0.23 & 38 & 0.24 & 37 & 2.81 & 29 \\
\hline Arkansas & White Bluff & 6584 & 8 & 1.31 & 18 & 2.36 & 22 & 0.24 & 36 & 0.24 & 34 & 5.85 & 19 \\
\hline Arizona & Coronado & 5060 & 23 & 1.83 & 16 & 1.70 & 24 & 0.16 & 44 & 0.17 & 44 & 2.92 & 28 \\
\hline California & Stockton Cogen & 2337 & 45 & 0.14 & 45 & 0.68 & 35 & 0.13 & 45 & 0.12 & 45 & 0.23 & 45 \\
\hline Colorado & Rawhide & 3587 & 37 & 0.73 & 30 & 0.35 & 39 & 0.31 & 25 & 0.36 & 6 & 1.28 & 39 \\
\hline Connecticut & Bridgeport Station & 3655 & 36 & 0.70 & 31 & 0.94 & 30 & 0.38 & 8 & 0.34 & 10 & 2.16 & 32 \\
\hline Delaware & $\begin{array}{l}\text { NRG Energy Center } \\
\text { Dover }\end{array}$ & 5295 & 20 & 2.32 & 9 & 5.24 & 9 & 0.35 & 13 & 0.31 & 19 & 12.87 & 10 \\
\hline Florida & Big Bend & 6489 & 11 & 0.48 & 38 & 0.96 & 29 & 0.34 & 17 & 0.44 & 3 & 3.85 & 25 \\
\hline Georgia & Bowen & 6338 & 12 & 0.28 & 41 & 0.30 & 40 & 0.33 & 22 & 0.32 & 16 & 1.20 & 40 \\
\hline lowa & $\begin{array}{l}\text { Walter Scott Jr } \\
\text { Energy Center }\end{array}$ & 4572 & 29 & 0.59 & 34 & 1.09 & 27 & 0.31 & 26 & 0.27 & 26 & 2.29 & 31 \\
\hline Idaho & $\begin{array}{l}\text { Amalgamated Sugar } \\
\text { LLC Nampa }\end{array}$ & 5180 & 21 & 3.53 & 4 & 11.60 & 4 & 0.28 & 30 & 0.27 & 28 & 21.26 & 5 \\
\hline Illinois & $\begin{array}{l}\text { John Deere } \\
\text { Harvester Works }\end{array}$ & 3783 & 35 & 3.80 & 3 & 20.56 & 2 & 0.33 & 19 & 0.28 & 24 & 26.89 & 2 \\
\hline Indiana & $\begin{array}{l}\text { Sagamore Plant } \\
\text { Cogeneration }\end{array}$ & 5402 & 19 & 2.58 & 6 & 11.00 & 5 & 0.30 & 27 & 0.25 & 31 & 18.87 & 7 \\
\hline Kansas & $\begin{array}{l}\text { Tecumseh Energy } \\
\text { Center }\end{array}$ & 5014 & 24 & 1.34 & 17 & 3.17 & 16 & 0.27 & 32 & 0.24 & 36 & 5.64 & 20 \\
\hline Kentucky & Ghent & 6703 & 7 & 0.57 & 35 & 0.82 & 31 & 0.30 & 28 & 0.27 & 27 & 2.64 & 30 \\
\hline Louisiana & Dolet Hills & 7190 & 2 & 0.91 & 27 & 4.10 & 10 & 0.20 & 40 & 0.21 & 39 & 7.56 & 15 \\
\hline Massachusetts & Salem Harbor & 3266 & 42 & 0.87 & 29 & 4.01 & 11 & 0.33 & 21 & 0.29 & 23 & 4.68 & 23 \\
\hline Maryland & $\begin{array}{l}\text { Morgantown } \\
\text { Generating Plant }\end{array}$ & 5002 & 25 & 0.24 & 42 & 0.67 & 36 & 0.33 & 18 & 0.31 & 18 & 1.43 & 37 \\
\hline Michigan & Belle River & 3511 & 38 & 0.99 & 25 & 2.74 & 18 & 0.40 & 5 & 0.34 & 9 & 4.72 & 22 \\
\hline
\end{tabular}

\footnotetext{
${ }^{10}$ The deposition patterns vary between emissions cells due to meteorological variations. Yet, a strong tendency of deposition shares close to the emission of $\mathrm{NH}_{x}$ being largest, of $\mathrm{SO}_{x}$ being smaller, and of $\mathrm{NO}_{x}$ being smallest was observed in deposition model of P.-O. Roy et al. (2012). E.g. for an emissions cell in Minnesota 35\% of a $\mathrm{NH}_{\mathrm{x}}$ emission deposits within the emission cell and $42 \%$ within the emission cell and the four neighboring cells, while the corresponding numbers for $\mathrm{SO}_{x}$ are $20 \%$ and $26 \%$ and for $\mathrm{NO}_{x}$ are $8 \%$ and $15 \%$ respectively (see also Figure 3 ).
} 


\begin{tabular}{|c|c|c|c|c|c|c|c|c|c|c|c|c|c|}
\hline Minnesota & Virginia & 4231 & 33 & 1.85 & 14 & 1.34 & 25 & 0.54 & 1 & 0.55 & 1 & 7.36 & 16 \\
\hline Missouri & $\begin{array}{l}\text { Southwest Power } \\
\text { Station }\end{array}$ & 6222 & 14 & 0.70 & 32 & 2.61 & 21 & 0.26 & 33 & 0.25 & 30 & 5.16 & 21 \\
\hline Mississippi & Henderson & 6793 & 5 & 5.81 & 2 & 6.43 & 8 & 0.24 & 36 & 0.24 & 34 & 20.11 & 6 \\
\hline Montana & Lewis \& Clark & 4591 & 28 & 2.16 & 10 & 2.71 & 20 & 0.39 & 7 & 0.32 & 17 & 8.08 & 12 \\
\hline North Carolina & Mayo & 6502 & 10 & 0.35 & 39 & 1.00 & 28 & 0.37 & 12 & 0.35 & 8 & 3.09 & 26 \\
\hline North Dakota & Antelope Valley & 6518 & 9 & 1.86 & 13 & 2.12 & 23 & 0.41 & 4 & 0.34 & 11 & 9.67 & 11 \\
\hline Nebraska & Platte & 5523 & 17 & 1.93 & 12 & 3.81 & 13 & 0.26 & 34 & 0.24 & 33 & 7.93 & 14 \\
\hline $\begin{array}{l}\text { New } \\
\text { Hampshire }\end{array}$ & Schiller & 3408 & 40 & 1.18 & 24 & 3.88 & 12 & 0.47 & 2 & 0.46 & 2 & 8.03 & 13 \\
\hline New Jersey & $\begin{array}{l}\text { Chambers } \\
\text { Cogeneration LP }\end{array}$ & 3444 & 39 & 0.55 & 36 & 0.82 & 32 & 0.35 & 13 & 0.31 & 19 & 1.53 & 36 \\
\hline New Mexico & Four Corners & 3270 & 41 & 2.53 & 7 & 0.72 & 34 & 0.19 & 42 & 0.19 & 42 & 2.05 & 33 \\
\hline Nevada & TS Power Plant & 4295 & 32 & 0.20 & 43 & 0.19 & 45 & 0.20 & 39 & 0.20 & 41 & 0.33 & 44 \\
\hline New York & AES Greenidge LLC & 2627 & 44 & 0.93 & 26 & 0.75 & 33 & 0.40 & 6 & 0.36 & 5 & 1.70 & 35 \\
\hline Ohio & Muskingum River & 4522 & 30 & 1.21 & 22 & 13.36 & 3 & 0.37 & 9 & 0.33 & 12 & 22.91 & 4 \\
\hline Oklahoma & Hugo & 6300 & 13 & 0.89 & 28 & 2.82 & 17 & 0.19 & 41 & 0.20 & 40 & 4.67 & 24 \\
\hline Oregon & Boardman & 4909 & 26 & 1.97 & 11 & 3.44 & 15 & 0.29 & 29 & 0.26 & 29 & 7.13 & 17 \\
\hline Pennsylvania & $\begin{array}{l}\text { G F Weaton Power } \\
\text { Station }\end{array}$ & 4345 & 31 & 1.29 & 19 & 2.73 & 19 & 0.37 & 9 & 0.33 & 12 & 5.97 & 18 \\
\hline South Carolina & $\begin{array}{l}\text { US DOE Savannah } \\
\text { River Site (D Area) }\end{array}$ & 7085 & 4 & 12.90 & 1 & 36.24 & 1 & 0.35 & 15 & 0.35 & 7 & 120.97 & 1 \\
\hline South Dakota & Big Stone & 5672 & 16 & 3.46 & 5 & 3.52 & 14 & 0.42 & 3 & 0.37 & 4 & 15.66 & 8 \\
\hline Tennessee & Bull Run & 7109 & 3 & 0.29 & 40 & 0.21 & 43 & 0.32 & 23 & 0.31 & 21 & 1.11 & 41 \\
\hline Texas & Oak Grove & 5431 & 18 & 0.62 & 33 & 0.56 & 37 & 0.17 & 43 & 0.18 & 43 & 1.10 & 42 \\
\hline Utah & Huntington & 3183 & 43 & 1.23 & 21 & 0.46 & 38 & 0.24 & 35 & 0.24 & 32 & 1.31 & 38 \\
\hline Virginia & $\begin{array}{l}\text { Altavista Power } \\
\text { Station }\end{array}$ & 6038 & 15 & 1.27 & 20 & 0.19 & 44 & 0.35 & 16 & 0.33 & 15 & 3.04 & 27 \\
\hline Washington & $\begin{array}{l}\text { Transalta Centralia } \\
\text { Generation } \\
\end{array}$ & 5178 & 22 & 1.20 & 23 & 0.27 & 41 & 0.27 & 31 & 0.23 & 38 & 1.99 & 34 \\
\hline Wisconsin & Nelson Dewey & 3918 & 34 & 2.35 & 8 & 10.25 & 6 & 0.33 & 19 & 0.28 & 24 & 14.47 & 9 \\
\hline West Virginia & Kammer & 6711 & 6 & 1.85 & 15 & 8.55 & 7 & 0.37 & 9 & 0.33 & 12 & 23.48 & 3 \\
\hline Wyoming & Wygen III & 4835 & 27 & 0.20 & 44 & 0.26 & 42 & 0.32 & 24 & 0.29 & 22 & 0.67 & 43 \\
\hline
\end{tabular}

\subsubsection{Absolute interpretation of results}

Indicator scores varied 2 orders of magnitude from a minimum of 0.23 ha.year to a maximum of 121 ha.year for a power plant located in California and South Carolina respectively. This means that the equivalent production of annual residential electricity use in 2010 occupies carrying capacities of between 0.23 ha and 121 ha of land for 1 year depending on the scenario. These areas are abstract because they cannot be empirically observed as special pieces of land somehow dedicated to absorbing acidifying emissions. Instead results should be interpreted as space integrated carrying capacity occupation, which is driven by carrying capacities in grid cells on which large shares of emissions deposit. Note that indicator results hold no information on the extent to which an emission occupy the carrying capacity of the individual grid cells that are affected by its depositions. ${ }^{11}$ Table 1 shows that none of the 45 scenarios could be considered environmentally sustainable when using any of the two valuation principles because these require indicator scores to be below 0.050 ha.year (relative contribution to GDP principle) or 0.22 ha.year

\footnotetext{
${ }^{11}$ In a hypothetical example where carrying capacities of 4 grid cells of 1 ha are each occupied by $10 \%, 20 \%, 80 \%$ and $130 \%$ from depositions of an emission, the aggregated result would be 2.4 ha $(0.1 * 1$ ha $+0.2 * 1$ ha $+0.80 * 1$ ha $+1.3 * 1$ ha).
} 
(grandfathering principle). The scenario in California would, however, only require a slight reduction in indicator score (0.01 ha.year) to be considered environmentally sustainable from the application of the grandfathering perspective. Note that some of the scenarios may be considered environmentally sustainable by the use of other valuation principles than the two used in this study. If, for example, value factors had instead been derived from relative contribution to meeting human needs, a relatively high carrying capacity would perhaps be entitled to residential electricity, since it enables people to meet essential needs, such as heating and cooking (although residential electricity certainly can be used for meeting less essential needs too).

\subsubsection{Spatial variations}

Since the indicator score is directly proportional to all input parameters (equation 5), results are equally sensitive to variations of all input parameters, i.e. a doubling of any parameter will lead to a doubling of indicator results. From Table 1 it can be seen that the input parameter showing the strongest relative variation in the case study is the emission intensity (factors of almost 200 and 100 difference from smallest to largest for $\mathrm{SO}_{x}$ and $\mathrm{NO}_{\mathrm{x}}$ respectively) The cause of this variation is likely differences in flue gas cleaning systems, and for $\mathrm{SO}_{x}$ also differences in the sulfur content of the coal (Henriksson et al., 2014). By contrast the state specific annual per capita residential electricity consumption ( $P$ ) varies by a factor of 3, while CFs vary by a factor of 5 and 4 for $\mathrm{SO}_{\mathrm{x}}$ and $\mathrm{NO}_{\mathrm{x}}$. Variations in $\mathrm{P}$ and $\mathrm{CF}$ thereby have negligible contributions to the observed 2 orders of magnitude variations in indicator scores of the 45 scenarios. In other words, to achieve a low carrying capacity occupation it is more important to be supplied by a power plant with low emission intensities than for the emissions of the power plant to deposit in areas with high carrying capacity or to reduce residential electricity consumption, although the latter is the only factor that the consumer can easily influence. The power plant located in South Carolina had by far the highest emission intensities of both $\mathrm{SO}_{\mathrm{x}}$ and $\mathrm{NO}_{\mathrm{x}}$, which is the reason that the highest indicator score was observed for the scenario in this state (see Table 1 ). The power plant located in California had the $5^{\text {th }}$ lowest average emissions intensity of the two pollutants. In combination with the lowest CF for both pollutants and the lowest residential electricity consumption this explains why the scenario of California had the lowest indicator score (see Table 1).

With regards to the sensitivity of CFs to input parameters, equation 3 in turn shows that CFs are highest when depositions concentrate around receiving cells with low carrying capacities. This explains why the lowest CFs for both pollutants corresponds to the location of the California power plant for which the majority of depositions happens on grid cell with quite high carrying capacities. On the other hand the highest average CF is for the power plant in Minnesota for which the majority of depositions happens on grid cell with quite low carrying capacities, see Figure 4. 


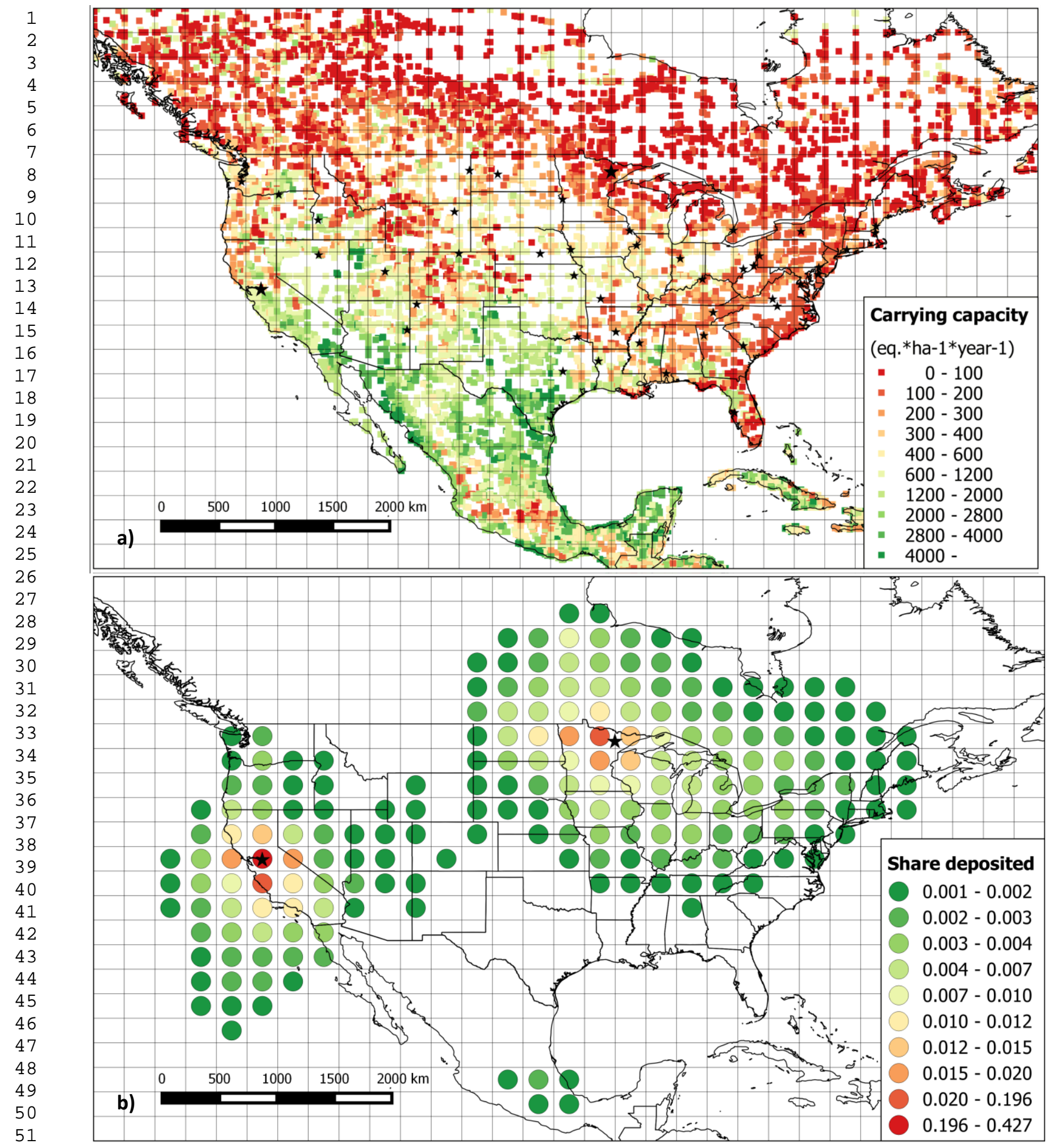

Figure 4: Maps of North America containing a) carrying capacities and power plants (stars), and b) deposition shares on cells receiving more than $\mathbf{0 . 1 \%}$ of $\mathrm{SO}_{\mathrm{x}}$ emissions from the power plants in California and Minnesota (enlarged stars). 


\subsubsection{Comparison with alternative CFs}

Our CFs express carrying capacity occupation per kg emission and are calculated as acid deposits divided by a pH-based carrying capacity integrated over space (see equation 3). In contrast, the CFs of Roy et al. (2014) express the marginal increase in concentration of $\mathrm{H}^{+}$-ions in soil solution, compared to modelled existing concentrations, per kg emission. These CFs are calculated as acid deposits multiplied by a so-called soil sensitivity factor which represents the change in existing soil $\mathrm{H}^{+}$related to a change in acid deposits integrated over space. Our CFs and the CFs of Roy et al. (2014) use the same fate factors for calculating acid deposits (Roy et al., 2012b) and thus differ only in the use of carrying capacity versus soil sensitivity factor. In Figure 5 we compare the two sets of CFs for the 45 power plant locations. Each set of CF is normalized to the CF of the power plants in Illinois, which ranks approximately in the middle of the 45 CFs for all pollutants and both studies.

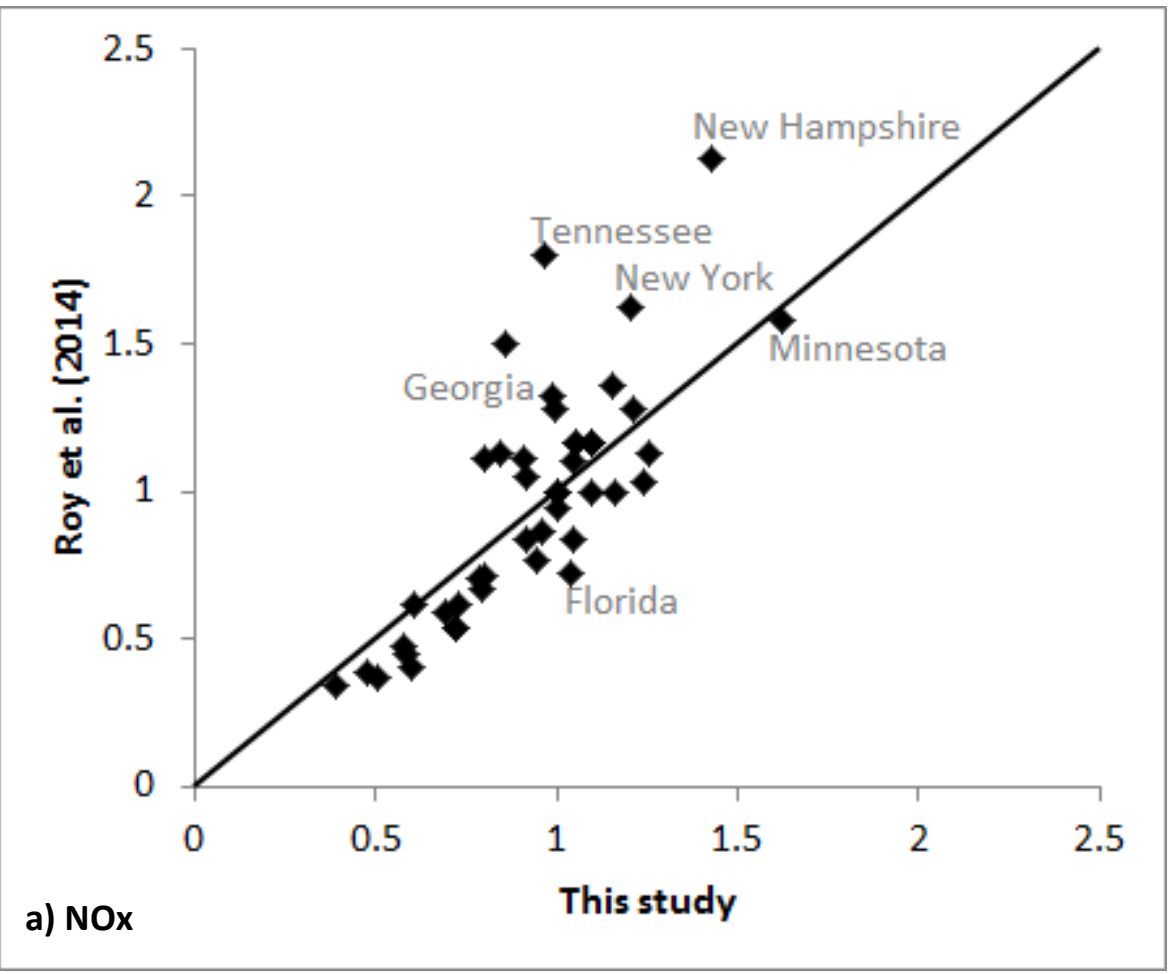



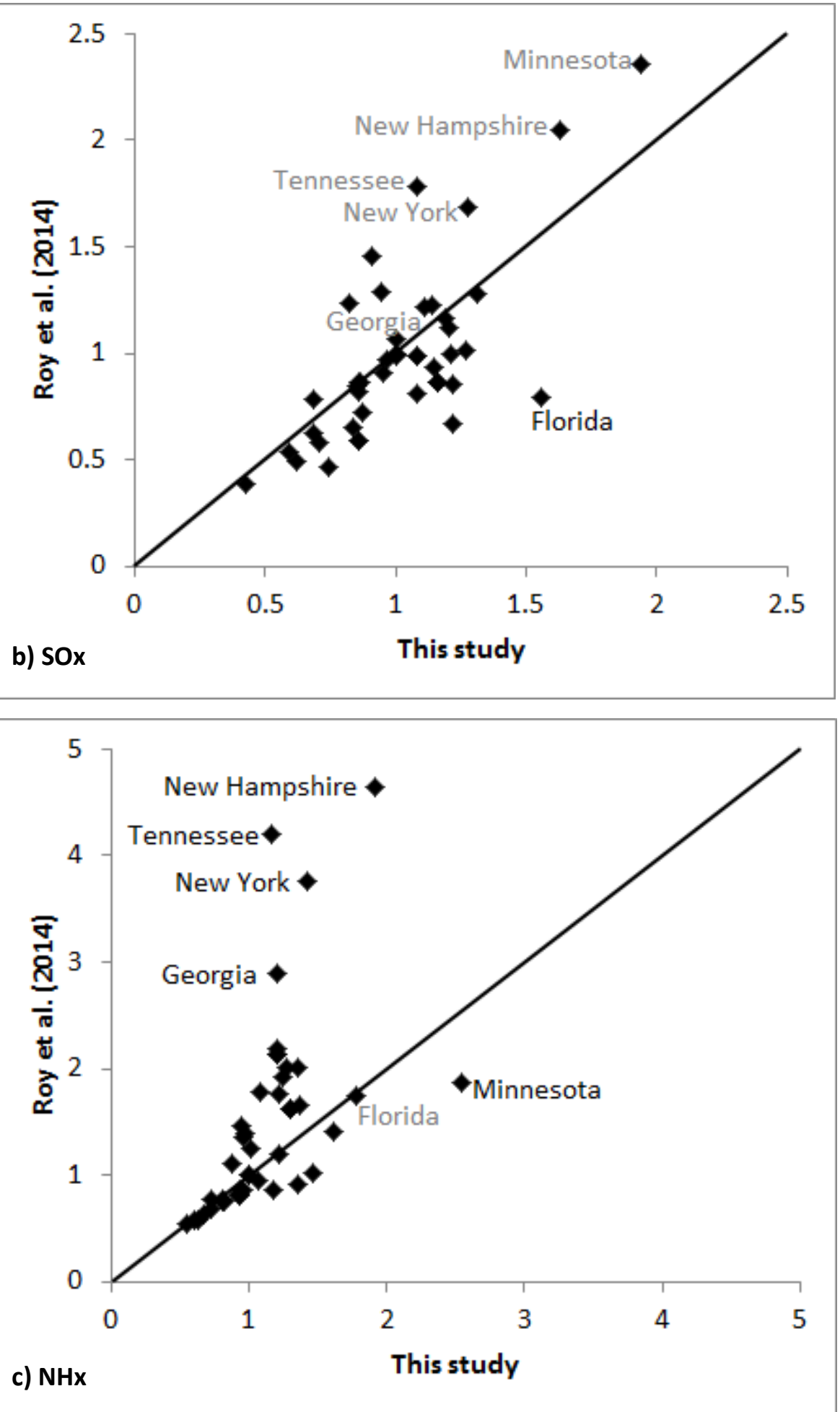

Figure 5: CFs of this study plotted against CF of Roy et al. (2014) for the 45 power plant locations for $\mathrm{NO}_{\mathrm{x}}, \mathrm{SO}_{\mathrm{x}}$ and $\mathrm{NH}_{\mathrm{x}}$. Each set of $\mathrm{CF}$ is normalized to the $\mathrm{CF}$ of the power plants in Illinois. State names are written for outliers (in grey across pollutants). CFs above the 1:1 line are relatively higher for Roy et al. (2014) than for this study and vice versa.

It can be seen that there is some agreement between the two sets of CFs for all pollutants, although the agreement appears lower for $\mathrm{NH}_{\mathrm{x}}$ than the other pollutants. The partial agreement can be explained from 
the common fate factors. Difference in agreement amongst the three pollutants can be explained from differences in deposition patterns of pollutants: Due to the relatively large shares of depositions of $\mathrm{NH}_{\mathrm{x}}$ close to the emission cell (see footnote 10 ) fewer grid cells receive large shares of an $\mathrm{NH}_{\mathrm{x}}$ emissions than for emissions of $\mathrm{SO}_{x}$ and $\mathrm{NO}_{\mathrm{x}}$. Differences between the relative values of carrying capacities and soil sensitivity factors in individual receiving cells will thus have the largest effect for $\mathrm{NH}_{\mathrm{x}} \mathrm{CFs}$. The range of CFs for the 45 power plant locations is for all pollutants larger for Roy et al. (2014) than for this study. This trend, which is strongest for $\mathrm{NH}_{\mathrm{x}}$ (Figure $5 \mathrm{c}$ ), can be explained from the high range of global soil sensitivity factors of 11 orders of magnitude compared to the range of carrying capacities in this study of just 2 orders of magnitude (see S5).

Two types of outliers can be seen on the plots of Figure 5. For the first type CFs in this study are relatively high, while CFs of Roy et al. (2014) are relatively low. This is the case for the CFs of Minnesota for $\mathrm{NH}_{\mathrm{x}}$ and CFs of Florida for $\mathrm{SO}_{x}$. In these cases the high $\mathrm{CFs}$ of this study are driven by relatively low carrying capacities in the grid cells receiving large shares of deposition. By comparison corresponding CFs of Roy et al. (2014) are moderate or low for Minnesota and Florida because soil sensitivity factors are moderate or low in the area receiving large shares of deposition. The observed discrepancies between soil sensitivity factors and carrying capacities can be explained from the fact that for some soils a relatively small acid deposition reduces the modelled natural $\mathrm{pH}$ by 0.25 , while a marginal increase in acid deposition, compared to the modelled existing deposition, leads to a low marginal pH decrease. See Figure $\mathrm{S} 7 \mathrm{~b}$ for a conceptual $\mathrm{pH}$ curve that illustrates this point. This discrepancy between carrying capacity and soil sensitivity factor occur for some soils that have low carrying capacities and for which the background acid deposition is relatively small. This is the case for the parts of the US Midwest and Canada that receive large shares of the depositions from the emission cell of the Minnesota power plant. In these scarcely populated areas modelled background depositions of the three pollutants are 1-2 orders of magnitude lower than those of the most densely populated part of the US East Coast (data not shown).

Outliers of the second type, i.e. low CFs of this study and high CFs of Roy et al. (2014), can be observed in Figure $5 \mathrm{c}$ for $\mathrm{NH}_{\mathrm{x}}$ for the grid cells of the New Hampshire, New York, Georgia and Tennessee power plants. In these cases the high CFs of Roy et al. (2014) are driven by high soil sensitivity factors in the emission cell and neighboring grid cells. These factors are high because modelled existing depositions are, due to high modelled existing depositions, somewhere in the steep interval of the $\mathrm{pH}$ curves of the soils, meaning that marginal increases in deposition can create high reductions in $\mathrm{pH}$ in these grid cells. See Figure S7c for a conceptual pH curve. Due to the large variation of soil sensitivity factors (see above), high factors in just a few of the grid cells receiving relatively high shares of an emission can to a very large extent drive CF values of Roy et al. (2014). By comparison the CFs of this study for the grid cells of the New Hampshire and New York power plants are no more than moderate in spite of low to moderate carrying capacities in the vicinity of the emission grid cell, because the power plants are close to the sea, meaning that relatively high shares of emissions deposits on water. 


\section{Discussion}

We have demonstrated the feasibility of modifying LCA indicators to AESI. Thereby we have shown that LCA can potentially solve some of the problems associated with current AESI, such as incomplete coverage of impact categories, varying quality of inventory data, varying or insufficient spatial resolution and the inconvenience to users of needing different software tools for accessing and using AESI. With point of departure in the experiences from the case study, this section discuss differences and complementarities between LCA based RESIs and AESI in decision support (aim 4) and proposes a research agenda for the support of AESI by LCA.

\subsection{Decision support related to absolute environmental sustainability}

The main characteristic of AESI is that they allow for the assessment of environmental sustainability of systems in absolute terms. This information can be useful on many levels. It may for instance quantitatively inform various emission reduction scenarios designed by e.g. municipalities, nations and supranational organizations with the purpose of achieving environmental sustainability. AESI can thus play similar roles as greenhouse gas emissions reduction scenarios, designed to prevent e.g. a temperature increase of $2^{\circ} \mathrm{C}$ (IPCC, 2013; Vuuren et al., 2011), that have been adopted at different governmental levels. Also AESI may support individuals motivated to learn what it takes to have an environmentally sustainable life style, i.e. one that is associated with environmental interferences that do not exceed the carrying capacity entitled to an individual person.

\subsection{Decision support related to ranking}

For a given impact category the ranking of systems or scenarios obtained by an AESI will in principal be identical to the ranking obtained by a RESI (relative environmental sustainability indicator) when the impact pathway model of the RESI is based on a linear approach (see the introduction section and S1). This is because the relationship between RESI and AESI CFs in such cases will be the same across pollutants and locations. There will therefore be no conflict between RESI based on the linear approach and AESI when used to support decisions where environmental performances of alternative solutions are part of the decision criteria. However, when the impact pathway model of a RESI is based on a marginal approach (see the introduction section and S1)there may be discrepancies in the relationships between AESI and RESI CFs across pollutants and locations, and thus in the ranking of systems or scenarios. This was observed to some extent in the case study when comparing the AESI developed in this study to the marginal based RESI of Roy et al. (2014) (see Figure 5). Thus, if the aim is to oppose reductions in soil solution pH, as quantified by Roy et al. (2014), the optimal solution may be different than the one corresponding to the aim of achieving the lowest possible carrying capacity occupation. Given these discrepancies between AESI and marginal based RESI, which type of indicator should ideally be used to support decisions related to environmental sustainability? The answer, we will argue in the next sub-section, is neither of the two, but both combined.

\subsubsection{Risk of sub-optimization}

If either marginal based RESIs or AESI are used in isolation there is a risk of sub-optimal decision support. In the case of marginal based RESIs Huijbregts et al. (2011) argued that quantifying marginal changes in environmental interferences can be misleading in cases where changes are small, but existing levels of environmental interferences are unacceptably high. For the impact category terrestrial acidification this may be the case for receiving cells in which existing depositions are so high that the corresponding existing $\mathrm{pH}$ is at the lower buffering zone of a pH curve (see Figure S7d and S7e). At this zone additional depositions 
of hydrogen ions are effectively buffered through reaction with aluminium oxides and hydroxides from clay particles. In such cases RESI based CFs will be low and marginal emission increases will thus seem relatively unproblematic although the state of the soil ecosystems is highly degraded by existing depositions. Another case of sub-optimal decision support is when marginal changes are small and existing levels of environmental interferences are low, i.e. far from exceeding thresholds (see Figure S7a). Although a small marginal increase in existing levels of environmental interferences can here seem unproblematic for environmental sustainability this conclusion is not scalable. The marginal approach thus suffers from a freeriding bias, i.e. only "the drop that spills the cup" is blamed for the crossing of a threshold. This is especially problematic in situations where the combined environmental pressure is increasing, which has for example been the case in large parts of China during the last couple of decades. In such situations CFs based on marginal RESIs will potentially be highly time dependent.

Decisions made only with the aid of AESI can also be suboptimal. For instance they may lead to choices that favour systems whose emissions end up in spatial units with high carrying capacity. Such choices can be suboptimal because they do not consider emissions of existing or future anthropogenic systems that, combined with the additional emissions, risk to exceed carrying capacities in these spatial units. An ideal quantification of entitlement would eliminate this risk of sub-optimization because it would take into account existing and potential competing systems, but the risk is quite real considering the difficulties of carrying out an ideal quantification of entitlement (see Section 2.4).

\subsubsection{Combining marginal based RESI and AESI to avoid sub-optimization}

The differences between the AESI and marginal based RESI are not only technical, but in fact also ethical: The CFs for terrestrial acidification developed in this study are compatible with decision making grounded in rule based ethics according to which a decision is considered "good" if it follows one or more prescribed rules that may be either universal or situation-dependent (Ekvall et al., 2005). In AESI the rule is that a decision should, whenever possible, lead to anthropogenic systems that do not occupy more carrying capacity than they can be considered entitled to. If this is not possible within the decision space, the rule is that a decision should lead to the lowest possible carrying capacity occupation amongst alternatives. Thus if all societal decisions were to follow these rules a transition towards environmental sustainability would in principle happen. ${ }^{12}$ In contrast, the decision-making that the marginal RESI of Roy et al. (2014) supports is grounded in consequential ethics, according to which a decision is "good" if its consequences are better than those of alternative(s) (Ekvall et al., 2005). The rule and consequential based ethics are conflicting in cases where following the prescribed rule(s) does not lead to the best consequences and vice versa. ${ }^{13}$

In real life, decisions are unlikely to be based entirely on either rule or consequential ethics, because decisions are often taken in consensus processes and because individuals rarely $100 \%$ adhere to a specific ethical mindset (Hofstetter, 1998). Therefore the different ethical perspectives of marginal based RESI and AESI can be seen as complementary rather than competing. In the case study, our AESI was used to

\footnotetext{
${ }^{12}$ Note that the only way to guarantee that total carrying capacity is not exceeded by the combined environmental interferences of all anthropogenic systems is to (somewhat oxymoronically) ensure that the same valuation principle is used to calculate carrying capacity entitlement of all systems.

${ }^{13}$ Consider the hypothetical situation where a person has the option of saving 5 lives by taking 1 (innocent) life. Doing this would lead to the best consequence, compared to inaction, but would also violate the rule of not killing an (innocent) person (Thomson, 1976).
} 
evaluate the sustainability of the 45 scenarios absolutely and to point to the scenario associated with the lowest carrying capacity occupation. The RESI oriented CFs of Roy et al. (2014) could on the other hand point to the scenario associated with the lowest marginal increase in environmental interferences. Both types of information are valuable in decision processes, which aim to simultaneously reduce existing levels of environmental interferences efficiently and maintain, or take steps towards achieving, environmental sustainability of society as a whole and of its individual anthropogenic systems.

\subsection{Research agenda on AESI in a life cycle perspective}

This study is intended primarily as a proof of concept and its theme must be expanded upon in future research for the proposed modification of LCA to measure environmental sustainability in absolute terms to be useful in decision support. Below we outline a few key challenges that deserve academic attention.

The designs of AESI are associated with several choices, to which indicator scores may show different degrees of sensitivities. In our modification of the LCA indicator for terrestrial acidification to AESI the choices of control variable, threshold value and the use of PROFILE to translate the threshold into carrying capacities all have potentially high contribution to uncertainty in indicator scores and efforts to reduce this uncertainty should be made (see S9 for an elaboration). Similar choices are unavoidable in any AESI. It is therefore important for indicator designers to 1 ) be aware of these choices and communicate them explicitly to users, so they can be considered in the decision support along with the indicator scores, 2) to quantify the sensitivity of indicator scores to changes in choices, and 3) to use these quantifications to effectively reduce overall uncertainties in indicator scores. As most choices are, at least partially, related to value judgement, consensus processes involving e.g. environmental scientists, indicator designers and indicator users may be feasible for reducing overall uncertainties.

Uncertainties in LCls also deserve attention when using AESI. Because many current societies cannot be considered environmentally sustainable a key use of AESI is to support transitions towards environmentally sustainable societies. Such transitions per definition involve large changes in technologies. For example, environmental interferences from energy use are expected to change considerably in many countries over the next decades. As a result, environmental interferences of many product systems will also change in the future. It is therefore important to carefully evaluate, and if necessary modify, existing $\mathrm{LCl}$ unit processes in absolute environmental sustainability assessments, which aims to capture the effects of future technological transformations (Miller and Keoleian, 2015).

A core characteristic of LCA is that it covers a comprehensive set of impact categories. In this context a relevant question is how to aggregate AESI scores from different impact categories. One option is to simply add the scores since they can be expressed in the same metric (ha·year) for all impact categories. However, a weighting step may be required as the consequences of exceeding carrying capacities can vary in severity between impacts categories. Some factors influencing the severity of exceedance are the social and/or economic consequences, the spatial extent and the time required for reversion of damage. In addition, care should be taken when attempting to aggregate indicator scores across impact categories, since the interaction between different types of environmental interferences within a specific territory is complex and not well understood. For some combinations of impact categories additivity between carrying capacity occupations may be a good assumption. In other cases, however, a territory that has its carrying capacity 
$100 \%$ occupied for one impact category may have unoccupied carrying capacity for other impact categories ${ }^{14}$, which means that simply adding indicator scores across impact categories would overestimate the actual area equivalent of carrying capacity occupation. Another challenge related to aggregating indicator scores is the need for absolute sustainability references for the LCA impact categories that are not related to ecosystems, i.e. those related to human health impacts and depletion of non-renewable resources. Carrying capacity does per definition not apply to such impact categories, but other more normative sustainability references may be quantified (McElroy et al., 2008).

Another key challenge is how to integrate a carrying capacity entitlement module in LCA software that is relevant and requires only a manageable data input by the software user. Ideally the user should only have to choose a valuation principle and define the duration of environmental interventions $(t)$ of each emission location. The software would then calculate $T_{\text {affected }}$ and $A_{\text {affected, }}$ identify competing systems and subsequently calculate VF to arrive at the carrying capacity entitlement (see equation 4 ) for each emission location and compare this to the corresponding indicator score. This would require the software to be equipped with a fate model, calculating $T_{\text {affected }}$ and $A_{\text {affected }}$ for each emission location, and to be linked to a complete spatially derived emission inventory that contains information needed to calculate VF, such as contribution to GDP, for each of its anthropogenic systems. For many emissions in a typical product life cycle location and duration ( $t$ ) will be partly or completely unknown. The AESI should therefore be equipped with a meaningful default choice for location and duration that is compatible with the calculation of carrying capacity entitlement.

\section{Supporting Information}

Supporting information is available online and contains methodological details and elaboration of results and discussions.

\section{References}

ACCCE, 2014. Energy Cost Impacts on American Families, 2001-2014. American Coalition for Clean Coal Electricity

Azevedo, L.B., van Zelm, R., Hendriks, a J., Bobbink, R., Huijbregts, M. a J., 2013. Global assessment of the effects of terrestrial acidification on plant species richness. Environ. Pollut. 174, 10-5.

Bey, I., Jacob, D.J., Yantosca, R.M., Logan, J.A., Field, B.D., Fiore, A.M., Li, Q.B., Liu, H.G.Y., Mickley, L.J., Schultz, M.G., 2001. Global modeling of tropospheric chemistry with assimilated meteorology: Model description and evaluation. J. Geophys. Res. 106, 23073-23095.

Bjørn, A., Diamond, M., Birkved, M., Hauschild, M.Z., 2014. Chemical footprint method for improved communication of freshwater ecotoxicity impacts in the context of ecological limits. Environ. Sci. Technol. 48, 13253-13262.

Bjørn, A., Hauschild, M.Z., 2015. Introducing carrying capacity based normalization in LCA: framework and development of references at midpoint level. Int. J. Life cycle Assess. 20, 1005-1018.

Bjørn, A., Richardson, K., Hauschild, M.Z., 2015. Environmentally sustainable or not? Managing and reducing indicator uncertainties. Ecol. Indic. In review.

\footnotetext{
${ }^{14}$ This situation will for example occur when carrying capacities are derived from a threshold of affected species and when the species that are most sensitive to one type of environmental interferences (e.g. acidification) are different than the species that are most sensitive to another type (e.g. chemicals with eco-toxicity potentials).
} 
Borucke, M., Moore, D., Cranston, G., Gracey, K., Iha, K., Larson, J., Lazarus, E., Morales, J.C., Wackernagel, M., Galli, A., 2013. Accounting for demand and supply of the biosphere's regenerative capacity: The National Footprint Accounts' underlying methodology and framework. Ecol. Indic. 24, 518-533.

Castellani, V., Sala, S., 2012. Ecological Footprint and Life Cycle Assessment in the sustainability assessment of tourism activities. Ecol. Indic. 16, 135-147.

DoE, 2015. Clean Energy in My State [WWW Document]. Department of Energy. URL http://apps1.eere.energy.gov/states/

Ecoinvent, 2015. Ecoinvent version 3 [WWW Document]. URL http://www.ecoinvent.org/

Ekvall, T., Tillman, A.-M., Molander, S., 2005. Normative ethics and methodology for life cycle assessment. J. Clean. Prod. 13, 1225-1234.

EMEP, 2015. Emissions as used in EMEP models [WWW Document]. WebDab - EMEP database. The European Monitoring and Evaluation Programme. URL http://www.ceip.at/ms/ceip_home1/ceip_home/webdab_emepdatabase/emissions_emepmodels/

EPA, 2014. Ninth edition with year 2010 data (Version 1.0) [WWW Document]. eGRID. Environmental Protection Agency. URL http://www.epa.gov/cleanenergy/energy-resources/egrid/index.html

Goodland, R., 1995. The Concept of Environmental Sustainability. Annu. Rev. Ecol. Syst. 26, 1-24.

Greenpeace, 2012a. Scorecard. Greenpeace.

Greenpeace, 2012b. Guide to Greener Electronics - Ranking Criteria Explained: August 2012, v. 18 onwards. Greenpeace

Hak, T., Moldan, B., Dahl, A.L., 2012. Editorial. Ecol. Indic. 17, 1-3.

Hauschild, M.Z., Huijbregts, M.A.J., 2015. Life Cycle Impact Assessment. Springer Netherlands.

Henriksson, P.J.G., Zhang, W., Guinée, J.B., 2014. Updated unit process data for coal-based energy in China including parameters for overall dispersions. Int. J. Life Cycle Assess. 20, 185-195.

Hoekstra, A.Y., Mekonnen, M.M., 2012. The water footprint of humanity. Proc. Natl. Acad. Sci. U. S. A. 109, 3232-3237.

Hofstetter, P., 1998. Perspectives in life cycle impact assessment : A structures approach to combine models of the technosphere, ecosphere and valuesphere. Kluwer Academic Publishers.

Hsu, A., Emerson, J., Levy, M., Sherbinin, A. de, Johnson, L., Malik, O., Schwartz, J., Jaiteh, M., 2014. The 2014 Environmental Performance Index. New Haven, CT.

Huijbregts, M. A. J., Hellweg, S., Frischknecht, R., Hungerbühler, K., Hendriks, a. J., 2008. Ecological footprint accounting in the life cycle assessment of products. Ecol. Econ. 64, 798-807.

Huijbregts, M. A. J., Schöpp, W., Verkuijlen, E., Heijungs, R., Reijnders, L., 2000. Spatially Explicit Characterization of Acidifying and Eutrophying Air Pollution in Life-Cycle Assessment. J. Ind. Ecol. 4, 75-92.

Huijbregts, M.A.J., Hellweg, S., Hertwich, E., 2011. Do We Need a Paradigm Shift in Life Cycle Impact Assessment ? Environ. Sci. Technol. 45, 3833-3834.

IEA, 2012. Electricity Information - IEA Statistics. International Energy Agency.

IPCC, 2013. Climate Change 2013: The Physical Science Basis. Contribution of Working Group I to the Fifth Assessment Report of the Intergovernmental Panel on Climate Change. Cambridge University Press, Cambridge, United Kingdom and New York, NY, USA.

Kitzes, J., Galli, A., Bagliani, M., Barrett, J., Dige, G., Ede, S., Erb, K., Giljum, S., Haberl, H., Hails, C., JoliaFerrier, L., Jungwirth, S., Lenzen, M., Lewis, K., Loh, J., Marchettini, N., Messinger, H., Milne, K., Moles, R., Monfreda, C., Moran, D., Nakano, K., Pyhälä, A., Rees, W., Simmons, C., Wackernagel, M., Wada, Y., Walsh, C., Wiedmann, T., 2009. A research agenda for improving national Ecological Footprint accounts. Ecol. Econ. 68, 1991-2007.

McElroy, M.W., Jorna, R.J., Engelen, J. Van, 2008. Sustainability Quotients and the Social Footprint. Corporate Social Responsibility and Environment Management 234, 223-234.

Miller, S. a, Keoleian, G. a, 2015. Framework for analyzing transformative technologies in life cycle assessment. Environ. Sci. Technol. 49, 3067-75. 
Moldan, B., Janoušková, S., Hák, T., 2012. How to understand and measure environmental sustainability: Indicators and targets. Ecol. Indic. 17, 4-13.

Posch, M., Seppälä, J., Hettelingh, J.-P., Johansson, M., Margni, M., Jolliet, O., 2008. The role of atmospheric dispersion models and ecosystem sensitivity in the determination of characterisation factors for acidifying and eutrophying emissions in LCIA. Int. J. Life Cycle Assess. 13, 477-486.

PRé, 2015. SimaPro - World's Leading LCA Software [WWW Document]. URL http://www.presustainability.com/simapro

Roy, P.-O., Azevedo, L.B., Margni, M., van Zelm, R., Deschênes, L., Huijbregts, M.A.J., 2014. Characterization factors for terrestrial acidification at the global scale: A systematic analysis of spatial variability and uncertainty. Sci. Total Environ. 500-501C, 270-276.

Roy, P.-O., Deschênes, L., Margni, M., 2012a. Life Cycle Impact Assessment of Terrestrial Acidification: Modeling Spatially Explicit Soil Sensitivity at the Global Scale. Environ. Sci. Technol. 46, 8270-8278.

Roy, P.-O., Huijbregts, M., Deschênes, L., Margni, M., 2012b. Spatially-differentiated atmospheric sourcereceptor relationships for nitrogen oxides, sulfur oxides and ammonia emissions at the global scale for life cycle impact assessment. Atmos. Environ. 62, 74-81.

Sayre, N.F., 2008. The genesis, history, and limits of carrying capacity. Ann. Assoc. Am. Geogr. 98, 120-134.

Singh, R.K., Murty, H.R., Gupta, S.K., Dikshit, a. K., 2012. An overview of sustainability assessment methodologies. Ecol. Indic. 15, 281-299.

Sparks, D.S., 2002. Environmental Soil Chemistry, 2nd ed. Academic Press.

Spranger, T., Lorenz, U., Gregor, H.-D., 2004. Manual on methodologies and criteria for Modelling and Mapping Critical Loads \& Levels and Air Pollution Effects, Risks and Trends. Federal Environmental Agency (Umweltbundesamt), Berlin.

Steffen, W., Richardson, K., Rockstrom, J., Cornell, S.E., Fetzer, I., Bennett, E.M., Biggs, R., Carpenter, S.R., de Vries, W., de Wit, C.A., Folke, C., Gerten, D., Heinke, J., Mace, G.M., Persson, L.M., Ramanathan, V., Reyers, B., Sorlin, S., 2015. Planetary boundaries: Guiding human development on a changing planet. Science 347(6223).Tegen, I., Fung, I., 1994. Modeling of mineral dust in the atmosphere: Sources, transport, and optical thickness. J. Geophys. Res. 99, 22897-22914.

Thinkstep, 2015. GaBi LCA Software [WWW Document]. URL http://www.thinkstep.com/software/gabi-Ica/ Thomson, J.J., 1976. Killing, letting die, and the trolley problem. Monist 59, 204-217.

USCB, 2012. United States Summary: 2010, Population and Housing Unit Counts, 2010 Census of Population and Housing. United States Census Bureau.

USCB, 2015. Annual Estimates of the Resident Population: April 1, 2010 to July 1, 2014. U.S. Census Bureau, Population Division [WWF Document]. URL http://factfinder.census.gov/faces/tableservices/jsf/pages/productview.xhtml?pid=PEP_2014_PEPAN NRES\&src $=p t$

Vuuren, D.P., Edmonds, J., Kainuma, M., Riahi, K., Thomson, A., Hibbard, K., Hurtt, G.C., Kram, T., Krey, V., Lamarque, J.-F., Masui, T., Meinshausen, M., Nakicenovic, N., Smith, S.J., Rose, S.K., 2011. The representative concentration pathways: an overview. Clim. Change 109, 5-31.

Warfvinge, P., Sverdrup, H., 1992. Calculating critical loads of acid deposition with PROFILE - A steady-state soil chemistry model. Water, Air, Soil Pollut. 63, 119-143.

WRI, 2005. Millennium Ecosystem Assessment: Ecosystems and human well-being. Synthesis. Island Press, World Resources Institute, Washington, DC.

Zijp, M.C., Posthuma, L., van de Meent, D., 2014. Definition and Applications of a Versatile Chemical Pollution Footprint Methodology. Environ. Sci. Technol. 48, 10588-10597. 


\title{
A proposal to measure absolute environmental sustainability in Life Cycle Assessment
}

\section{Modifying life cycle assessment to measure absolute environmental sustainability}

\author{
Anders Bjørn ${ }^{1}$, Manuele Margni ${ }^{2}$, Pierre-Olivier Roy ${ }^{2}$, Cécile Bulle ${ }^{3}$ and Michael Zwicky \\ Hauschild $^{1}$ \\ ${ }^{1}$ The Technical University of Denmark, Produktionstorvet, Building 424, $2800 \mathrm{Kgs}$. Lyngby, Denmark \\ ${ }^{2}$ CIRAIG, Polytechnique Montréal, 2500, chemin Polytechnique, H3T 1J4, Montréal (QC), Canada \\ ${ }^{3}$ CIRAIG, Ecole des Sciences de la Gestion, Université du Québec à Montréal, 315, rue Sainte-Catherine \\ Est, H2X 3X2, Montréal (QC), Canada \\ E-mail contact : anbjo@dtu.dk
}

\begin{abstract}
Environmental monitoring indicates that progress towards the goal of environmental sustainability in many cases is slow, non-existing or negative. Indicators that use environmental carrying capacity references to evaluate whether anthropogenic systems are, or will potentially be, environmentally sustainable are therefore increasingly important. Such absolute indicators exist, but suffer from shortcomings such as incomplete coverage of environmental interferences, varying data quality of inventory data-and varying or insufficient spatial resolution. The purpose of this article is to demonstrate that Life Cycle Assessment (LCA) can potentially reduce or eliminate these shortcomings.

We developed a generic mathematical framework for the use of carrying capacity as environmental sustainability reference in spatially resolved life cycle impact assessment models and applied this framework to the LCA impact category terrestrial acidification. In this application carrying capacity was expressed as acid deposition (eq. $\mathrm{mol} \mathrm{H}^{+} \cdot \mathrm{ha}^{-1} \cdot$ year $^{-1}$ ) and derived from two complementary $\mathrm{pH}$ related thresholds. A geochemical steady-state model was used to calculate a carrying capacity corresponding to these thresholds for 99,515 spatial units worldwide. Carrying capacities were coupled with deposition factors from a global deposition model to calculate characterisation factors (CF), which expresses space integrated occupation of carrying capacity (ha.year) per kg emission. Principles for calculating the entitlement to carrying capacity of anthropogenic systems were then outlined, and the logic of considering it was demonstrated thata studied system ean be considered-environmentally sustainable if its indicator score (carrying capacity occupation) does not exceed its carrying capacity entitlement was demonstrated. The developed CFs and entitlement calculation principles were applied to a case study evaluating emission scenarios for personal residential electricity consumption supplied by production from 45 US coal fired electricity plant.

Median values of derived CFs are $0.16-0.19$ ha $\cdot y e a r \cdot \mathrm{kg}^{-1}$ for common acidifying compounds. CFs are generally highest in Northern Europe, Canada and Alaska due to the low carrying capacity of soils in these regions. Differences in indicator scores of the case study emission scenarios are to a larger extent driven by variations in pollution intensities of electricity plants than by spatial variations in CFs. None of the 45 emission scenarios could be considered environmentally sustainable when using the relative contribution
\end{abstract}


to GDP or the grandfathering (entitlement proportionality to past emissions) valuation principles to calculating carrying capacity entitlements. It is argued that CFs containing carrying capacity references are complementary to existing CFs in supporting decisions aimed at simultaneously reducing environmental interferences efficiently and maintaining or achieving environmental sustainability.

We have demonstrated that LCA indicators can be modified from being relative to being absolute indicators of environmental sustainability. Further research should focus on quantifying uncertainties related to choices in indicator design and on reducing uncertainties effectively by achieving consensus on these ehoices.

\section{Keywords:}

LCA; Terrestrial acidification; Carrying capacity; characterisation factors; entitlement

\section{Introduction}

During the last decades the number of sustainability indicators and their use in decision-making has greatly increased (Hak et al., 2012; Singh et al., 2012). Many such indicators rank the sustainability of anthropogenic systems. For instance Switzerland ranked highest and Somalia lowest in the 2014 Environmental Performance Index of countries (Hsu et al., 2014). Another example is Greenpeace's Guide to Greener Electronics (2012b;2012a), which ranks 16 large electronics companies. Here we term indicators used for ranking relative environmental sustainability indicators (RESI) because indicator scores of studied anthropogenic systems are relative because they are evaluated by comparison to indicator scores of one or more reference systems, chosen specifically to match the nature or function of the studied system. While RESI can reveal how the sustainability performance of system $X$ compare to that of a chosen reference system, it cannot evaluate whether system $X$ can be considered sustainable on an absolute scale (Moldan et al., 2012). This limitation is very problematic considering that the state of the environment is declining by and large (Steffen et al., 2015; WRI, 2005). Therefore the global economy and its subsystems are in fact drifting further away from the goal of environmental sustainability, originally defined as "seek[ing] to improve human welfare by protecting the sources of raw materials used for human needs and ensuring that the sinks for human wastes are not exceeded, in order to prevent harm to humans" (Goodland 1995).

This shortcoming of RESI may be addressed by supplementing RESI by indicators containing reference values of environmental sustainability (Moldan et al., 2012). We term such indicators absolute environmental sustainability indicators (AESI) because the environmental sustainability references are absolute, since they are based on characteristics of natural systems independent of the study. While ranking of products or systems is also possible in AESI, the environmental sustainability of a system can additionally be evaluated on an absolute scale, i.e. answering the question "is system X environmentally sustainable or not?" Figure 1 illustrates the difference and complementarity between RESI and AESI. 
a)

Reference of choice

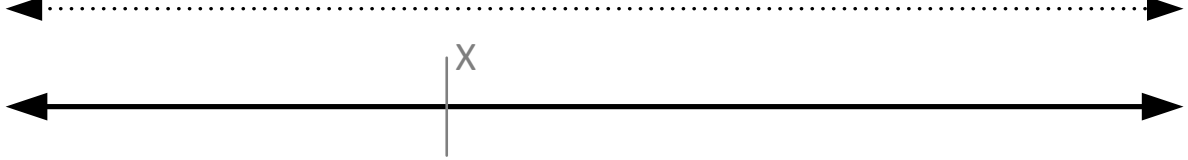

Higher interference

Lower interference

b)

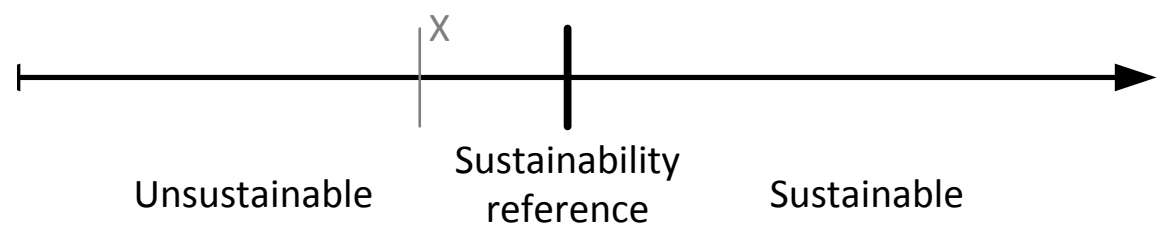

Figure 1: The concepts of relative (a) and absolute (b) environmental sustainability indicators. The ranking of the hypothetical system $X$ depends on the chosen reference(s) (a). System $X$ is environmentally unsustainable because its environmental interference is higher than the sustainability reference (b).

The concept of carrying capacity (Sayre, 2008) can be applied in AESI to operationalize and quantify references for environmental sustainability as defined by Goodland (1995). Following Bjørn and Hauschild (2015) we define carrying capacity as "the maximum sustained environmental interference a natural system can withstand without experiencing negative changes in structure or functioning that are difficult or impossible to revert." Here we use "environmental interference" as a generic term for anthropogenic changes to any point in an impact pathway (from emission or resource use to ultimate damage). It follows that total environmental interferences on natural systems, whether caused by resource uses or emissions, can be considered environmentally sustainable if their level is below the affected eco-system's carrying capacity.

"Footprinting" indicators, that use carrying capacity as sustainability reference value, can be characterized as AESI. The popular ecological footprint indicator expresses demands on nature in units of "global hectares" and compares this to land availability (termed "biocapacity") to facilitate an evaluation of whether demands are environmentally sustainable (Borucke et al., 2013). This has inspired other footprint indicators such as the well-established water footprint (Hoekstra and Mekonnen, 2012) and first generation chemical footprints (Bjørn et al., 2014; Zijp et al., 2014). Existing footprinting indicators, however, have weaknesses such as: 1 ) the incomplete coverage of all environmental interferences that are threatening environmental sustainability, 2) the varying data sources which are generally crude for assessments at the product scale (Huijbregts et al., 2008; Kitzes et al., 2009), 3) the variations in spatial resolution amongst footprints ${ }^{1}$, which can be a source of bias due to the potentially high spatial variability of carrying capacity (Bjørn and Hauschild, 2015), and 4) the inconvenience for users that each indicator is made available by means of a unique software tool. We believe that the life cycle assessment (LCA) method has the potential to overcome these weaknesses of current AESI.

\footnotetext{
${ }^{1}$ The ecological footprint normalises land demands in the unit "global hectares", which means that indicator results are unaffected by spatial differences in yield, while water- and chemical footprints are spatially resolved to varying extents.
} 
LCA aims to cover all relevant environmental interferences over the life cycle (from raw materials to waste management) of a product (or other anthropogenic systems). LCA requires a life cycle inventory (LCI), which compiles the physical inputs and outputs (resource uses and emissions) of a product during its life cycle, and is commonly based on product system specific data supplemented by a common life cycle inventory database of unit processes (e.g. the average electricity generation of a country). LCA uses characterisation factors (CFs), which express the relationship between the resource uses or emissions of a $\mathrm{LCl}$ and measures of resulting environmental interference. CFs are obtained from mathematical representations of cause effect-chains that can be spatially resolved and allow the conversion of a $\mathrm{LCl}$ into indicator scores for a number of mutually exclusive and collectively exhaustive "impact categories" such as climate change, eutrophication and eco-toxicity.

The characteristics of LCA make it potentially suitable for reducing or eliminating the listed weaknesses of current AESI. However LCA indicators can be characterized as RESI: Indicator scores are typically used to rank the environmental performance of functionally comparable product systems or scenarios, based on their potential to, via their emissions or resource uses, create a small change in the level of environmental interferences. This small change is either calculated as a marginal change in the known existing level of environmental interference or as an approximated linear change in interference within the zone between 0 and a chosen level of interference (see S1 for a conceptual figure of the two approaches) (Hauschild and Huijbregts, 2015). LCA indicators therefore generally do not include carrying capacity as sustainability reference values (Castellani and Sala, 2012). To harness the potentials of LCA in AESI, LCA indicators need to be modified to quantifying occupations of carrying capacity instead of quantifying small changes in levels of environmental interferences. The overall purpose of this article is to provide an initial contribution to this development.

This article aims to 1) develop a generic mathematical expression for calculating spatially resolved occupation of carrying capacity for any emissions based LCA impact category, 2) use this method tentatively on the terrestrial acidification LCA impact category, 3) demonstrate the applicability of the method in a case study, , 4) compare the relevance and complementarity of AESI and RESI in decision support.

\section{Methods}

\subsection{Definitions and interpretations}

To support the operationalization of carrying capacity (defined as "the maximum sustained environmental interference a natural system can withstand without experiencing negative changes in structure or functioning that are difficult or impossible to revert") we introduce two definitions: 1 ) control variable: "a numerical indicator of the structure and/or functioning of a natural system."; 2) Threshold: "the maximum value of a control variable a natural system can withstand without experiencing negative changes in structure and/or functioning that are difficult or impossible to revert." The carrying capacity is generally closer to the cause in an impact pathway than the threshold from which it is derived. Carrying capacity is static because it is calculated from a situation where a control variable value equals a threshold value at steady state (Bjørn and Hauschild, 2015). Note that the definitions of threshold and carrying capacity leave room for interpretation (what are negative changes and at what point do these become difficult to revert?). This interpretative flexibility is intentional as it reflects the ambiguity in the definition of environmental 
sustainability of Goodland (1995) with respect to preventing "harm to humans": Humans may be physically harmed by a reduction of material eco-system services (e.g. access to clean water) caused by severe environmental degradation. According to some, humans may also be harmed culturally and spiritually by effects on or disappearance of a single vulnerable species caused by just minor environmental degradation. Environmental sustainability can thus be interpreted anthropocentrically or eco-centrically (or somewhere in between), which can greatly influence the choice of threshold and resulting quantification of carrying capacity. The sensitivity of AESI scores to this interpretation of environmental sustainability and other choices is analysed in Bjørn et al. (2015).

\subsection{Characterisation framework}

In LCA characterisation factors (CF) are multiplied with each inventoried emission or resource use (Q) of pollutants or resource $(x)$ that contribute to a given impact category and the products are summed to calculate the indicator score (IS) for that impact category:

$$
I S=\sum_{x} C F_{x} \cdot Q_{x}
$$

By integrating carrying capacity as sustainable reference value in CFs, indicator scores can be expressed as occupation of carrying capacity. We propose this integration by dividing spatially resolved conventional CF constituents by carrying capacity (CC) for any emissions based indicator (aim 1):

$$
C F_{x, i, k}=\sum_{j} \frac{F F_{x, i, k, j} \cdot X F_{i, j} \cdot E F_{i, j}}{C C_{j}}
$$

Here CF (ha*year* ${ }^{*} g_{\text {emitted }}{ }^{-1}$ ) is the characterisation factor for substance $\mathrm{x}$ emitted within spatial unit $\mathrm{i}$ into environmental compartment $\mathrm{k}$ (air, soil or water). $\mathrm{FF}$ is a fate factor linking an emission of pollutant $\mathrm{x}$ within $\mathrm{i}$ into $\mathrm{k}$ to its fate typically expressed as a change in concentration or mass in the receiving spatial unit $\mathrm{j}$. XF is an exposure factor which accounts for the fraction of pollutant $x$ that species of concern in $j$ are exposed to. $E F$ is an effect factor, which calculates the effect increase on these species in $\mathrm{j}$ from an increased exposure of $\mathrm{x} . \mathrm{CC}$ is the carrying capacity in $\mathrm{j}$. The metric of CC depends on the metrics of FF, XF and EF and differs from one impact category to another. Note that equation 2 applies to indicators of effects on species. If indicator scores are expressed closer to the cause of these effects the denominator should only contain FF or FF.XF. When following equation 1 by multiplying CFs with emissions $(\mathrm{kg})$ the indicator score is expressing the carrying capacity occupation in a unit of ha.year, which indicates an area in which carrying capacity for a given impact category is occupied for a time. If the time frame during which pollutants are emitted is known, the indicator score can be expressed in a unit of ha, which resembles that of the ecological footprint method (Borucke et al., 2013).

Note that our proposed framework is only compatible with indicators for which FF, XF or EF are of a linear nature, i.e. that calculate the approximated linear environmental change from an emission within the zone between 0 and a chosen level of interference (see S1). Our proposed framework is not compatible with marginal CF components because these are derivatives of estimated existing levels of environmental interference, while carrying capacity should be independent of existing levels of environmental interference (Bjørn and Hauschild, 2015). 


\subsection{Application to terrestrial acidification}

We demonstrate the calculation of proposed characterisation factors for the LCA impact category terrestrial acidification, for which no AESI currently exists (aim 2). The spatial derivation was based on the only existing global deposition model of Roy et al. (2012) having a $2.0^{\circ} \times 2.5^{\circ}$ resolution (i.e. composed of 13,104 grid cells).

\subsubsection{Choice of control variable and threshold}

As a basis for carrying capacity two complementary thresholds of the control variable "soil solution pH" were chosen. The first threshold was based on a deviation of natural $\mathrm{pH}$ corresponding to the point where the numerical decrease in $\mathrm{pH}$ starts increasing for every additional quantity of deposition. At this point the functioning of the soil ecosystem starts changing as the carbonate buffering system is weakening and additional depositions will bring the system close to its chemical $\mathrm{pH}$ threshold. ${ }^{2}$ Based on a screening of $\mathrm{pH}$ curves modelled with the geochemical steady-state model PROFILE (Warfvinge and Sverdrup, 1992) we found that a $\mathrm{pH}$ decrease of 0.25 , compared to natural $\mathrm{pH}$, generally corresponded well with this point where $\mathrm{pH}$ starts responding non-linearly to additional depositions (see S2). The second threshold was required to take into account naturally acidic soils for which the critical factor threatening ecosystem structure is not $\mathrm{pH}$ decrease, but rather the mobilisation of toxic aluminium (III) from the buffering of acid depositions through reaction with aluminium oxides and hydroxides from clay particles (Sparks, 2002). This buffering process occurs in the $\mathrm{pH}$ interval 2.8-4.2 and we therefore chose $\mathrm{pH} 4.2$, below which aluminium (III) starts to mobilize, as the second threshold. ${ }^{3}$ In other words, we interpreted environmental sustainability, with regards to the interference of acidifying compounds with natural soils, to correspond to a situation where natural buffer systems are not weakened and aluminium (III) is not mobilized.

\subsubsection{Calculation of carrying capacity}

The carrying capacity was, inspired by the critical loads concept (Spranger et al., 2004), expressed as a critical deposition of acidifying compounds (eq. ha $^{-1} \cdot$ year $^{-1}$, where 1 eq refers to 1 mol H$^{+}$-eq.). The carrying capacity was derived for 99,515 spatial units, covering the global terrestrial area (Roy et al., 2012a), by running PROFILE in 9 steps gradually increasing depositions of $\mathrm{SO}_{\mathrm{x}}$ above natural levels for each spatial unit until a change of $0.25 \mathrm{pH}$ units or an absolute $\mathrm{pH}$ value below 4.2 was reached. Natural depositions were modelled based on Tegen and Fung (1994) and Bey et al. (2001) as described in Roy et al. (2012b). The design of the 9 steps is explained in S2. We found that $10 \%$ of spatial units were for at least one deposition step affected by a non-convergence error in PROFILE. For these cells the carrying capacity was approximated by neighbouring cells using a kriging function, see S4. Area-weighted averages of the carrying capacities of the 99,515 spatial units of PROFILE were used to estimate the carrying capacities of the 13,104 grid cells of the deposition model of Roy et al. (2012). CFs were then calculated according to equation 2

\footnotetext{
${ }^{2}$ We did not choose the steepest point of the chemical $\mathrm{pH}$ threshold as basis for carrying capacity because this point is often $2 \mathrm{pH}$ units or more below natural $\mathrm{pH}$, which represents a $\mathrm{pH}$ decrease that few species can tolerate (Azevedo et al., 2013) and can therefore not be considered as reference for environmental sustainability.

${ }^{3}$ Our choice of an absolute threshold of $4.2 \mathrm{pH}$ units is in good agreement with a proposal within the critical loads framework that a pH of 4 could be used to calculate critical loads for forest soils (Spranger et al., 2004).
} 
using atmospheric fate factors (FF, keq $_{\text {deposited }}{ }^{*} \mathrm{~kg}_{\text {emitted }}{ }^{-1}$ ) of Roy et al. $(2012)^{4}$ and excluding XF and EF in the denominator because $\mathrm{CC}$ is expressed as a critical deposition:

$$
C F_{x, i}=\sum_{j} \frac{F F_{x, i, j}}{C C_{j}}
$$

\subsection{Carrying capacity entitlement}

Our CFs can in principle be used to evaluate whether a society as a whole is environmentally sustainable because the indicator score, expressing the area equivalent of fully occupied carrying capacity, from all activities of the society can be compared to the actual area of the relevant ecosystem. An individual system embedded in society, such as a product, a person or company, can in turn be considered environmentally sustainable if it does not occupy more of the total carrying capacity than it can be considered entitled to. Carrying capacity entitlement is a normative concept because it depends on the perceived value of a studied system relative to those of "competing systems" that rely on occupying carrying capacity in the same area where the studied system occupies carrying capacity. Therefore environmental sustainability references for individual anthropogenic systems embedded in society are inherently normative. Below we outline three steps in deriving and applying these environmental sustainability references

\subsubsection{Identify competing systems}

Ideally competing systems would be identified by combining a source-receptor fate model with a spatially differentiated emission inventory covering all anthropogenic systems of society in a chosen reference year: The fate model would first identify the spatial units affected by emissions of the studied system. The fate model would then identify all the systems of the societal total emission inventory whose emissions affect the spatial units previously identified. These systems would be labeled competing systems because they rely on occupying parts of the same carrying capacity as the studied system for their functioning. Note that the group of competing systems is potentially unique for each affected spatial unit (of which there may be thousands). This is impractical to operate with and therefore three simplifications are introduced: 1) a cutoff criterion is established whereby only spatial units receiving above a specified share of emissions from the studied system (e.g. $0.1 \%$ ) are considered (the territory of these spatial units are termed $T_{\text {affected }}$ and its area is termed $A_{\text {affected }}$, 2) all emissions that occur within $T_{\text {affected }}$ are, in this part of the AESI, assumed to occur in the spatial unit where the emission from the studied system occurs and thus assumed to have the same fate, 3 ) it is assumed that no emissions within $T_{\text {affected }}$ leave $T_{\text {affected }}$ and that no emissions from outside enters. These three simplifications are visually presented in Figure 2.

\footnotetext{
${ }^{4}$ The fate factors of Roy et al. (2012) were expressed in $\mathrm{kg}_{\text {deposited }}{ }^{*} \mathrm{~kg}_{\text {emitted }}{ }^{-1}$. For this study $\mathrm{kg}_{\text {deposited }}$ was converted to $\mathrm{keq}_{\text {deposited }}$ by division by the molecular weight of the emissions and multiplication by the electrical charges of their corresponding ions, following Posch et al. (2008).
} 


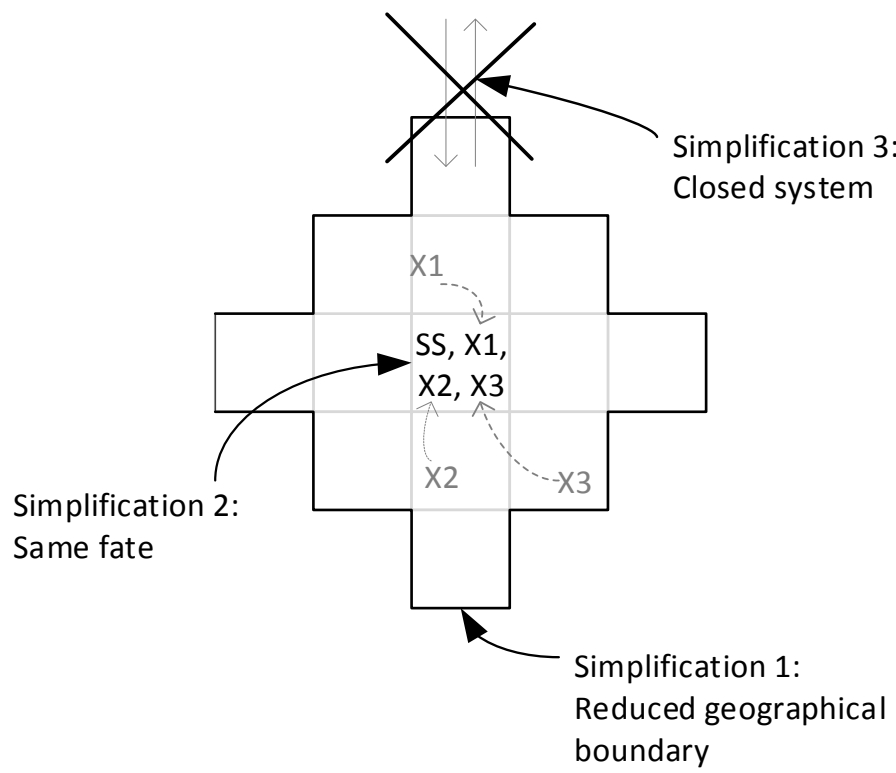

Figure 2: Illustration of three simplifications for identifying competing systems (X1-X3) of a studied system (SS) located in the middle grid cell and affecting 13 grid cells above an arbitrary emission distribution threshold. These 13 grid cells make up $T_{\text {affected }}$ and have the area $A_{\text {affected }}$. The dotted arrows indicate a change in location of X1-X3.

The consequence of the simplifications is that only one carrying capacity entitlement needs to be calculated for each emission location of a studied system and that the group of competing systems is the same for all anthropogenic systems within $T_{\text {affected. }}$. The simplifications can be defended in situations where potential competing systems are rather homogenously distributed in space and have emissions of similar magnitude. When this is not the case it may be more appropriate to follow the ideal approach outlined above to identifying competing systems.

\subsubsection{Quantify relative value of studied system}

The perceived value of a studied system relative to identified systems competing for carrying capacity in the same territory may be quantified using different valuation principles, such as 1) relative contribution to GDP, or 2) "grandfathering" where the relative value of a system is considered proportional to its relative indicator score in a chosen past reference year (i.e. if total carrying capacity was exceeded in the reference year, the indicator scores of all systems in that reference year should be reduced by the percentage that is needed to reduce the total indicator score below the total carrying capacity. The perceived relative value of a studied system may be expressed as a value factor (VF) between 0 and 1 of the total value (i.e. the sum of the perceived value of the studied system and those of competing systems).

\subsubsection{Calculate carrying capacity entitlement and compare to AESI score}

The time-integrated area in which carrying capacity can be entitled to a studied system ( $A_{\text {entitled, }}$ in ha·year) can be calculated by multiplying $A_{\text {affected }}$ for the studied system by the duration of the emissions $(t)$ and the value factor (VF) for each emissions location (i):

$$
A_{\text {entitled } \_i}=A_{\text {affected } \_i} \cdot t_{i} \cdot V F_{i}
$$

If $A_{\text {entitled }}$ exceeds the AESI score of a studied system for one or more emission locations (i) the studied system cannot be considered environmentally sustainable. 


\subsection{Case study}

We applied the derived CFs to emissions caused by the electricity production from one randomly selected coal fired electricity plant in each of 45 states of contiguous United States ${ }^{5}$ in 2010. For each of the electricity plants we calculated an emission inventory corresponding to the residential electricity consumption of an average inhabitant in the concerned state in the year 2010. The case study provided a vehicle for demonstrating the use of the proposed indicator for terrestrial acidification on 45 scenarios of realistic residential electricity consumption in a hypothetical situation where this is entirely supplied fuelled by coal (aim 3). ${ }^{6}$ We use the term "scenario" to stress that we are not attempting to model the actual situation. The case study also allows for discussing the relevance of LCA-supported AESI compared to using LCA to rank environmental performance (aim 4).

State specific annual-per capita annual residential electricity consumption was obtained from the US Department of Energy (DoE, 2015) and used to define the quantities of electricity produced (P) by each of 45 power plants (i) to meet the demand byfor an average inhabitant. Power plant specific emissions intensities (EI) expressing emissions of $\mathrm{SO}_{x}$ and $\mathrm{NO}_{x}(\mathrm{x})$ per $\mathrm{kWh}$ of generated electricity were obtained from the eGRID database of the US EPA (2014), which contains data on a total of 541 US coal fired electricity plants in 45 states. ${ }^{7}$ El was multiplied by $\mathrm{P}$ to obtain the emissions $(\mathrm{Q})$ of $\mathrm{SO}_{\mathrm{x}}$ and $\mathrm{NO}_{\mathrm{x}}$ per power plant (i). Indicator scores (IS) for each power plant were hence, following equation 1 , calculated as:

$$
I S_{i}=\sum_{x} C F_{i, x} \cdot Q_{x}=\sum_{x} C F_{i, x} \cdot P_{i} \cdot E I_{i, x}
$$

Here $\mathrm{CF}_{i, \mathrm{k}}$ is the characterisation factor derived for pollutant $\mathrm{x}\left(\mathrm{SO}_{\mathrm{x}}\right.$ or $\left.\mathrm{NO}_{\mathrm{x}}\right)$ for the grid cell in which power plant $\mathrm{i}$ is located.

Indicator scores were evaluated by comparing them to carrying capacity entitlements established calculated following the simplified approach outlined above: We used the fate model of Roy et al. (2012) to identify spatial units receiving depositions caused by emissions of the different power plants. This global model predicts that all its 13,104 grid cells of the global model-receives a share of an emission from any of the power plants (Roy et al., 2012b). However, most grid cells receive a very small share. For identifying competing systems we therefore used a cut-off value of $0.1 \%$ deposition of an emission. This resulted in an affected territory ( $T_{\text {affected }}$ ) for each $\mathrm{i}$ in which around $70 \%$ of an emission deposits (depending on the pollutant and i). ${ }^{8} A_{\text {affected }}$ (the area of $T_{\text {affected }}$ ) for all $i$ and both pollutant-are were found to be approximately equivalent to the area of the entire contiguous United States. Since all power plants are located in contiguous United States there is a great geographical overlap between $T_{\text {affected }}$ of the 45 emission scenario locations. This overlap justified the additional simplification of assigning the terrestrial area of contiguous United States_,765,300,400ha (USCB, 2012), a common T $\mathrm{affected}_{-}$and its area, 765,300,400ha (USCB, 2012), a

\footnotetext{
${ }^{5}$ The contiguous United States consists of the 48 adjoining U.S. states plus Washington, D.C. (federal district).

${ }^{6}$ In reality residential electricity use is supplied by various energy technologies that, due to an integrated federal grid, may be located far away (i.e. in another state) than the location of consumption.

${ }^{7}$ The states of Maine, Rhode Island and Vermont were not covered by the eGRID database of coal fired electricity plants, presumably because they have none.

${ }^{8}$ The remaining share of an emission, on average $30 \%$, deposits on grid cells receiving less than $0.1 \%$ of the emission and accumulates in high altitude, near the stratosphere.
} 
common $A_{\text {affected }}$-for all i. Competing systems for all $i$ are consequently all systems that emit acidifying compounds to air within the contiguous United States.

In quantifying the value factors (VF) of the 45 studied emissions scenarios two alternative valuations were applied to explore the sensitivity of case study outcomes to this form of value judgment. The first valuation was based on the relative contribution to GDP, estimated by dividing personal or household expenditure on a studied product or service by pre-tax income. In 2009 (no data for 2010) an average US household spent $2.0 \%$ of its pre-tax income on residential electricity (ACCCE, 2014). The relative contribution to GDP valuation principle thus grants residential electricity consumption a value of 0.02 relative to all other anthropogenic systems within $\mathrm{T}_{\text {affected }}$. The alternative valuation was based on the-grandfathering principle, according to which US residential electricity consumption is entitled to maintain its past share of total environmental interferences. In $201038 \%$ of US total electricity consumption was consumed by the residential sector (IEA, 2012), meaning that $38 \%$ of environmental interferences from total electricity consumption could be attributed to the residential sector. We could not obtain the share of environmental interference with respect to terrestrial acidification taken up by total electricity consumption of the total US environmental interference with respect to terrestrial acidification. We therefore approximated this share by the corresponding share in EU27, where in 2010 23\% of total environmental interferences was presumably taken up by electricity production.:- Our use of the grandfathering valuation principle thus grants residential electricity consumption in the US a tentative value of $9 \%(38 \%$ of $23 \%$ ) relative to all otheranthropogenic systems within $T_{\text {affected }}$.

Since both valuation principles were applied to average residential electricity consumption in the US, the value factors for the 45 scenarios are the same (i.e. not calculated specifically for each emissions scenario, although this is in theory possible) and can be calculated by dividing the nationwide relative values with the US-population of contiguous United States $(306,675,006$ 312,245,116 in 2010 (UNDESA USCB, 2015z)). $A_{\text {entitled }}$ was subsequently calculated for the alternative valuation principles following equation 4 : Relative contribution to GDP: $A_{\text {entitled }}=A_{\text {affected }} \cdot t \cdot V F=765,300,400 \mathrm{ha} \cdot 1$ year $\cdot \frac{0.02}{306,675,006312,245,116}=0.05049 \mathrm{ha} \cdot$ year $(6)$ Grandfathering:

$A_{\text {entitled }}=A_{\text {affected }} \cdot t \cdot V F=765,300,400 \mathrm{ha} \cdot 1$ year $\cdot \frac{0.09}{306,675,006312,245,116}=0.221$ ha $\cdot$ year

The two alternative $A_{\text {entitlted }}$ were compared to the indicator scores of the 45 scenarios to evaluate which of them could be considered environmentally sustainable. We then compared the spatial variation in each of the components of equation 5 , including the CF components of equation 3 , to analyse the sensitivity of indicator scores of the 45 scenarios to each of these components. As a basis for discussing the relevance of

\footnotetext{
${ }^{9}$ Environmental interferences were calculated using the tentative CFs for terrestrial acidification developed in this study (average of the 45 emission locations) on the emission inventory for EU27 of EMEP (2015). The sector "Combustion in energy and transformation industries (stationary sources)" of the EMEP inventory was assumed to cover electricity production only.
} 
AESI compared to RESI we furthermore compared the CFs of the 45 power plant locations with corresponding CFs of Roy et al. (2014).

\section{Results}

\subsection{Carrying capacities and characterisation factors}

Estimated carrying capacities (CC) ranged from less than 100 eq. $\cdot \mathrm{ha}^{-1} \cdot \mathrm{year}^{-1}$ to more than $4000 \mathrm{eq} \cdot \mathrm{ha}^{-1} \cdot \mathrm{year}^{-}$ ${ }^{1}$ with a median value around 500 eq. ha $^{-1} \cdot$ year $^{-1}$. The global distribution is shown in S5. Numerical CFs for all 13,104 grid cells for $\mathrm{NO}_{\mathrm{x}}, \mathrm{SO}_{\mathrm{x}}$ and $\mathrm{NH}_{\mathrm{x}}$ are available in a spreadsheet in $\mathrm{S6}$, from which they may be exported to LCA software such as GaBi (Thinkstep, 2015) or Simapro (PRé, 2015) and thereby linked to LCI databases such as Ecolnvent (2015). CFs for SO $\mathrm{x}$ ranged from less than $0.0054 \mathrm{ha} \cdot \mathrm{year} \cdot \mathrm{kg}^{-1}$ (10 ${ }^{\text {th }}$ percentile) to more than $0.41 \mathrm{ha} \cdot y e a r \cdot \mathrm{kg}^{-1}$ ( $90^{\text {th }}$ percentile) with a median value of $0.16 \mathrm{ha} \cdot \mathrm{year} \cdot \mathrm{kg}^{-1}$ (when excluding CFs for locations in the open sea, which are generally close to 0 ). In absolute terms the median $\mathrm{CF}$ for $\mathrm{SO}_{\mathrm{x}}$ can be interpreted as $1 \mathrm{~kg} \mathrm{SO}_{x}$ emitted occupying the carrying capacity of 0.048 hectares (corresponding to a square with $22 \mathrm{~m}$ sides) for 1 year. Figure 3 shows the distribution of $\mathrm{CFs}$ for all global locations of $\mathrm{NO}_{\mathrm{x}}$, $\mathrm{SO}_{\mathrm{x}}$ and $\mathrm{NH}_{\mathrm{x}}$.

\section{a) NOx}

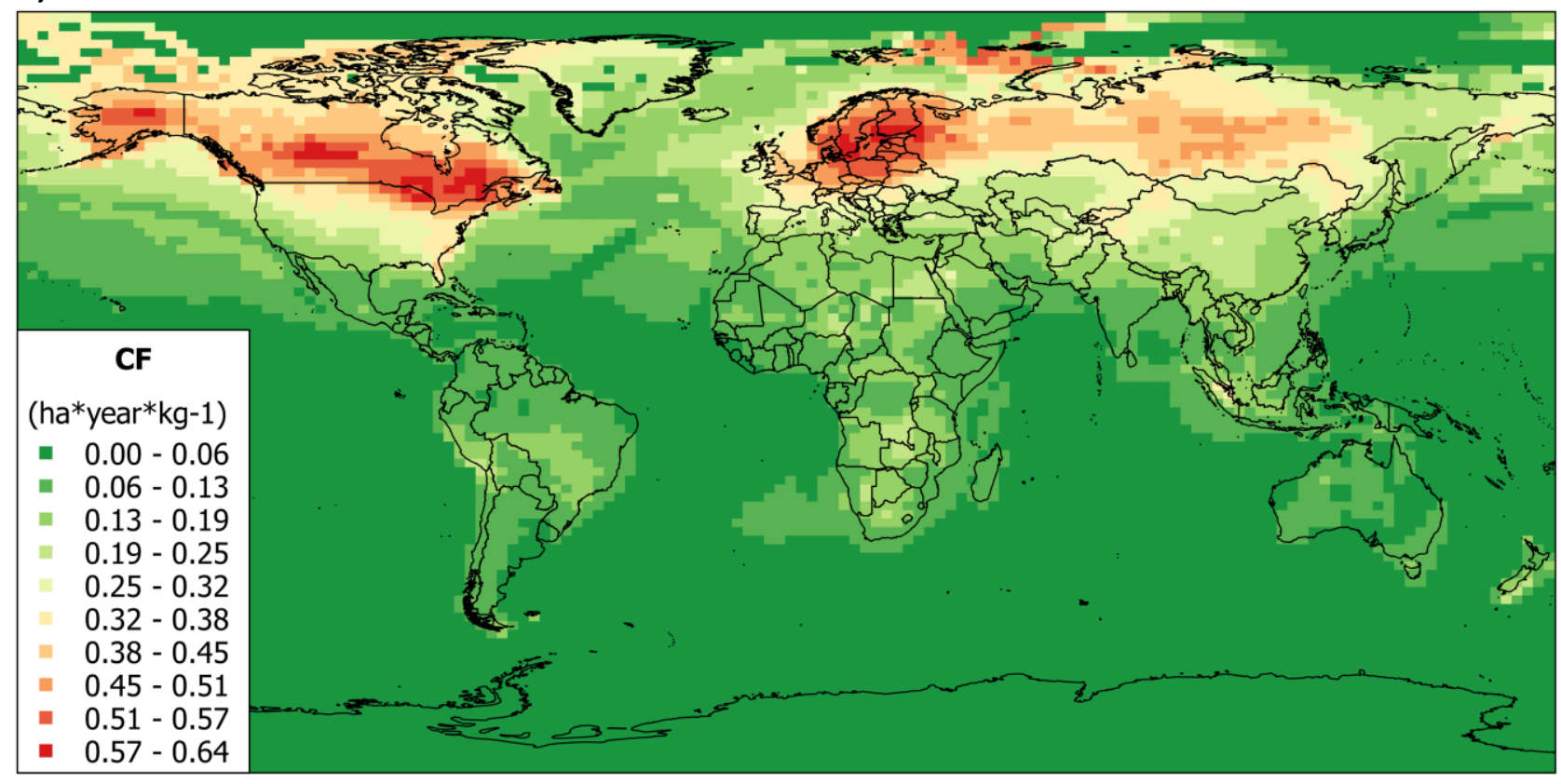




\section{c) $\mathrm{NHx}$}

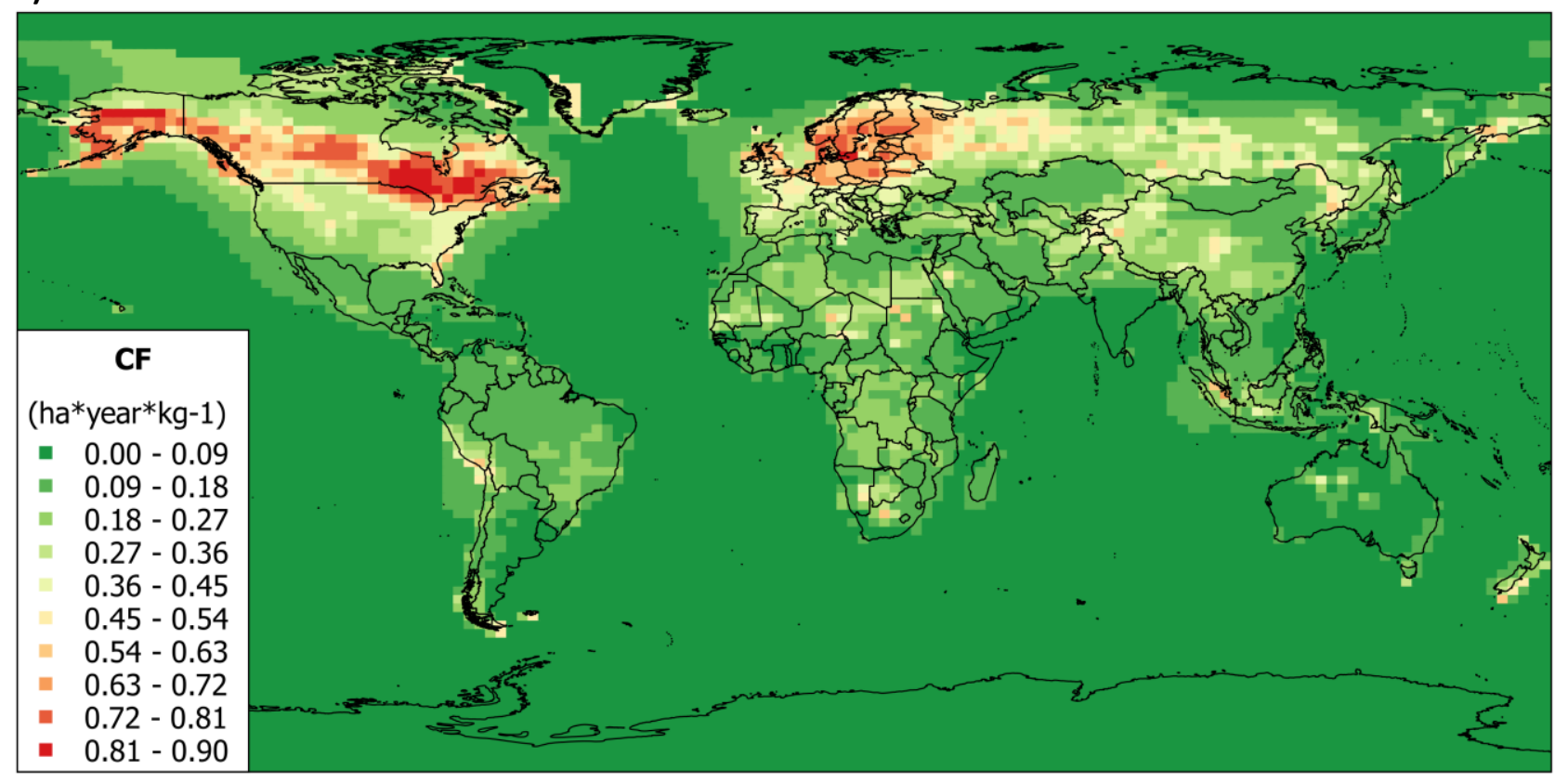

Figure 3: Global distribution of CFs for $\mathrm{NO}_{\mathrm{x}}(\mathrm{a}), \mathrm{SO}_{\mathrm{x}}(\mathrm{b})$ and $\mathrm{NH}_{\mathrm{x}}(\mathrm{c})$

It can be seen that CFs are generally highest in Northern Europe, Canada and Alaska, which is caused by the relatively low carrying capacity of soils in these regions (see S5). The highest CFs for $\mathrm{NO}_{\mathrm{x}}, \mathrm{SO}_{\mathrm{x}}$ and $\mathrm{NH}_{\mathrm{x}}$ corresponds to emission locations in Canada (latitude $55^{\circ}$; longitude $-112.5^{\circ}$ ), Denmark/Sweden (latitude $55^{\circ}$, longitude $12.5^{\circ}$ ) and Alaska (latitude $65^{\circ}$, longitude $-157.5^{\circ}$ ) respectively. It can also be seen that local differences in CFs (e.g. between neighbouring cells) are lowest for $\mathrm{NO}_{\mathrm{x}}$, higher for $\mathrm{SO}_{\mathrm{x}}$ and highest for $\mathrm{NH}_{\mathrm{x}}$. This is because the share of an emission that deposits in or close to the emission cell is largest for $\mathrm{NH}_{\mathrm{X}}$, 
smaller for $\mathrm{SO}_{\mathrm{x}}$ and smallest for $\mathrm{NO}_{\mathrm{x}} \cdot{ }^{10}$ In other words, local differences in carrying capacity have a much larger influence on $\mathrm{CFs}$ for $\mathrm{NH}_{\mathrm{x}}$ than for $\mathrm{NO}_{\mathrm{x}}$. This observation was also made by Huijbregts et al. (2000) for the spatial pattern of European CFs based on the critical loads concept (Spranger et al., 2004).

\subsection{Case study}

Table 1 shows the input parameters for equation 5 and indicator scores for the 45 emission scenarios.

Table 1: Input parameters for equation 5, indicator scores and comparison to two carrying capacity entitlements for 45 scenarios in the reference year 2010.

\begin{tabular}{|c|c|c|c|c|c|c|c|c|c|c|c|c|c|}
\hline 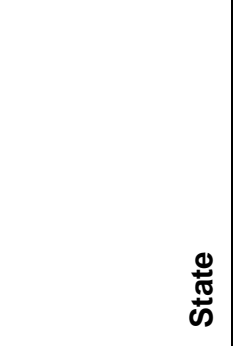 & 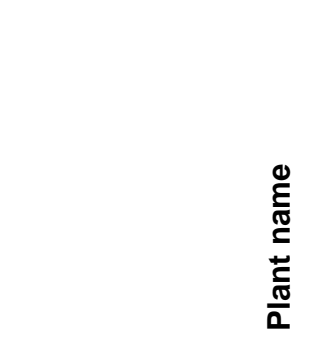 & 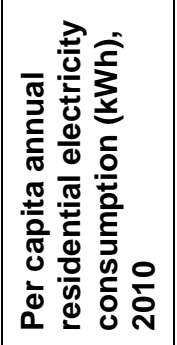 & 姜 & 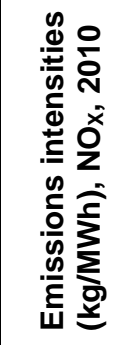 & 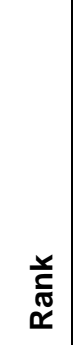 & 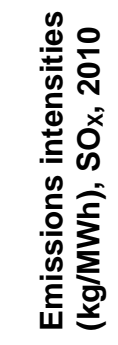 & 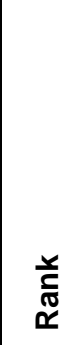 & 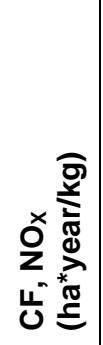 & 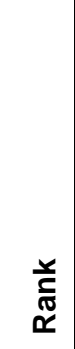 & 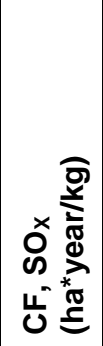 & 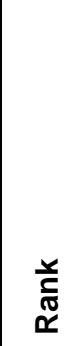 & 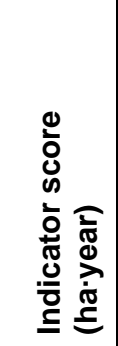 & 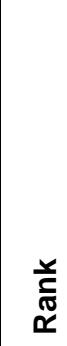 \\
\hline Alabama & Barry & 7425 & 1 & 0.50 & 37 & 1.11 & 26 & 0.23 & 38 & 0.24 & 37 & 2.81 & 29 \\
\hline Arkansas & White Bluff & 6584 & 8 & 1.31 & 18 & 2.36 & 22 & 0.24 & 36 & 0.24 & 34 & 5.85 & 19 \\
\hline Arizona & Coronado & 5060 & 23 & 1.83 & 16 & 1.70 & 24 & 0.16 & 44 & 0.17 & 44 & 2.92 & 28 \\
\hline California & Stockton Cogen & 2337 & 45 & 0.14 & 45 & 0.68 & 35 & 0.13 & 45 & 0.12 & 45 & 0.23 & 45 \\
\hline Colorado & Rawhide & 3587 & 37 & 0.73 & 30 & 0.35 & 39 & 0.31 & 25 & 0.36 & 6 & 1.28 & 39 \\
\hline Connecticut & Bridgeport Station & 3655 & 36 & 0.70 & 31 & 0.94 & 30 & 0.38 & 8 & 0.34 & 10 & 2.16 & 32 \\
\hline Delaware & $\begin{array}{l}\text { NRG Energy Center } \\
\text { Dover }\end{array}$ & 5295 & 20 & 2.32 & 9 & 5.24 & 9 & 0.35 & 13 & 0.31 & 19 & 12.87 & 10 \\
\hline Florida & Big Bend & 6489 & 11 & 0.48 & 38 & 0.96 & 29 & 0.34 & 17 & 0.44 & 3 & 3.85 & 25 \\
\hline Georgia & Bowen & 6338 & 12 & 0.28 & 41 & 0.30 & 40 & 0.33 & 22 & 0.32 & 16 & 1.20 & 40 \\
\hline lowa & $\begin{array}{l}\text { Walter Scott Jr } \\
\text { Energy Center }\end{array}$ & 4572 & 29 & 0.59 & 34 & 1.09 & 27 & 0.31 & 26 & 0.27 & 26 & 2.29 & 31 \\
\hline Idaho & $\begin{array}{l}\text { Amalgamated Sugar } \\
\text { LLC Nampa }\end{array}$ & 5180 & 21 & 3.53 & 4 & 11.60 & 4 & 0.28 & 30 & 0.27 & 28 & 21.26 & 5 \\
\hline Illinois & $\begin{array}{l}\text { John Deere } \\
\text { Harvester Works }\end{array}$ & 3783 & 35 & 3.80 & 3 & 20.56 & 2 & 0.33 & 19 & 0.28 & 24 & 26.89 & 2 \\
\hline Indiana & $\begin{array}{l}\text { Sagamore Plant } \\
\text { Cogeneration }\end{array}$ & 5402 & 19 & 2.58 & 6 & 11.00 & 5 & 0.30 & 27 & 0.25 & 31 & 18.87 & 7 \\
\hline Kansas & $\begin{array}{l}\text { Tecumseh Energy } \\
\text { Center }\end{array}$ & 5014 & 24 & 1.34 & 17 & 3.17 & 16 & 0.27 & 32 & 0.24 & 36 & 5.64 & 20 \\
\hline Kentucky & Ghent & 6703 & 7 & 0.57 & 35 & 0.82 & 31 & 0.30 & 28 & 0.27 & 27 & 2.64 & 30 \\
\hline Louisiana & Dolet Hills & 7190 & 2 & 0.91 & 27 & 4.10 & 10 & 0.20 & 40 & 0.21 & 39 & 7.56 & 15 \\
\hline Massachusetts & Salem Harbor & 3266 & 42 & 0.87 & 29 & 4.01 & 11 & 0.33 & 21 & 0.29 & 23 & 4.68 & 23 \\
\hline Maryland & $\begin{array}{l}\text { Morgantown } \\
\text { Generating Plant }\end{array}$ & 5002 & 25 & 0.24 & 42 & 0.67 & 36 & 0.33 & 18 & 0.31 & 18 & 1.43 & 37 \\
\hline Michigan & Belle River & 3511 & 38 & 0.99 & 25 & 2.74 & 18 & 0.40 & 5 & 0.34 & 9 & 4.72 & 22 \\
\hline
\end{tabular}

\footnotetext{
${ }^{10}$ The deposition patterns vary between emissions cells due to meteorological variations. Yet, a strong tendency of deposition shares close to the emission of $\mathrm{NH}_{x}$ being largest, of $\mathrm{SO}_{x}$ being smaller, and of $\mathrm{NO}_{x}$ being smallest was observed in deposition model of P.-O. Roy et al. (2012). E.g. for an emissions cell in Minnesota 35\% of a $\mathrm{NH}_{\mathrm{x}}$ emission deposits within the emission cell and $42 \%$ within the emission cell and the four neighboring cells, while the corresponding numbers for $\mathrm{SO}_{x}$ are $20 \%$ and $26 \%$ and for $\mathrm{NO}_{x}$ are $8 \%$ and $15 \%$ respectively (see also Figure 3 ).
} 


\begin{tabular}{|c|c|c|c|c|c|c|c|c|c|c|c|c|c|}
\hline Minnesota & Virginia & 4231 & 33 & 1.85 & 14 & 1.34 & 25 & 0.54 & 1 & 0.55 & 1 & 7.36 & 16 \\
\hline Missouri & $\begin{array}{l}\text { Southwest Power } \\
\text { Station }\end{array}$ & 6222 & 14 & 0.70 & 32 & 2.61 & 21 & 0.26 & 33 & 0.25 & 30 & 5.16 & 21 \\
\hline Mississippi & Henderson & 6793 & 5 & 5.81 & 2 & 6.43 & 8 & 0.24 & 36 & 0.24 & 34 & 20.11 & 6 \\
\hline Montana & Lewis \& Clark & 4591 & 28 & 2.16 & 10 & 2.71 & 20 & 0.39 & 7 & 0.32 & 17 & 8.08 & 12 \\
\hline North Carolina & Mayo & 6502 & 10 & 0.35 & 39 & 1.00 & 28 & 0.37 & 12 & 0.35 & 8 & 3.09 & 26 \\
\hline North Dakota & Antelope Valley & 6518 & 9 & 1.86 & 13 & 2.12 & 23 & 0.41 & 4 & 0.34 & 11 & 9.67 & 11 \\
\hline Nebraska & Platte & 5523 & 17 & 1.93 & 12 & 3.81 & 13 & 0.26 & 34 & 0.24 & 33 & 7.93 & 14 \\
\hline \begin{tabular}{|l|} 
New \\
Hampshire
\end{tabular} & Schiller & 3408 & 40 & 1.18 & 24 & 3.88 & 12 & 0.47 & 2 & 0.46 & 2 & 8.03 & 13 \\
\hline New Jersey & \begin{tabular}{|l|} 
Chambers \\
Cogeneration LP \\
\end{tabular} & 3444 & 39 & 0.55 & 36 & 0.82 & 32 & 0.35 & 13 & 0.31 & 19 & 1.53 & 36 \\
\hline New Mexico & Four Corners & 3270 & 41 & 2.53 & 7 & 0.72 & 34 & 0.19 & 42 & 0.19 & 42 & 2.05 & 33 \\
\hline Nevada & TS Power Plant & 4295 & 32 & 0.20 & 43 & 0.19 & 45 & 0.20 & 39 & 0.20 & 41 & 0.33 & 44 \\
\hline New York & AES Greenidge LLC & 2627 & 44 & 0.93 & 26 & 0.75 & 33 & 0.40 & 6 & 0.36 & 5 & 1.70 & 35 \\
\hline Ohio & Muskingum River & 4522 & 30 & 1.21 & 22 & 13.36 & 3 & 0.37 & 9 & 0.33 & 12 & 22.91 & 4 \\
\hline Oklahoma & Hugo & 6300 & 13 & 0.89 & 28 & 2.82 & 17 & 0.19 & 41 & 0.20 & 40 & 4.67 & 24 \\
\hline Oregon & Boardman & 4909 & 26 & 1.97 & 11 & 3.44 & 15 & 0.29 & 29 & 0.26 & 29 & 7.13 & 17 \\
\hline Pennsylvania & $\begin{array}{l}\text { G F Weaton Power } \\
\text { Station }\end{array}$ & 4345 & 31 & 1.29 & 19 & 2.73 & 19 & 0.37 & 9 & 0.33 & 12 & 5.97 & 18 \\
\hline South Carolina & $\begin{array}{l}\text { US DOE Savannah } \\
\text { River Site (D Area) }\end{array}$ & 7085 & 4 & 12.90 & 1 & 36.24 & 1 & 0.35 & 15 & 0.35 & 7 & 120.97 & 1 \\
\hline South Dakota & \begin{tabular}{|l|} 
Big Stone \\
\end{tabular} & 5672 & 16 & 3.46 & 5 & 3.52 & 14 & 0.42 & 3 & 0.37 & 4 & 15.66 & 8 \\
\hline Tennessee & Bull Run & 7109 & 3 & 0.29 & 40 & 0.21 & 43 & 0.32 & 23 & 0.31 & 21 & 1.11 & 41 \\
\hline Texas & Oak Grove & 5431 & 18 & 0.62 & 33 & 0.56 & 37 & 0.17 & 43 & 0.18 & 43 & 1.10 & 42 \\
\hline Utah & Huntington & 3183 & 43 & 1.23 & 21 & 0.46 & 38 & 0.24 & 35 & 0.24 & 32 & 1.31 & 38 \\
\hline Virginia & $\begin{array}{l}\text { Altavista Power } \\
\text { Station } \\
\end{array}$ & 6038 & 15 & 1.27 & 20 & 0.19 & 44 & 0.35 & 16 & 0.33 & 15 & 3.04 & 27 \\
\hline Washington & $\begin{array}{l}\text { Transalta Centralia } \\
\text { Generation } \\
\end{array}$ & 5178 & 22 & 1.20 & 23 & 0.27 & 41 & 0.27 & 31 & 0.23 & 38 & 1.99 & 34 \\
\hline Wisconsin & Nelson Dewey & 3918 & 34 & 2.35 & 8 & 10.25 & 6 & 0.33 & 19 & 0.28 & 24 & 14.47 & 9 \\
\hline West Virginia & Kammer & 6711 & 6 & 1.85 & 15 & 8.55 & 7 & 0.37 & 9 & 0.33 & 12 & 23.48 & 3 \\
\hline Wyoming & Wygen III & 4835 & 27 & 0.20 & 44 & 0.26 & 42 & 0.32 & 24 & 0.29 & 22 & 0.67 & 43 \\
\hline
\end{tabular}

\subsubsection{Absolute interpretation of results}

Indicator scores varied 2 orders of magnitude from a minimum of 0.23 ha.year to a maximum of 121 ha.year for a power plant located in California and South Carolina respectively. This means that the equivalent production of annual residential electricity use in 2010 occupies carrying capacities of between 0.23 ha and 121 ha of land for 1 year depending on the scenario. These areas are abstract because they cannot be empirically observed as special pieces of land somehow dedicated to absorbing acidifying emissions. Instead results should be interpreted as space integrated carrying capacity occupation, which is driven by carrying capacities in grid cells on which large shares of emissions deposit. Note that indicator results hold no information on the extent to which an emission occupy the carrying capacity of the individual grid cells that are affected by its depositions. ${ }^{11}$ Table 1 shows that none of the 45 scenarios could be considered environmentally sustainable when using any of the two valuation principles because these require indicator scores to be below $0.049 \underline{050}$ ha.year (relative contribution to GDP principle) or $0.2 \underline{21}$

\footnotetext{
${ }^{11}$ In a hypothetical example where carrying capacities of 4 grid cells of 1 ha are each occupied by $10 \%, 20 \%, 80 \%$ and $130 \%$ from depositions of an emission, the aggregated result would be 2.4 ha $(0.1 * 1$ ha $+0.2 * 1$ ha $+0.80 * 1$ ha $+1.3 * 1$ ha).
} 
ha·year (grandfathering principle). The scenario in California would, however, only require a slight reduction in indicator score $(0.0 \underline{1} z$ ha.year) to be considered environmentally sustainable from the application of the grandfathering perspective. Note that some of the scenarios may be considered environmentally sustainable by the use of other valuation principles than the two used in this study. If, for example, value factors had instead been derived from relative contribution to meeting human needs, a relatively high carrying capacity would perhaps be entitled to residential electricity, since it enables people to meet essential needs, such as heating and cooking (although residential electricity certainly can be used for meeting less essential needs too).

\subsubsection{Spatial variations}

Since the indicator score is directly proportional to all input parameters (equation 5), results are equally sensitive to variations of all input parameters, i.e. a doubling of any parameter will lead to a doubling of indicator results. From Table 1 it can be seen that the input parameter showing the strongest relative variation in the case study is the emission intensity (factors of almost 200 and 100 difference from smallest to largest for $\mathrm{SO}_{x}$ and $\mathrm{NO}_{\mathrm{x}}$ respectively) The cause of this variation is likely differences in flue gas cleaning systems, and for $\mathrm{SO}_{x}$ also differences in the sulfur content of the coal (Henriksson et al., 2014). By contrast the state specific annual per capita residential electricity consumption (P) varies by a factor of 3, while CFs vary by a factor of 5 and 4 for $\mathrm{SO}_{\mathrm{x}}$ and $\mathrm{NO}_{\mathrm{x}}$. Variations in $\mathrm{P}$ and $\mathrm{CF}$ thereby have negligible contributions to the observed 2 orders of magnitude variations in indicator scores of the 45 scenarios. In other words, to achieve a low carrying capacity occupation it is more important to be supplied by a power plant with low emission intensities than for the emissions of the power plant to deposit in areas with high carrying capacity or to reduce residential electricity consumption, although the latter is the only factor that the consumer can easily influence. The power plant located in South Carolina had by far the highest emission intensities of both $\mathrm{SO}_{\mathrm{x}}$ and $\mathrm{NO}_{\mathrm{x}}$, which is the reason that the highest indicator score was observed for the scenario in this state (see Table 1 ). The power plant located in California had the $5^{\text {th }}$ lowest average emissions intensity of the two pollutants. In combination with the lowest CF for both pollutants and the lowest residential electricity consumption this explains why the scenario of California had the lowest indicator score (see Table 1).

With regards to the sensitivity of CFs to input parameters, equation 3 in turn shows that CFs are highest when depositions concentrate around receiving cells with low carrying capacities. This explains why the lowest CFs for both pollutants corresponds to the location of the California power plant for which the majority of depositions happens on grid cell with quite high carrying capacities. On the other hand the highest average CF is for the power plant in Minnesota for which the majority of depositions happens on grid cell with quite low carrying capacities, see Figure 4. 


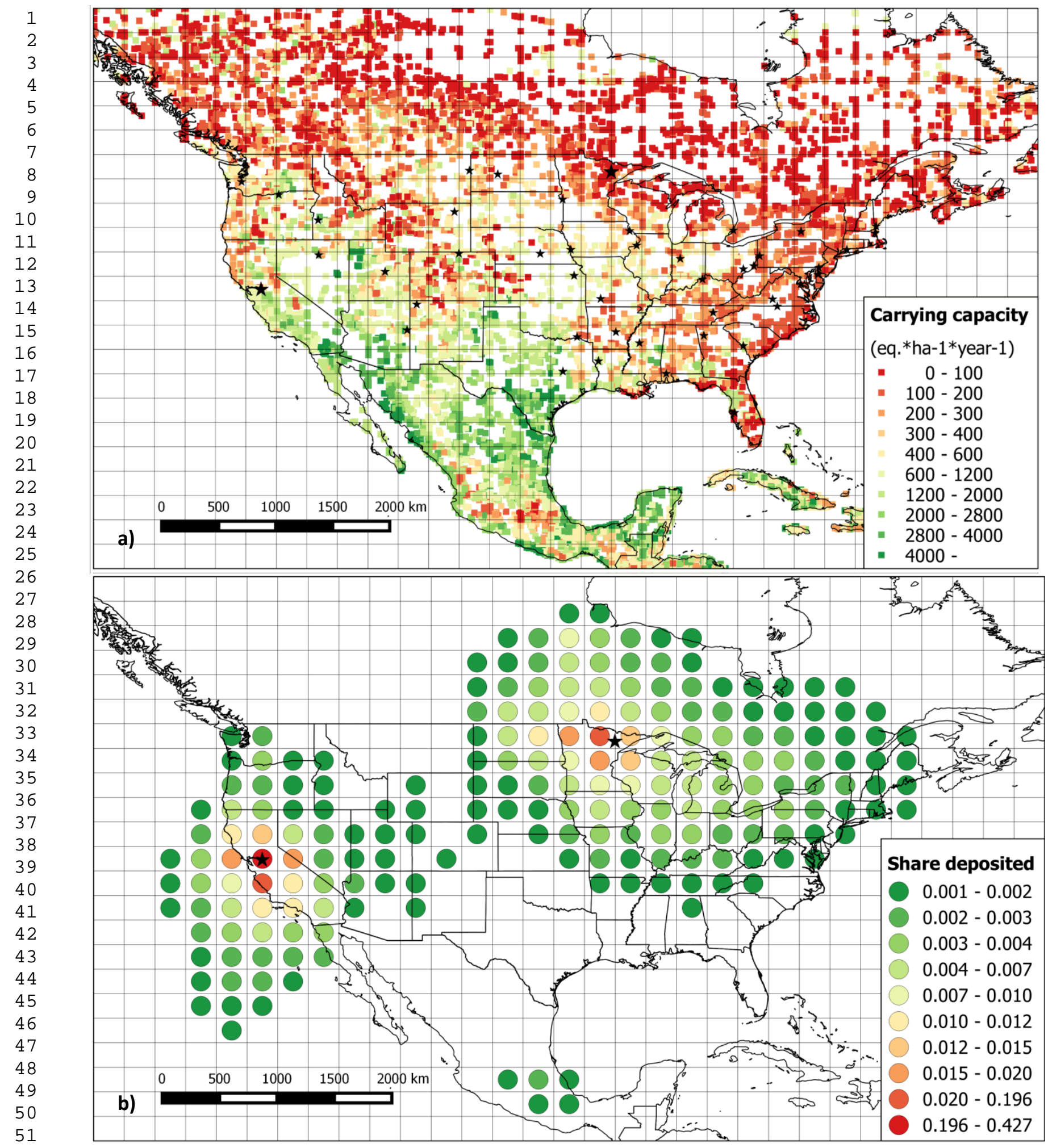

Figure 4: Maps of North America containing a) carrying capacities and power plants (stars), and b) deposition shares on cells receiving more than $\mathbf{0 . 1 \%}$ of $\mathrm{SO}_{\mathrm{x}}$ emissions from the power plants in California and Minnesota (enlarged stars). 


\subsubsection{Comparison with alternative CFs}

Our CFs express carrying capacity occupation per kg emission and are calculated as acid deposits divided by a pH-based carrying capacity integrated over space (see equation 3). In contrast, the CFs of Roy et al. (2014) express the marginal increase in concentration of $\mathrm{H}^{+}$-ions in soil solution, compared to modelled existing concentrations, per kg emission. These CFs are calculated as acid deposits multiplied by a so-called soil sensitivity factor which represents the change in existing soil $\mathrm{H}^{+}$related to a change in acid deposits integrated over space. Our CFs and the CFs of Roy et al. (2014) use the same fate factors for calculating acid deposits (Roy et al., 2012b) and thus differ only in the use of carrying capacity versus soil sensitivity factor. In Figure 5 we compare the two sets of CFs for the 45 power plant locations. Each set of CF is normalized to the CF of the power plants in Illinois, which ranks approximately in the middle of the 45 CFs for all pollutants and both studies.

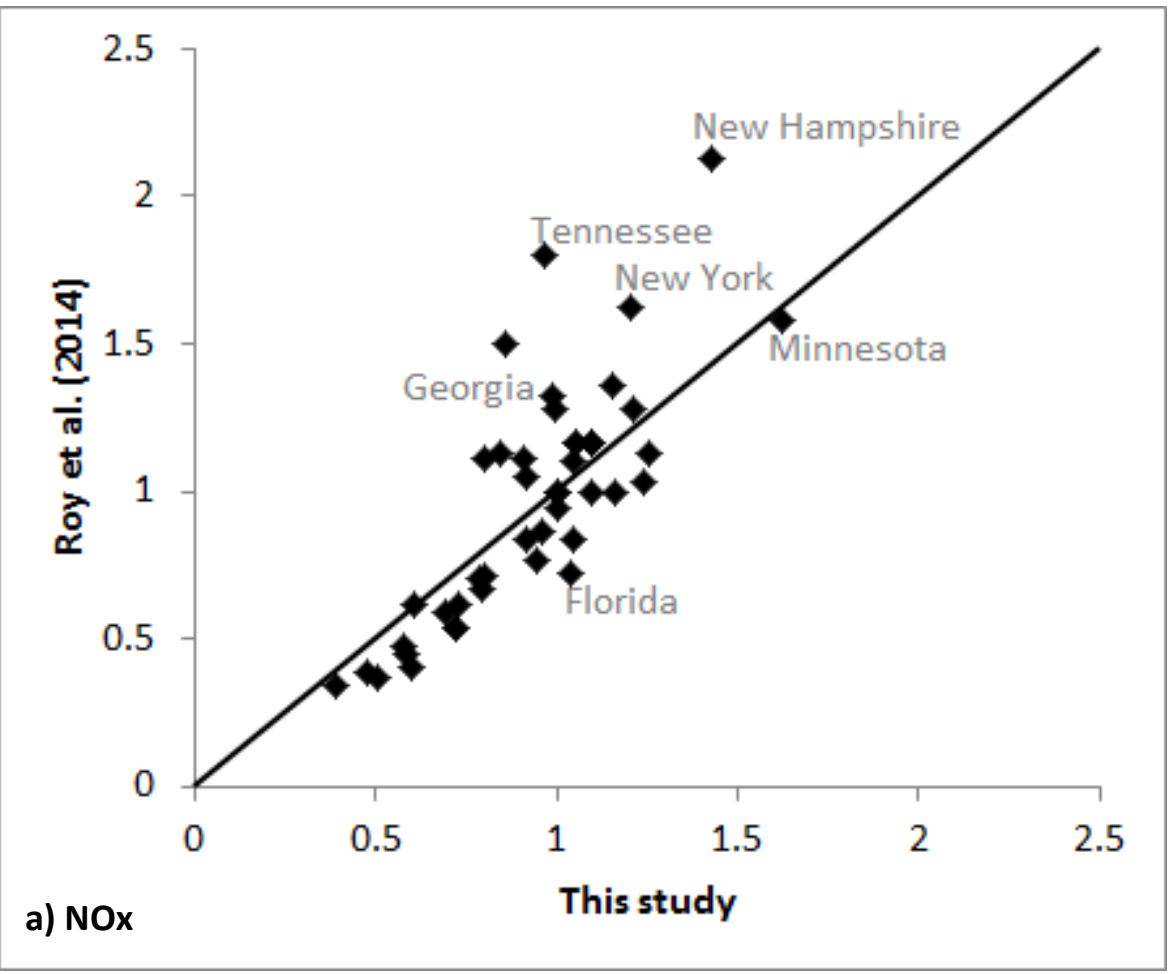



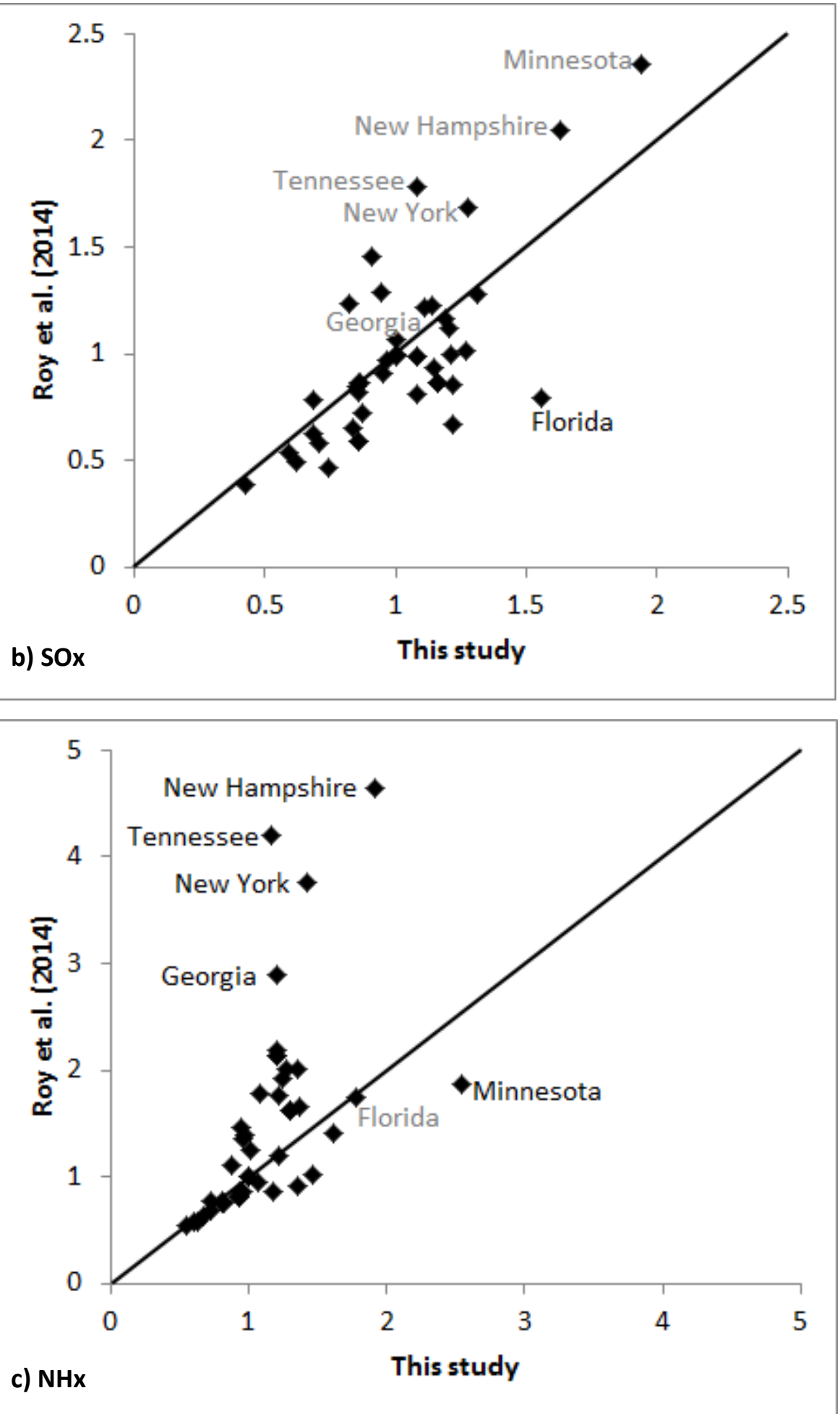

Figure 5: CFs of this study plotted against CF of Roy et al. (2014) for the 45 power plant locations for $\mathrm{NO}_{\mathrm{x}}, \mathrm{SO}_{\mathrm{x}}$ and $\mathrm{NH}_{\mathrm{x}}$. Each set of $\mathrm{CF}$ is normalized to the $\mathrm{CF}$ of the power plants in Illinois. State names are written for outliers (in grey across pollutants). CFs above the 1:1 line are relatively higher for Roy et al. (2014) than for this study and vice versa.

It can be seen that there is some agreement between the two sets of CFs for all pollutants, although the agreement appears lower for $\mathrm{NH}_{\mathrm{x}}$ than the other pollutants. The partial agreement can be explained from 
the common fate factors. Difference in agreement amongst the three pollutants can be explained from differences in deposition patterns of pollutants: Due to the relatively large shares of depositions of $\mathrm{NH}_{\mathrm{x}}$ close to the emission cell (see footnote 10 ) fewer grid cells receive large shares of an $\mathrm{NH}_{\mathrm{x}}$ emissions than for emissions of $\mathrm{SO}_{x}$ and $\mathrm{NO}_{\mathrm{x}}$. Differences between the relative values of carrying capacities and soil sensitivity factors in individual receiving cells will thus have the largest effect for $\mathrm{NH}_{\mathrm{x}} \mathrm{CFs}$. The range of CFs for the 45 power plant locations is for all pollutants larger for Roy et al. (2014) than for this study. This trend, which is strongest for $\mathrm{NH}_{\mathrm{x}}$ (Figure $5 \mathrm{c}$ ), can be explained from the high range of global soil sensitivity factors of 11 orders of magnitude compared to the range of carrying capacities in this study of just 2 orders of magnitude (see S5).

Two types of outliers can be seen on the plots of Figure 5. For the first type CFs in this study are relatively high, while CFs of Roy et al. (2014) are relatively low. This is the case for the CFs of Minnesota for $\mathrm{NH}_{\mathrm{x}}$ and CFs of Florida for $\mathrm{SO}_{x}$. In these cases the high $\mathrm{CFs}$ of this study are driven by relatively low carrying capacities in the grid cells receiving large shares of deposition. By comparison corresponding CFs of Roy et al. (2014) are moderate or low for Minnesota and Florida because soil sensitivity factors are moderate or low in the area receiving large shares of deposition. The observed discrepancies between soil sensitivity factors and carrying capacities can be explained from the fact that for some soils a relatively small acid deposition reduces the modelled natural $\mathrm{pH}$ by 0.25 , while a marginal increase in acid deposition, compared to the modelled existing deposition, leads to a low marginal pH decrease. See Figure $\mathrm{S} 7 \mathrm{~b}$ for a conceptual pH curve that illustrates this point. This discrepancy between carrying capacity and soil sensitivity factor occur for some soils that have low carrying capacities and for which the background acid deposition is relatively small. This is the case for the parts of the US Midwest and Canada that receive large shares of the depositions from the emission cell of the Minnesota power plant. In these scarcely populated areas modelled background depositions of the three pollutants are 1-2 orders of magnitude lower than those of the most densely populated part of the US East Coast (data not shown).

Outliers of the second type, i.e. low CFs of this study and high CFs of Roy et al. (2014), can be observed in Figure $5 \mathrm{c}$ for $\mathrm{NH}_{\mathrm{x}}$ for the grid cells of the New Hampshire, New York, Georgia and Tennessee power plants. In these cases the high CFs of Roy et al. (2014) are driven by high soil sensitivity factors in the emission cell and neighboring grid cells. These factors are high because modelled existing depositions are, due to high modelled existing depositions, somewhere in the steep interval of the $\mathrm{pH}$ curves of the soils, meaning that marginal increases in deposition can create high reductions in $\mathrm{pH}$ in these grid cells. See Figure S7c for a conceptual pH curve. Due to the large variation of soil sensitivity factors (see above), high factors in just a few of the grid cells receiving relatively high shares of an emission can to a very large extent drive CF values of Roy et al. (2014). By comparison the CFs of this study for the grid cells of the New Hampshire and New York power plants are no more than moderate in spite of low to moderate carrying capacities in the vicinity of the emission grid cell, because the power plants are close to the sea, meaning that relatively high shares of emissions deposits on water. 


\section{Discussion}

We have demonstrated the feasibility of modifying LCA indicators to AESI. Thereby we have shown that LCA can potentially solve some of the problems associated with current AESI, such as incomplete coverage of impact categories, varying quality of inventory data, varying or insufficient spatial resolution and the inconvenience to users of needing different software tools for accessing and using AESI. With point of departure in the experiences from the case study, this section discuss differences and complementarities between LCA based RESIs and AESI in decision support (aim 4) and proposes a research agenda for the support of AESI by LCA.

\subsection{Decision support related to absolute environmental sustainability}

The main characteristic of AESI is that they allow for the assessment of environmental sustainability of systems in absolute terms. This information can be useful on many levels. It may for instance quantitatively inform various emission reduction scenarios designed by e.g. municipalities, nations and supranational organizations with the purpose of achieving environmental sustainability. AESI can thus play similar roles as greenhouse gas emissions reduction scenarios, designed to prevent e.g. a temperature increase of $2^{\circ} \mathrm{C}$ (IPCC, 2013; Vuuren et al., 2011), that have been adopted at different governmental levels. Also AESI may support individuals motivated to learn what it takes to have an environmentally sustainable life style, i.e. one that is associated with environmental interferences that do not exceed the carrying capacity entitled to an individual person.

\subsection{Decision support related to ranking}

For a given impact category the ranking of systems or scenarios obtained by an AESI will in principal be identical to the ranking obtained by a RESI (relative environmental sustainability indicator) when the impact pathway model of the RESI is based on a linear approach (see the introduction section and S1). This is because the relationship between RESI and AESI CFs in such cases will be the same across pollutants and locations. There will therefore be no conflict between RESI based on the linear approach and AESI when used to support decisions where environmental performances of alternative solutions are part of the decision criteria. However, when the impact pathway model of a RESI is based on a marginal approach (see the introduction section and S1)there may be discrepancies in the relationships between AESI and RESI CFs across pollutants and locations, and thus in the ranking of systems or scenarios. This was observed to some extent in the case study when comparing the AESI developed in this study to the marginal based RESI of Roy et al. (2014) (see Figure 5). Thus, if the aim is to oppose reductions in soil solution pH, as quantified by Roy et al. (2014), the optimal solution may be different than the one corresponding to the aim of achieving the lowest possible carrying capacity occupation. Given these discrepancies between AESI and marginal based RESI, which type of indicator should ideally be used to support decisions related to environmental sustainability? The answer, we will argue in the next sub-section, is neither of the two, but both combined.

\subsubsection{Risk of sub-optimization}

If either marginal based RESIs or AESI are used in isolation there is a risk of sub-optimal decision support. In the case of marginal based RESIs Huijbregts et al. (2011) argued that quantifying marginal changes in environmental interferences can be misleading in cases where changes are small, but existing levels of environmental interferences are unacceptably high. For the impact category terrestrial acidification this may be the case for receiving cells in which existing depositions are so high that the corresponding existing $\mathrm{pH}$ is at the lower buffering zone of a pH curve (see Figure S7d and S7e). At this zone additional depositions 
of hydrogen ions are effectively buffered through reaction with aluminium oxides and hydroxides from clay particles. In such cases RESI based CFs will be low and marginal emission increases will thus seem relatively unproblematic although the state of the soil ecosystems is highly degraded by existing depositions. Another case of sub-optimal decision support is when marginal changes are small and existing levels of environmental interferences are low, i.e. far from exceeding thresholds (see Figure S7a). Although a small marginal increase in existing levels of environmental interferences can here seem unproblematic for environmental sustainability this conclusion is not scalable. The marginal approach thus suffers from a freeriding bias, i.e. only "the drop that spills the cup" is blamed for the crossing of a threshold. This is especially problematic in situations where the combined environmental pressure is increasing, which has for example been the case in large parts of China during the last couple of decades. In such situations CFs based on marginal RESIs will potentially be highly time dependent.

Decisions made only with the aid of AESI can also be suboptimal. For instance they may lead to choices that favour systems whose emissions end up in spatial units with high carrying capacity. Such choices can be suboptimal because they do not consider emissions of existing or future anthropogenic systems that, combined with the additional emissions, risk to exceed carrying capacities in these spatial units. An ideal quantification of entitlement would eliminate this risk of sub-optimization because it would take into account existing and potential competing systems, but the risk is quite real considering the difficulties of carrying out an ideal quantification of entitlement (see Section 2.4).

\subsubsection{Combining marginal based RESI and AESI to avoid sub-optimization}

The differences between the AESI and marginal based RESI are not only technical, but in fact also ethical: The CFs for terrestrial acidification developed in this study are compatible with decision making grounded in rule based ethics according to which a decision is considered "good" if it follows one or more prescribed rules that may be either universal or situation-dependent (Ekvall et al., 2005). In AESI the rule is that a decision should, whenever possible, lead to anthropogenic systems that do not occupy more carrying capacity than they can be considered entitled to. If this is not possible within the decision space, the rule is that a decision should lead to the lowest possible carrying capacity occupation amongst alternatives. Thus if all societal decisions were to follow these rules a transition towards environmental sustainability would in principle happen. ${ }^{12}$ In contrast, the decision-making that the marginal RESI of Roy et al. (2014) supports is grounded in consequential ethics, according to which a decision is "good" if its consequences are better than those of alternative(s) (Ekvall et al., 2005). The rule and consequential based ethics are conflicting in cases where following the prescribed rule(s) does not lead to the best consequences and vice versa. ${ }^{13}$

In real life, decisions are unlikely to be based entirely on either rule or consequential ethics, because decisions are often taken in consensus processes and because individuals rarely $100 \%$ adhere to a specific ethical mindset (Hofstetter, 1998). Therefore the different ethical perspectives of marginal based RESI and AESI can be seen as complementary rather than competing. In the case study, our AESI was used to

\footnotetext{
${ }^{12}$ Note that the only way to guarantee that total carrying capacity is not exceeded by the combined environmental interferences of all anthropogenic systems is to (somewhat oxymoronically) ensure that the same valuation principle is used to calculate carrying capacity entitlement of all systems.

${ }^{13}$ Consider the hypothetical situation where a person has the option of saving 5 lives by taking 1 (innocent) life. Doing this would lead to the best consequence, compared to inaction, but would also violate the rule of not killing an (innocent) person (Thomson, 1976).
} 
evaluate the sustainability of the 45 scenarios absolutely and to point to the scenario associated with the lowest carrying capacity occupation. The RESI oriented CFs of Roy et al. (2014) could on the other hand point to the scenario associated with the lowest marginal increase in environmental interferences. Both types of information are valuable in decision processes, which aim to simultaneously reduce existing levels of environmental interferences efficiently and maintain, or take steps towards achieving, environmental sustainability of society as a whole and of its individual anthropogenic systems.

\subsection{Research agenda on AESI in a life cycle perspective}

This study is intended primarily as a proof of concept and its theme must be expanded upon in future research for the proposed modification of LCA to measure environmental sustainability in absolute terms to be useful in decision support. Below we outline a few key challenges that deserve academic attention.

The designs of AESI are associated with several choices, to which indicator scores may show different degrees of sensitivities. In our modification of the LCA indicator for terrestrial acidification to AESI the choices of control variable, threshold value and the use of PROFILE to translate the threshold into carrying capacities all have potentially high contribution to uncertainty in indicator scores and efforts to reduce this uncertainty should be made (see S9 for an elaboration). Similar choices are unavoidable in any AESI. It is therefore important for indicator designers to 1 ) be aware of these choices and communicate them explicitly to users, so they can be considered in the decision support along with the indicator scores, 2) to quantify the sensitivity of indicator scores to changes in choices, and 3) to use these quantifications to effectively reduce overall uncertainties in indicator scores. As most choices are, at least partially, related to value judgement, consensus processes involving e.g. environmental scientists, indicator designers and indicator users may be feasible for reducing overall uncertainties.

Uncertainties in LCls also deserve attention when using AESI. Because many current societies cannot be considered environmentally sustainable a key use of AESI is to support transitions towards environmentally sustainable societies. Such transitions per definition involve large changes in technologies. For example, environmental interferences from energy use are expected to change considerably in many countries over the next decades. As a result, environmental interferences of many product systems will also change in the future. It is therefore important to carefully evaluate, and if necessary modify, existing $\mathrm{LCl}$ unit processes in absolute environmental sustainability assessments, which aims to capture the effects of future technological transformations (Miller and Keoleian, 2015).

A core characteristic of LCA is that it covers a comprehensive set of impact categories. In this context a relevant question is how to aggregate AESI scores from different impact categories. One option is to simply add the scores since they can be expressed in the same metric (ha.year) for all impact categories. However, a weighting step may be required as the consequences of exceeding carrying capacities can vary in severity between impacts categories. Some factors influencing the severity of exceedance are the social and/or economic consequences, the spatial extent and the time required for reversion of damage. In addition, care should be taken when attempting to aggregate indicator scores across impact categories, since the interaction between different types of environmental interferences within a specific territory is complex and not well understood. For some combinations of impact categories additivity between carrying capacity occupations may be a good assumption. In other cases, however, a territory that has its carrying capacity 
$100 \%$ occupied for one impact category may have unoccupied carrying capacity for other impact categories $^{14}$, which means that simply adding indicator scores across impact categories would overestimate the actual area equivalent of carrying capacity occupation. Another challenge related to aggregating indicator scores is the need for absolute sustainability references for the LCA impact categories that are not related to ecosystems, i.e. those related to human health impacts and depletion of non-renewable resources. Carrying capacity does per definition not apply to such impact categories, but other more normative sustainability references may be quantified (McElroy et al., 2008).

Another key challenge is how to integrate a carrying capacity entitlement module in LCA software that is relevant and requires only a manageable data input by the software user. Ideally the user should only have to choose a valuation principle and define the duration of environmental interventions $(t)$ of each emission location. The software would then calculate $T_{\text {affected }}$ and $A_{\text {affected, identify competing systems and }}$ subsequently calculate VF to arrive at the carrying capacity entitlement (see equation 4 ) for each emission location and compare this to the corresponding indicator score. This would require the software to be equipped with a fate model, calculating $T_{\text {affected }}$ and $A_{\text {affected }}$ for each emission location, and to be linked to a complete spatially derived emission inventory that contains information needed to calculate $V F$, such as contribution to GDP, for each of its anthropogenic systems. For many emissions in a typical product life cycle location and duration ( $\mathrm{t}$ ) will be partly or completely unknown. The AESI should therefore be equipped with a meaningful default choice for location and duration that is compatible with the calculation of carrying capacity entitlement.

\section{Supporting Information}

Supporting information is available online and contains methodological details and elaboration of results and discussions.

\section{References}

ACCCE, 2014. Energy Cost Impacts on American Families, 2001-2014. American Coalition for Clean Coal Electricity

Azevedo, L.B., van Zelm, R., Hendriks, a J., Bobbink, R., Huijbregts, M. a J., 2013. Global assessment of the effects of terrestrial acidification on plant species richness. Environ. Pollut. 174, 10-5.

Bey, I., Jacob, D.J., Yantosca, R.M., Logan, J.A., Field, B.D., Fiore, A.M., Li, Q.B., Liu, H.G.Y., Mickley, L.J., Schultz, M.G., 2001. Global modeling of tropospheric chemistry with assimilated meteorology: Model description and evaluation. J. Geophys. Res. 106, 23073-23095.

Bjørn, A., Diamond, M., Birkved, M., Hauschild, M.Z., 2014. Chemical footprint method for improved communication of freshwater ecotoxicity impacts in the context of ecological limits. Environ. Sci. Technol. 48, 13253-13262.

Bjørn, A., Hauschild, M.Z., 2015. Introducing carrying capacity based normalization in LCA: framework and development of references at midpoint level. Int. J. Life cycle Assess. 20, 1005-1018.

Bjørn, A., Richardson, K., Hauschild, M.Z., 2015. Environmentally sustainable or not? Managing and reducing indicator uncertainties. Ecol. Indic. In review.

\footnotetext{
${ }^{14}$ This situation will for example occur when carrying capacities are derived from a threshold of affected species and when the species that are most sensitive to one type of environmental interferences (e.g. acidification) are different than the species that are most sensitive to another type (e.g. chemicals with eco-toxicity potentials).
} 
Borucke, M., Moore, D., Cranston, G., Gracey, K., Iha, K., Larson, J., Lazarus, E., Morales, J.C., Wackernagel, M., Galli, A., 2013. Accounting for demand and supply of the biosphere's regenerative capacity: The National Footprint Accounts' underlying methodology and framework. Ecol. Indic. 24, 518-533.

Castellani, V., Sala, S., 2012. Ecological Footprint and Life Cycle Assessment in the sustainability assessment of tourism activities. Ecol. Indic. 16, 135-147.

DoE, 2015. Clean Energy in My State [WWW Document]. Department of Energy. URL http://apps1.eere.energy.gov/states/

Ecoinvent, 2015. Ecoinvent version 3 [WWW Document]. URL http://www.ecoinvent.org/

Ekvall, T., Tillman, A.-M., Molander, S., 2005. Normative ethics and methodology for life cycle assessment. J. Clean. Prod. 13, 1225-1234.

EMEP, 2015. Emissions as used in EMEP models [WWW Document]. WebDab - EMEP database. The European Monitoring and Evaluation Programme. URL http://www.ceip.at/ms/ceip_home1/ceip_home/webdab_emepdatabase/emissions_emepmodels/

EPA, 2014. Ninth edition with year 2010 data (Version 1.0) [WWW Document]. eGRID. Environmental Protection Agency. URL http://www.epa.gov/cleanenergy/energy-resources/egrid/index.html

Goodland, R., 1995. The Concept of Environmental Sustainability. Annu. Rev. Ecol. Syst. 26, 1-24.

Greenpeace, 2012a. Scorecard. Greenpeace.

Greenpeace, 2012b. Guide to Greener Electronics - Ranking Criteria Explained: August 2012, v. 18 onwards. Greenpeace

Hak, T., Moldan, B., Dahl, A.L., 2012. Editorial. Ecol. Indic. 17, 1-3.

Hauschild, M.Z., Huijbregts, M.A.J., 2015. Life Cycle Impact Assessment. Springer Netherlands.

Henriksson, P.J.G., Zhang, W., Guinée, J.B., 2014. Updated unit process data for coal-based energy in China including parameters for overall dispersions. Int. J. Life Cycle Assess. 20, 185-195.

Hoekstra, A.Y., Mekonnen, M.M., 2012. The water footprint of humanity. Proc. Natl. Acad. Sci. U. S. A. 109, 3232-3237.

Hofstetter, P., 1998. Perspectives in life cycle impact assessment : A structures approach to combine models of the technosphere, ecosphere and valuesphere. Kluwer Academic Publishers.

Hsu, A., Emerson, J., Levy, M., Sherbinin, A. de, Johnson, L., Malik, O., Schwartz, J., Jaiteh, M., 2014. The 2014 Environmental Performance Index. New Haven, CT.

Huijbregts, M. A. J., Hellweg, S., Frischknecht, R., Hungerbühler, K., Hendriks, a. J., 2008. Ecological footprint accounting in the life cycle assessment of products. Ecol. Econ. 64, 798-807.

Huijbregts, M. A. J., Schöpp, W., Verkuijlen, E., Heijungs, R., Reijnders, L., 2000. Spatially Explicit Characterization of Acidifying and Eutrophying Air Pollution in Life-Cycle Assessment. J. Ind. Ecol. 4, 75-92.

Huijbregts, M.A.J., Hellweg, S., Hertwich, E., 2011. Do We Need a Paradigm Shift in Life Cycle Impact Assessment ? Environ. Sci. Technol. 45, 3833-3834.

IEA, 2012. Electricity Information - IEA Statistics. International Energy Agency.

IPCC, 2013. Climate Change 2013: The Physical Science Basis. Contribution of Working Group I to the Fifth Assessment Report of the Intergovernmental Panel on Climate Change. Cambridge University Press, Cambridge, United Kingdom and New York, NY, USA.

Kitzes, J., Galli, A., Bagliani, M., Barrett, J., Dige, G., Ede, S., Erb, K., Giljum, S., Haberl, H., Hails, C., JoliaFerrier, L., Jungwirth, S., Lenzen, M., Lewis, K., Loh, J., Marchettini, N., Messinger, H., Milne, K., Moles, R., Monfreda, C., Moran, D., Nakano, K., Pyhälä, A., Rees, W., Simmons, C., Wackernagel, M., Wada, Y., Walsh, C., Wiedmann, T., 2009. A research agenda for improving national Ecological Footprint accounts. Ecol. Econ. 68, 1991-2007.

McElroy, M.W., Jorna, R.J., Engelen, J. Van, 2008. Sustainability Quotients and the Social Footprint. Corporate Social Responsibility and Environment Management 234, 223-234.

Miller, S. a, Keoleian, G. a, 2015. Framework for analyzing transformative technologies in life cycle assessment. Environ. Sci. Technol. 49, 3067-75. 
Moldan, B., Janoušková, S., Hák, T., 2012. How to understand and measure environmental sustainability: Indicators and targets. Ecol. Indic. 17, 4-13.

Posch, M., Seppälä, J., Hettelingh, J.-P., Johansson, M., Margni, M., Jolliet, O., 2008. The role of atmospheric dispersion models and ecosystem sensitivity in the determination of characterisation factors for acidifying and eutrophying emissions in LCIA. Int. J. Life Cycle Assess. 13, 477-486.

PRé, 2015. SimaPro - World's Leading LCA Software [WWW Document]. URL http://www.presustainability.com/simapro

Roy, P.-O., Azevedo, L.B., Margni, M., van Zelm, R., Deschênes, L., Huijbregts, M.A.J., 2014. Characterization factors for terrestrial acidification at the global scale: A systematic analysis of spatial variability and uncertainty. Sci. Total Environ. 500-501C, 270-276.

Roy, P.-O., Deschênes, L., Margni, M., 2012a. Life Cycle Impact Assessment of Terrestrial Acidification: Modeling Spatially Explicit Soil Sensitivity at the Global Scale. Environ. Sci. Technol. 46, 8270-8278.

Roy, P.-O., Huijbregts, M., Deschênes, L., Margni, M., 2012b. Spatially-differentiated atmospheric sourcereceptor relationships for nitrogen oxides, sulfur oxides and ammonia emissions at the global scale for life cycle impact assessment. Atmos. Environ. 62, 74-81.

Sayre, N.F., 2008. The genesis, history, and limits of carrying capacity. Ann. Assoc. Am. Geogr. 98, 120-134.

Singh, R.K., Murty, H.R., Gupta, S.K., Dikshit, a. K., 2012. An overview of sustainability assessment methodologies. Ecol. Indic. 15, 281-299.

Sparks, D.S., 2002. Environmental Soil Chemistry, 2nd ed. Academic Press.

Spranger, T., Lorenz, U., Gregor, H.-D., 2004. Manual on methodologies and criteria for Modelling and Mapping Critical Loads \& Levels and Air Pollution Effects, Risks and Trends. Federal Environmental Agency (Umweltbundesamt), Berlin.

Steffen, W., Richardson, K., Rockstrom, J., Cornell, S.E., Fetzer, I., Bennett, E.M., Biggs, R., Carpenter, S.R., de Vries, W., de Wit, C.A., Folke, C., Gerten, D., Heinke, J., Mace, G.M., Persson, L.M., Ramanathan, V., Reyers, B., Sorlin, S., 2015. Planetary boundaries: Guiding human development on a changing planet. Science 347(6223).Tegen, I., Fung, I., 1994. Modeling of mineral dust in the atmosphere: Sources, transport, and optical thickness. J. Geophys. Res. 99, 22897-22914.

Thinkstep, 2015. GaBi LCA Software [WWW Document]. URL http://www.thinkstep.com/software/gabi-lca/ Thomson, J.J., 1976. Killing, letting die, and the trolley problem. Monist 59, 204-217.

UNDESA, 2012. Total Population - Both Sexes, United Nations Department of Economic and Social Affairs [WWW Document]. World Population Prospects. 2012 Revis. URL http://esa.un.org/wpp/ExcelData/population.htm

USCB, 2012. United States Summary: 2010, Population and Housing Unit Counts, 2010 Census of Population and Housing. United States Census Bureau.

USCB, 2015. Annual Estimates of the Resident Population: April 1, 2010 to July 1, 2014. U.S. Census Bureau, Population Division [WWF Document]. URL http://factfinder.census.gov/faces/tableservices/jsf/pages/productview.xhtml?pid=PEP 2014 PEPAN NRES\&src $=p t$

Vuuren, D.P., Edmonds, J., Kainuma, M., Riahi, K., Thomson, A., Hibbard, K., Hurtt, G.C., Kram, T., Krey, V., Lamarque, J.-F., Masui, T., Meinshausen, M., Nakicenovic, N., Smith, S.J., Rose, S.K., 2011. The representative concentration pathways: an overview. Clim. Change 109, 5-31.

Warfvinge, P., Sverdrup, H., 1992. Calculating critical loads of acid deposition with PROFILE - A steady-state soil chemistry model. Water, Air, Soil Pollut. 63, 119-143.

WRI, 2005. Millennium Ecosystem Assessment: Ecosystems and human well-being. Synthesis. Island Press, World Resources Institute, Washington, DC.

Zijp, M.C., Posthuma, L., van de Meent, D., 2014. Definition and Applications of a Versatile Chemical Pollution Footprint Methodology. Environ. Sci. Technol. 48, 10588-10597. 
Click here to download high resolution image

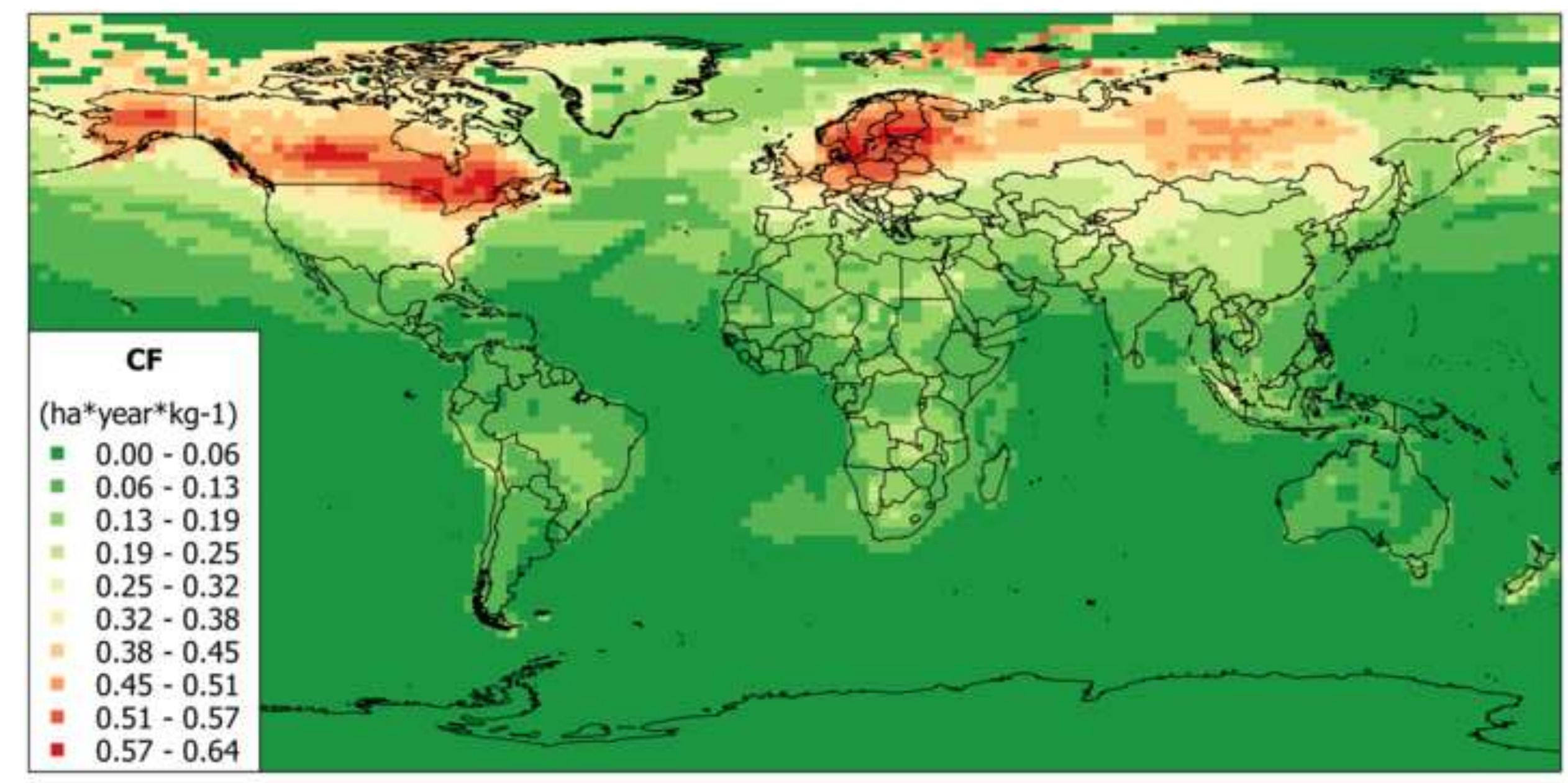


Click here to download high resolution image
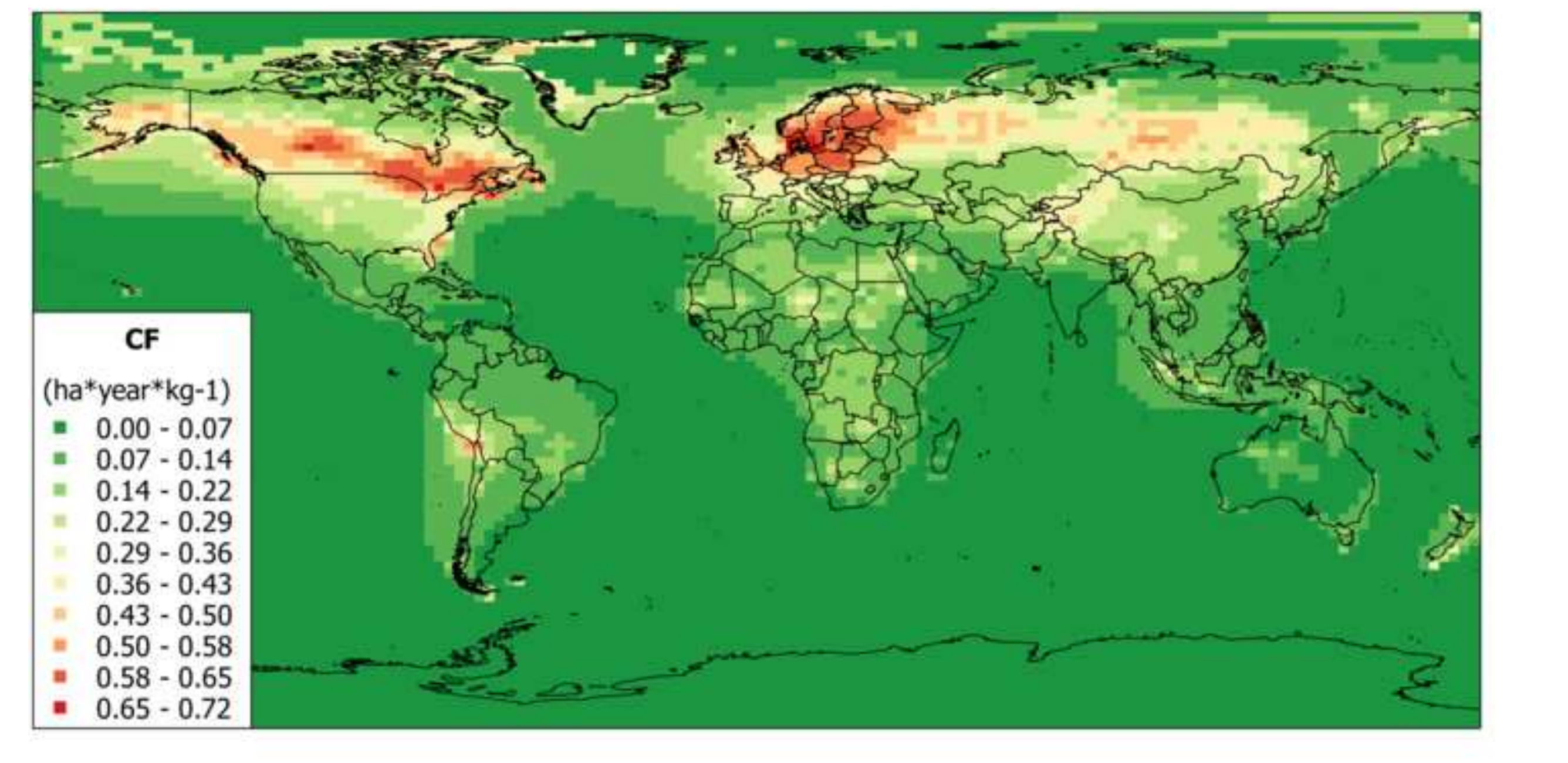

.

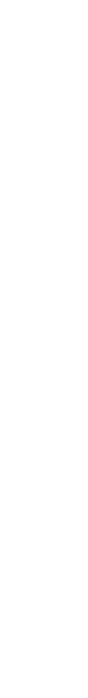


Click here to download high resolution image
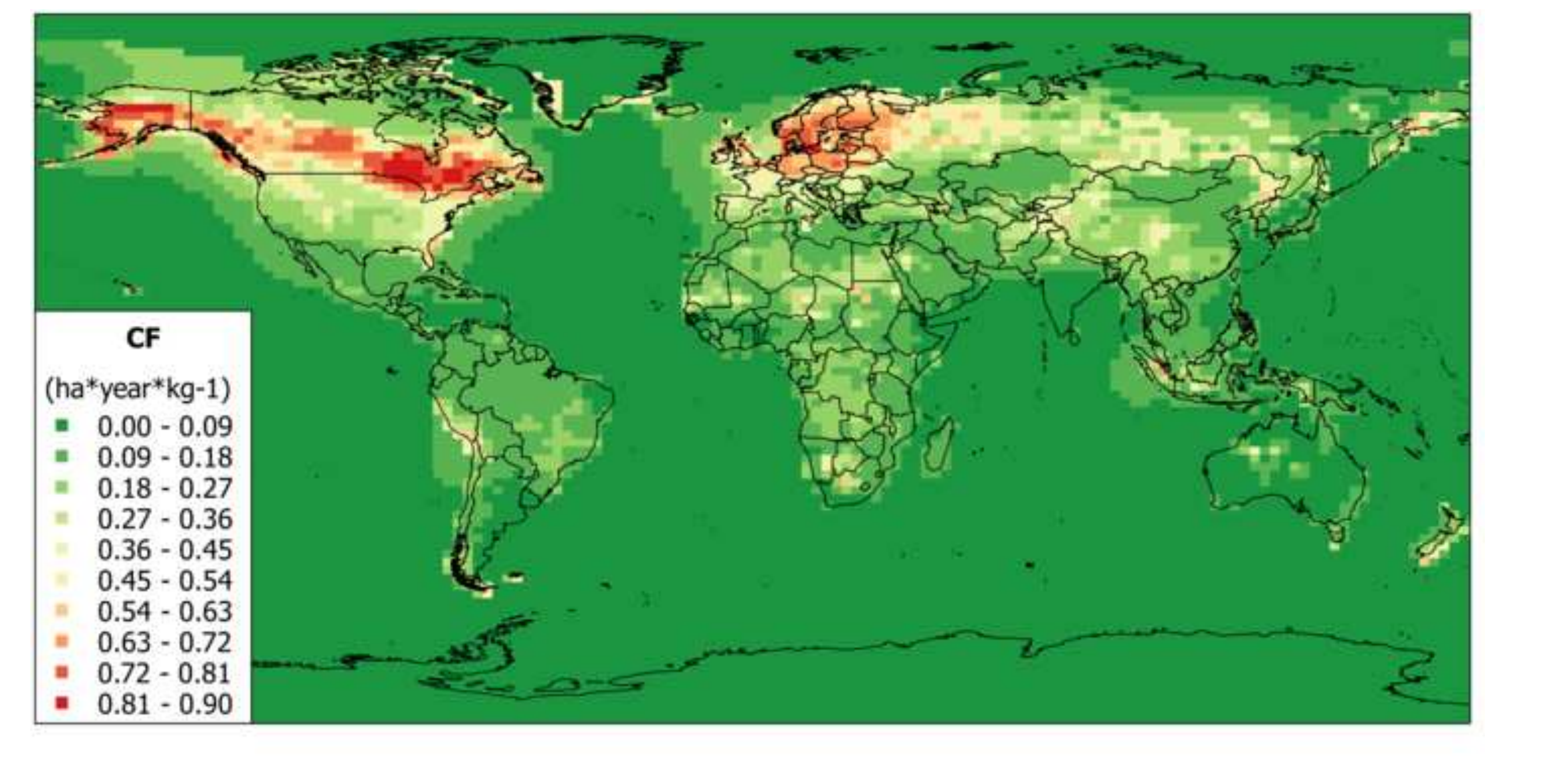


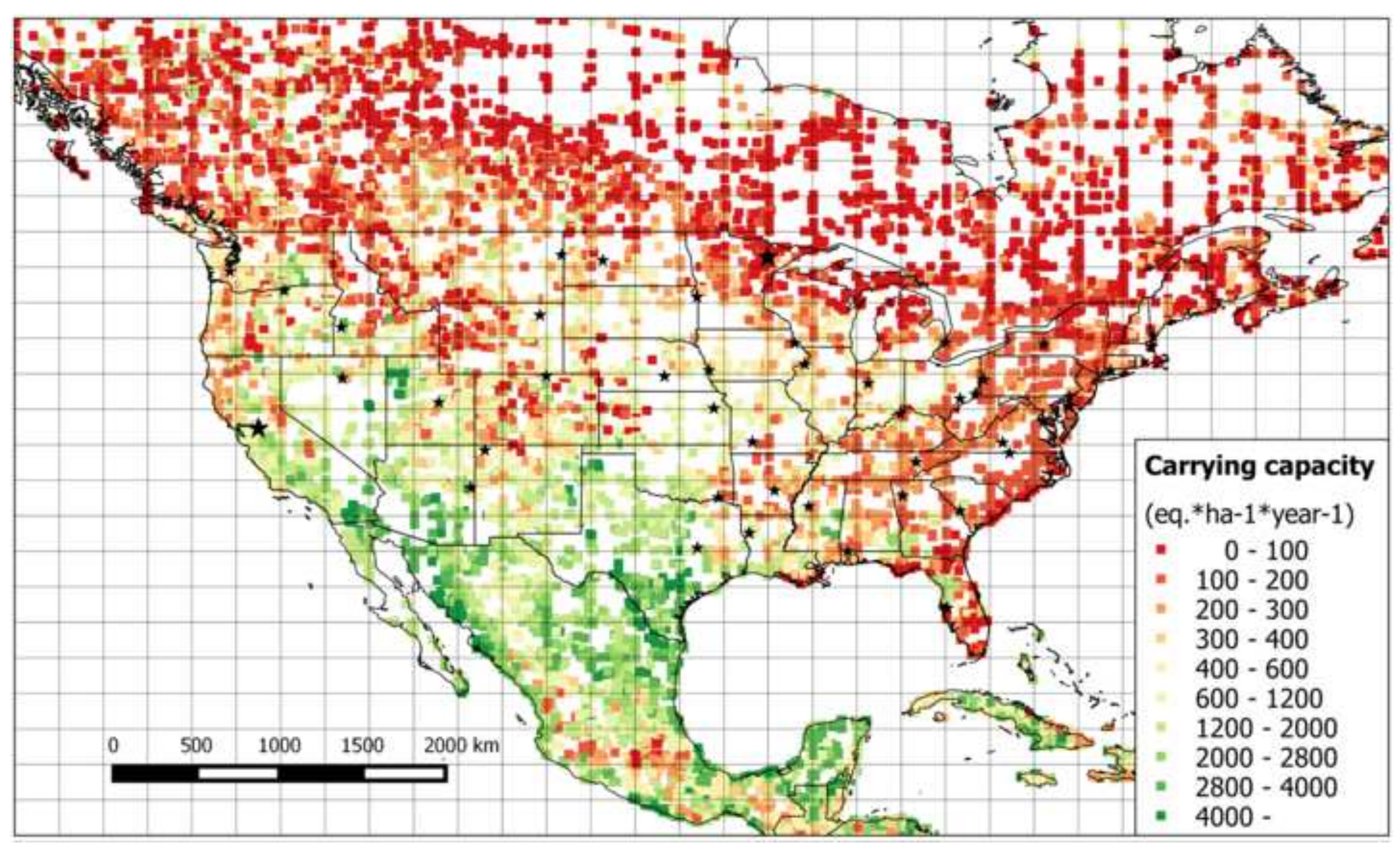

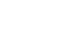

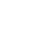

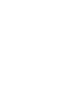

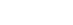

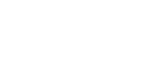
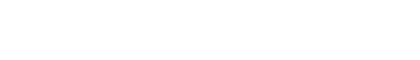

\begin{abstract}
(a)
\end{abstract}


Click here to download high resolution image

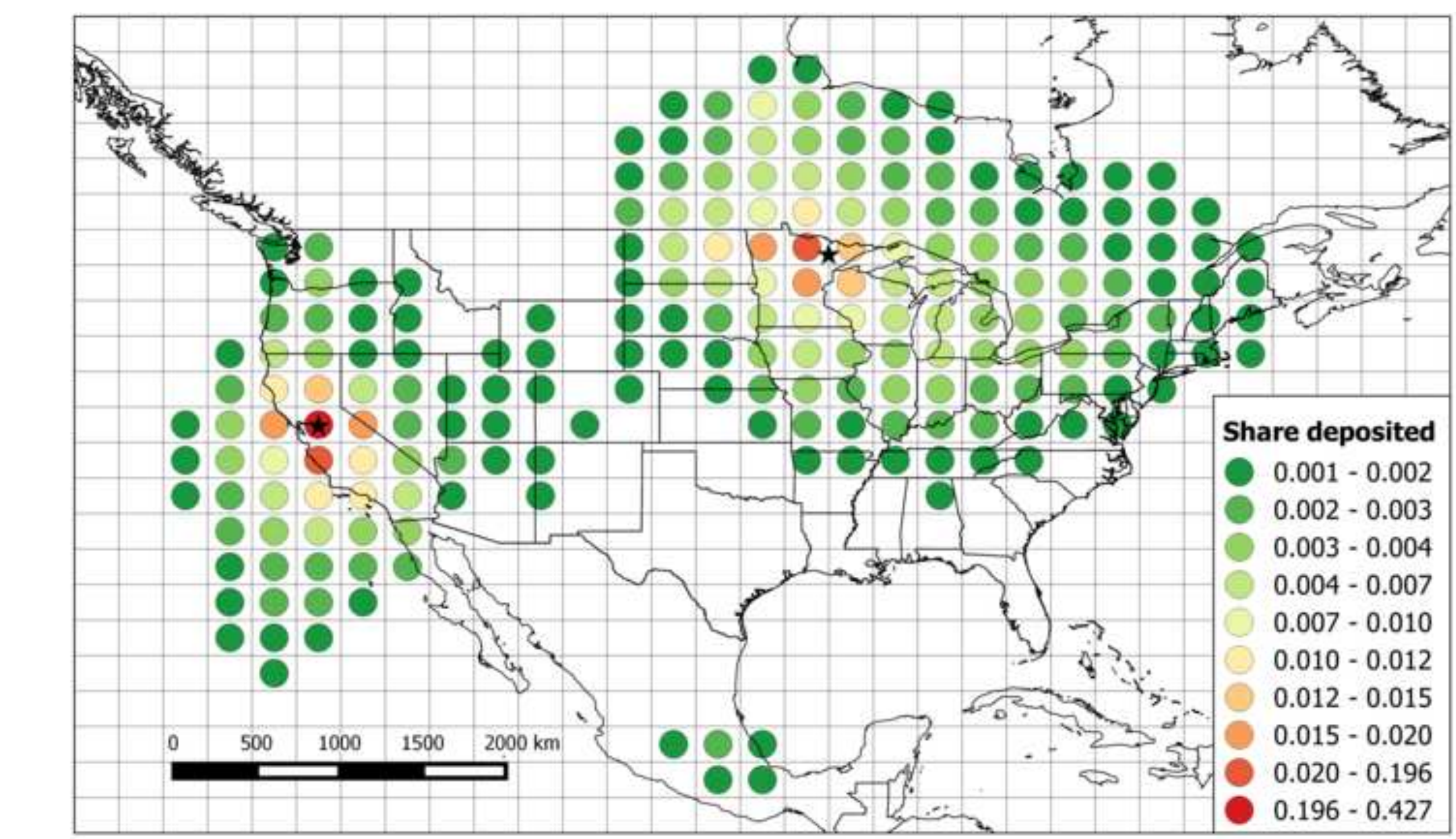


Figure 2

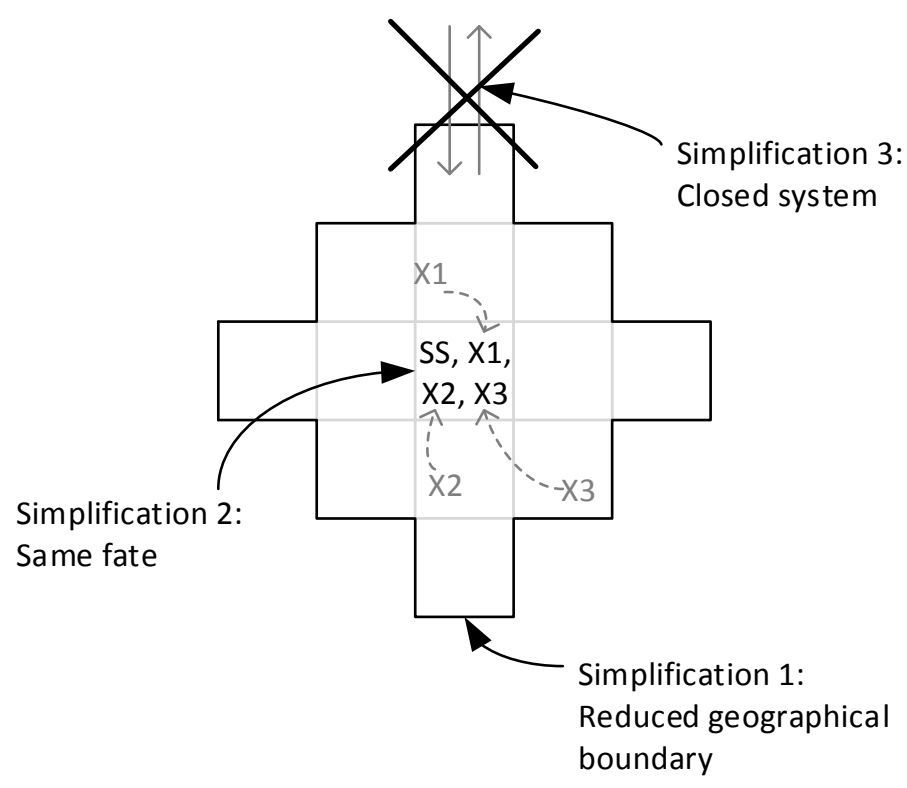




\section{Supporting information}

\section{A proposal to measure absolute environmental sustainability in Life Cycle Assessment}

Anders Bjørn ${ }^{1}$, Manuele Margni ${ }^{2}$, Pierre-Olivier Roy ${ }^{2}$, Cécile Bulle ${ }^{3}$ and Michael Zwicky Hauschild $^{1}$

${ }^{1}$ The Technical University of Denmark, Produktionstorvet, Building 424, $2800 \mathrm{Kgs}$. Lyngby, Denmark ${ }^{2}$ CIRAIG, Polytechnique Montréal, 2500, chemin Polytechnique, H3T 1J4, Montréal (QC), Canada

${ }^{3}$ CIRAIG, Ecole des Sciences de la Gestion, Université du Québec à Montréal, 315, rue Sainte-Catherine Est, H2X 3X2, Montréal (QC), Canada

E-mail contact : anbjo@dtu.dk

\section{Contents}

1. Linear and marginal approaches in LCA indicators ….................................................................... 2

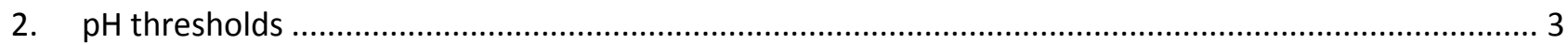

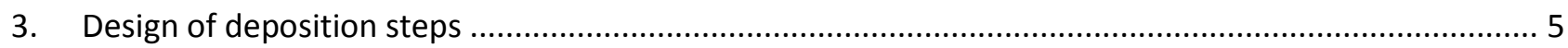

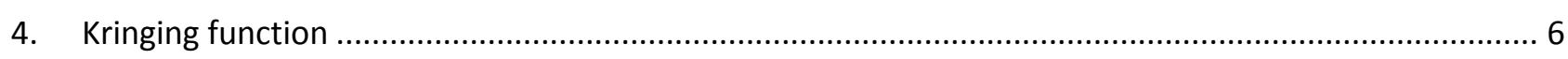

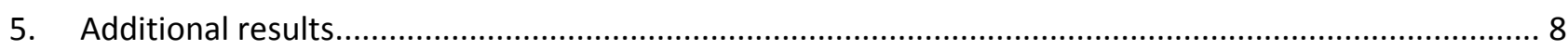

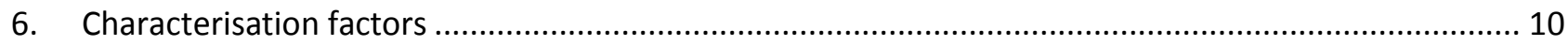

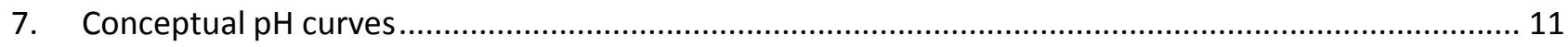

8. Key choices in the AESI for terrestrial acidification ...................................................................... 14

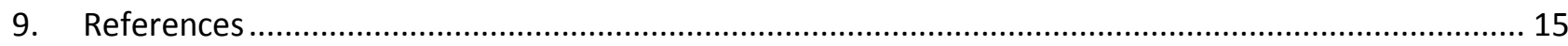




\section{Linear and marginal approaches in LCA indicators}

Figure S1.1 shows the two different approaches to calculating small changes in environmental interference from small changes in emissions and resource use.

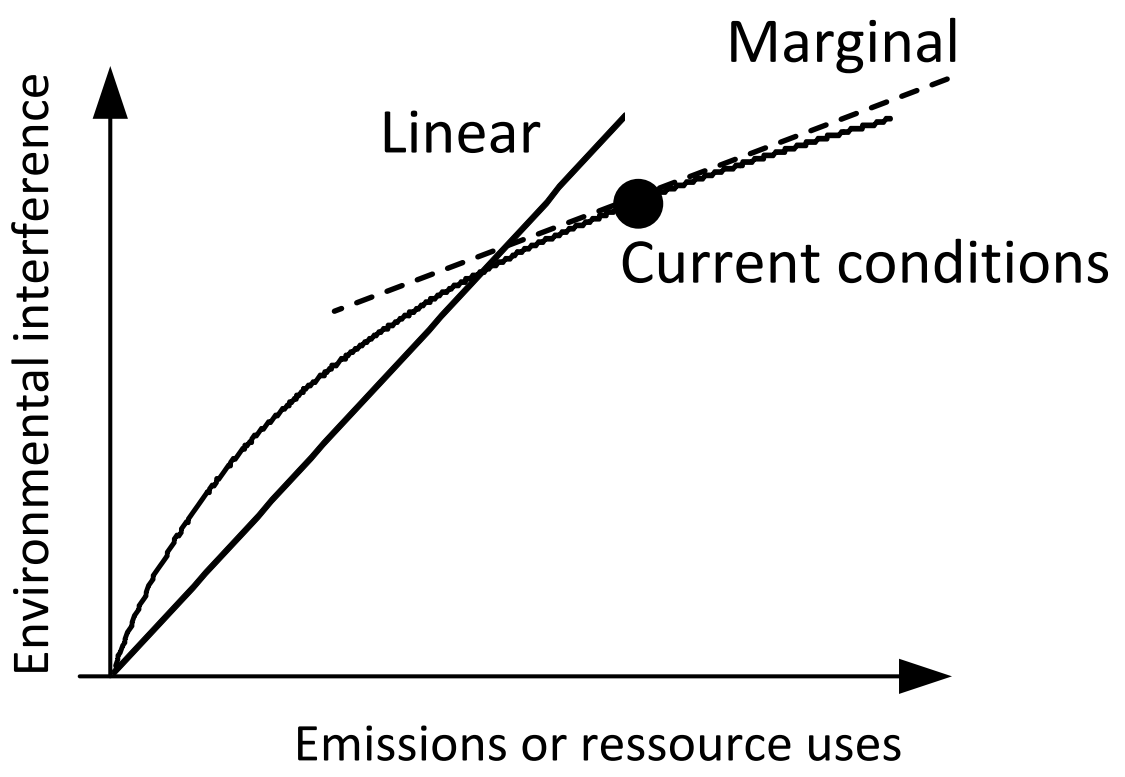

Figure S1.1: Linear and marginal approach in LCA indicators for a cause-effect curve. 


\section{2. pH thresholds}

To determine a $\mathrm{pH}$ threshold the $\mathrm{pH}$ for 70 random grid cells was simulated using PROFILE in a sequence of 71 steps. In the first step only grid specific natural depositions, from e.g. lightning, eruptive and noneruptive volcanoes, were modelled based on Tegen \& Fung (1994) and Bey et al. (2009). In the subsequent 70 steps the average background deposition of $\mathrm{SO}_{\mathrm{x}}$ (approx. $0.1 \mathrm{keq} / \mathrm{ha} / \mathrm{year}$ ) was increased by a factor of 5 for each step so that the average background deposition of $\mathrm{SO}_{\mathrm{x}}$ increase was by a factor 350 at the final step 70.

Figure S2.1 shows the simulated $\mathrm{pH}$ variations for three representative receiving grid cells according to an increase of deposition above the natural deposition. Depositions corresponding to a pH decrease of 0.25 and an absolute minimum $\mathrm{pH}$ of 4 are indicated.

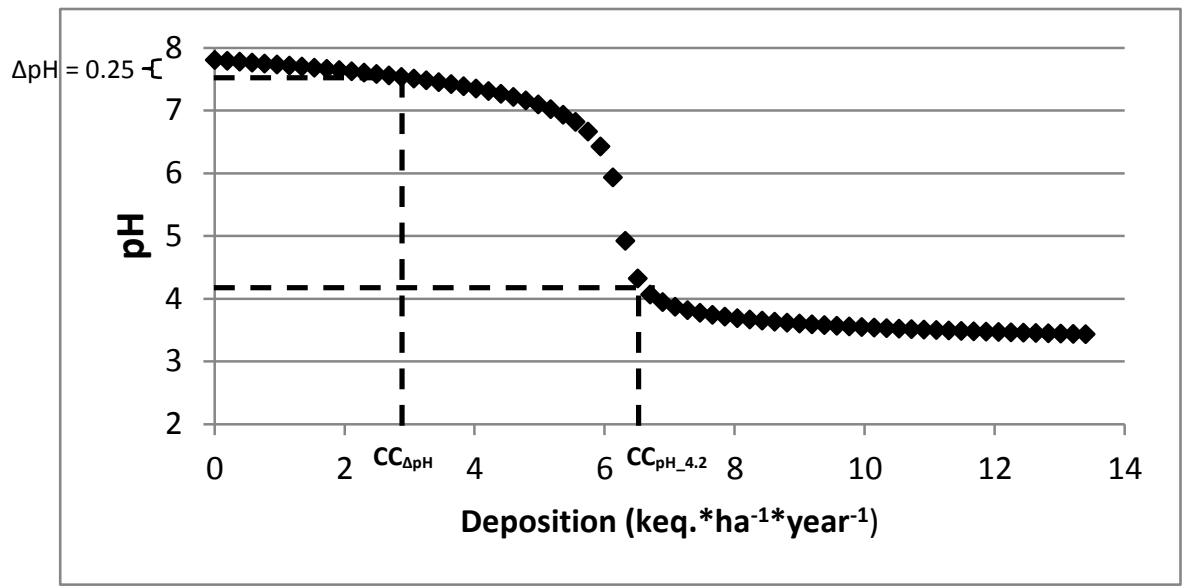

\section{a) grid cell \#129}

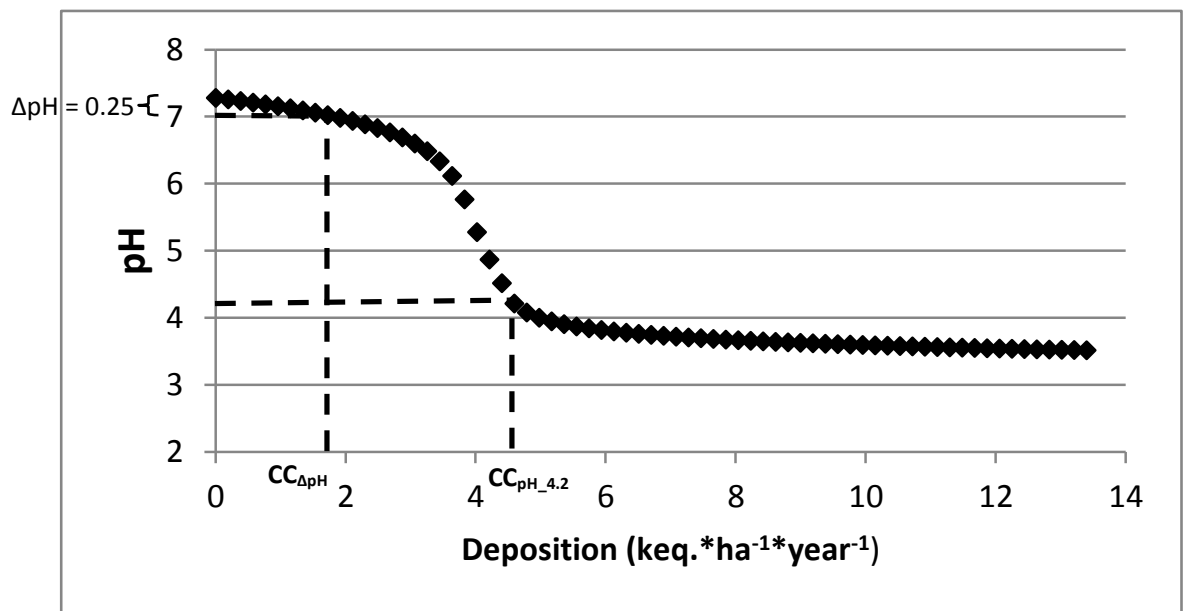

b) grid cell \#999 


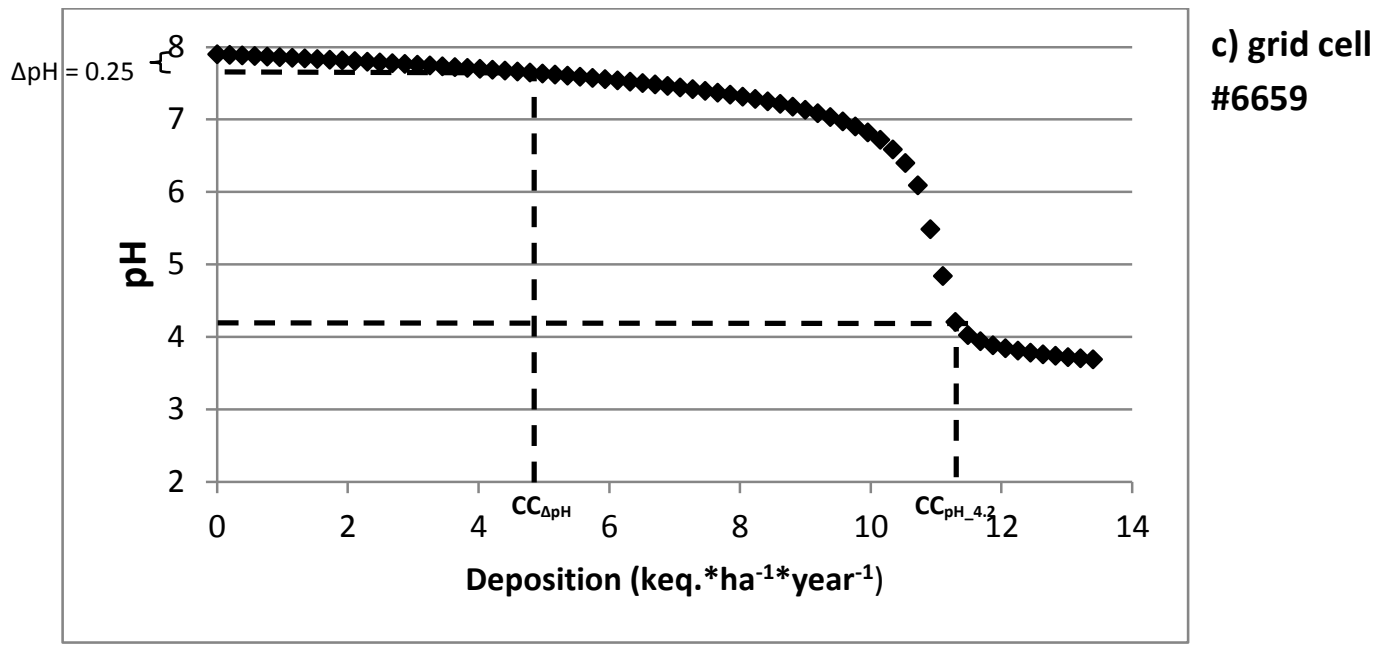

Figure S2.1: $\mathrm{pH}$ variations of receiving environment grid cell according to an increase of deposition of $\mathrm{SO}_{\mathrm{x}}$ above natural emissions for three representative receiving grid cells. Carrying capacities (CC) corresponding to a pH decrease of 0.25 and an absolute minimum $\mathrm{pH}$ of 4 are indicated. 


\section{Design of deposition steps}

Carrying capacity (eq. ${ }^{*}$ ha $^{-1} *$ year $^{-1}$ ) was calculated for the 70 random grid cells presented in S2 based on the 71 deposition steps. 1 eq refers to $1 \mathrm{~mol} \mathrm{H}^{+}$-eq. From this the distribution presented in Figure S3.1 was obtained.

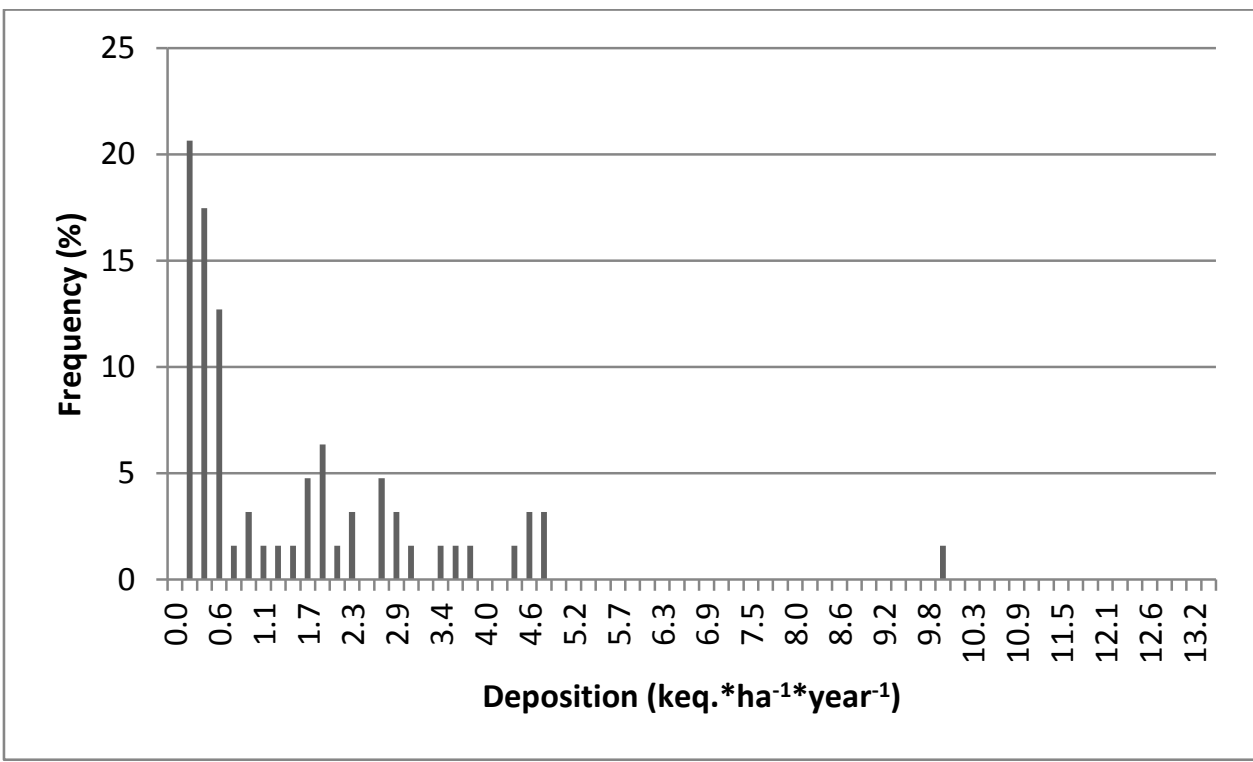

Figure S3.1: Threshold distribution for the $\mathbf{7 1}$ steps increasing deposition above natural emissions by a factor of 0 to 350.1 keq refers to $1000 \mathrm{~mol} \mathrm{H+-eq}$.

It appear that the distribution of carrying capacities in all grid cells may be best be described by a log normal distribution, since the highest frequency of carrying capacities are just above 0 and a long tail in the distribution can be observed as depositions are increased. In designing the deposition steps we aimed for a uniform distribution of grid cell carrying capacities, in other words $\approx 10 \%$ falling into each interval. We did not carry out more than 9 steps due to the computational capacity required to model pH for 99,515 cells in each deposition step. This lead to the carrying capacity intervals and values used in CF calculations shown in table S3.1:

Table S3.1: Deposition intervals

\begin{tabular}{|l|l|l|}
\hline Step & Carrying capacity interval & Carrying capacity used for CF calculations \\
\hline$\#$ & eq $^{*} a^{-1}{ }^{-1}$ year $^{-1}$ & eq $^{*} a^{-1}$ year $^{-1}$ \\
\hline 1 & $<100$ & 50 \\
\hline 2 & $100-200$ & 150 \\
\hline 3 & $200-300$ & 250 \\
\hline 4 & $300-400$ & 350 \\
\hline 5 & $400-600$ & 500 \\
\hline 6 & $600-1200$ & 900 \\
\hline 7 & $1200-2000$ & 1600 \\
\hline 8 & $2000-2800$ & 2400 \\
\hline 9 & $2800-4000$ & 3400 \\
\hline NA & $>4000$ & 5000 \\
\hline
\end{tabular}




\section{Kringing function}

The function is presented in a Matlab script below

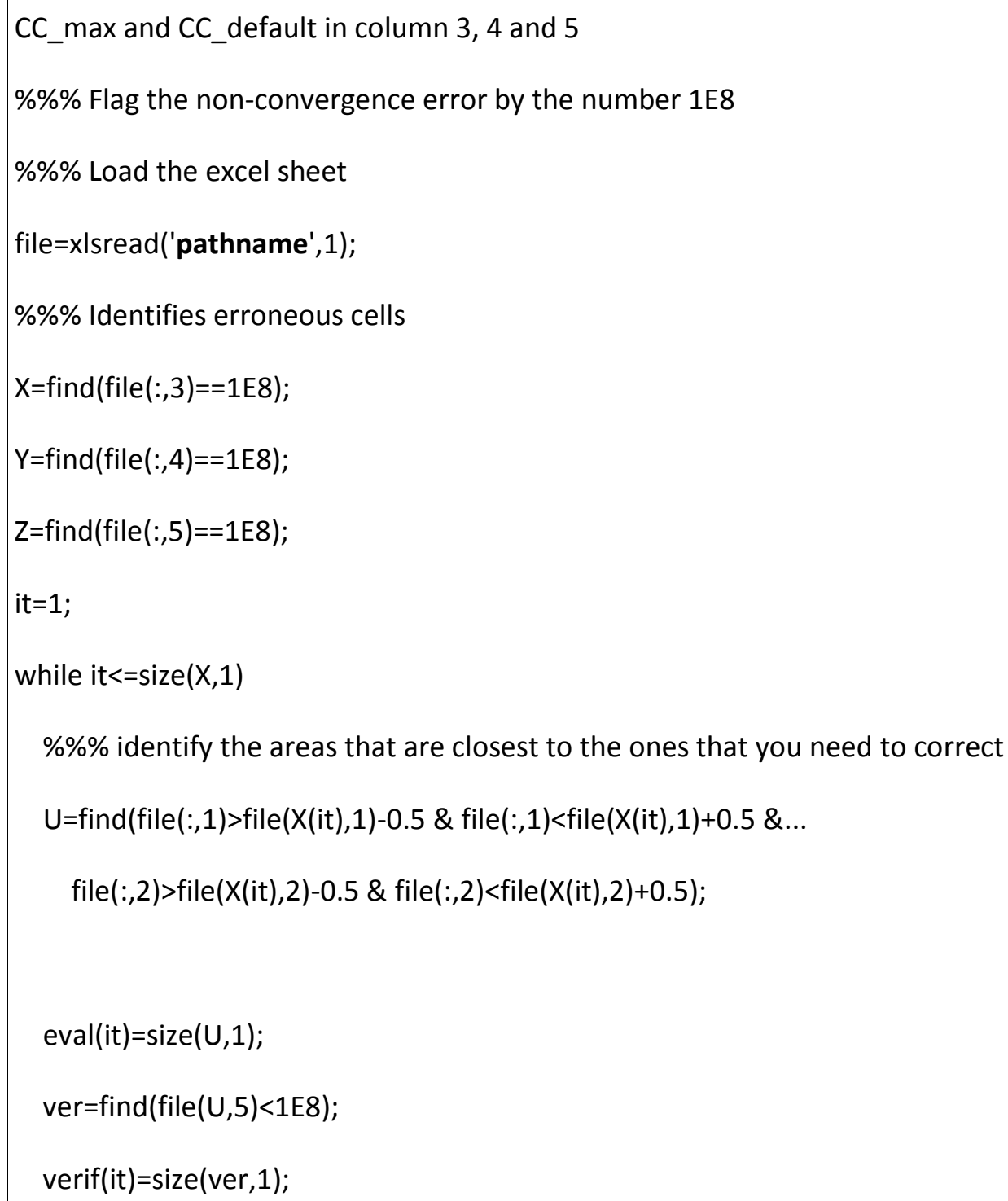




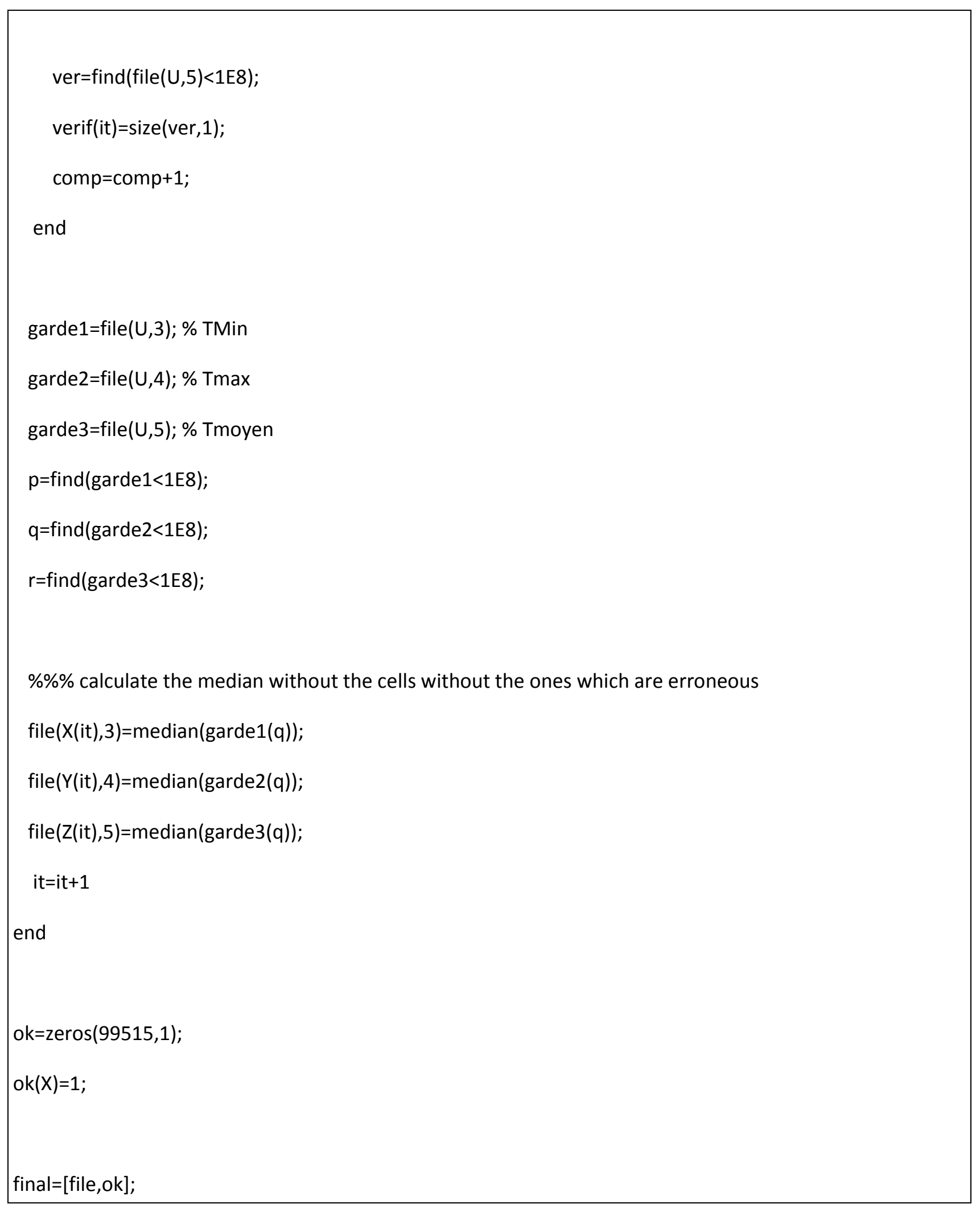




\section{Additional results}

Figure S5.1 shows the global distribution of carrying capacity. By comparison the soil sensitivity factors (SF) of Roy \& Desche (2012) for $\mathrm{NO}_{x}, \mathrm{SO}_{\mathrm{x}}$ and $\mathrm{NH}_{\mathrm{x}}$ are shown in Figures S5.2-S5.4.

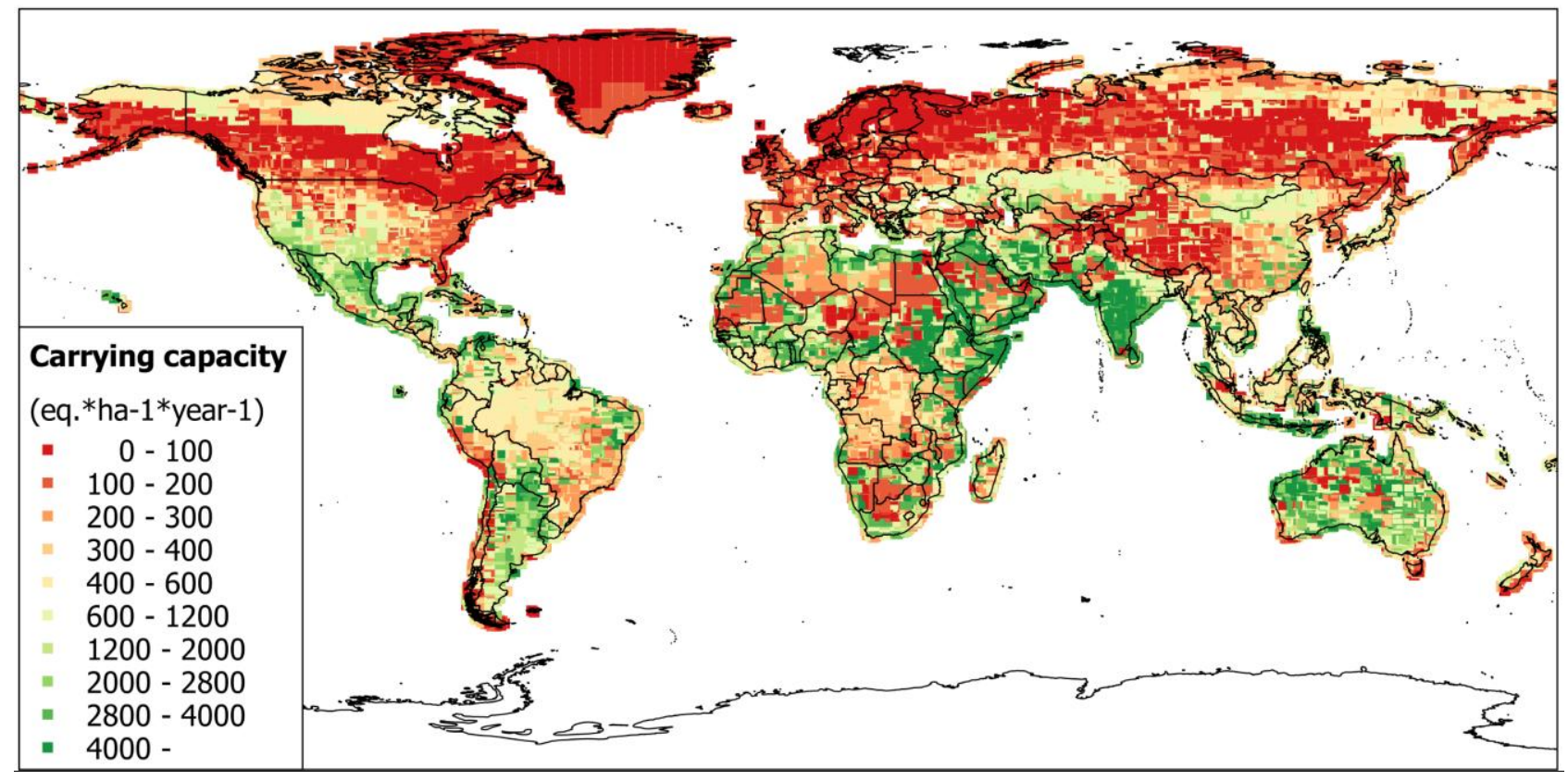

Figure S5.1: Carrying capacity.

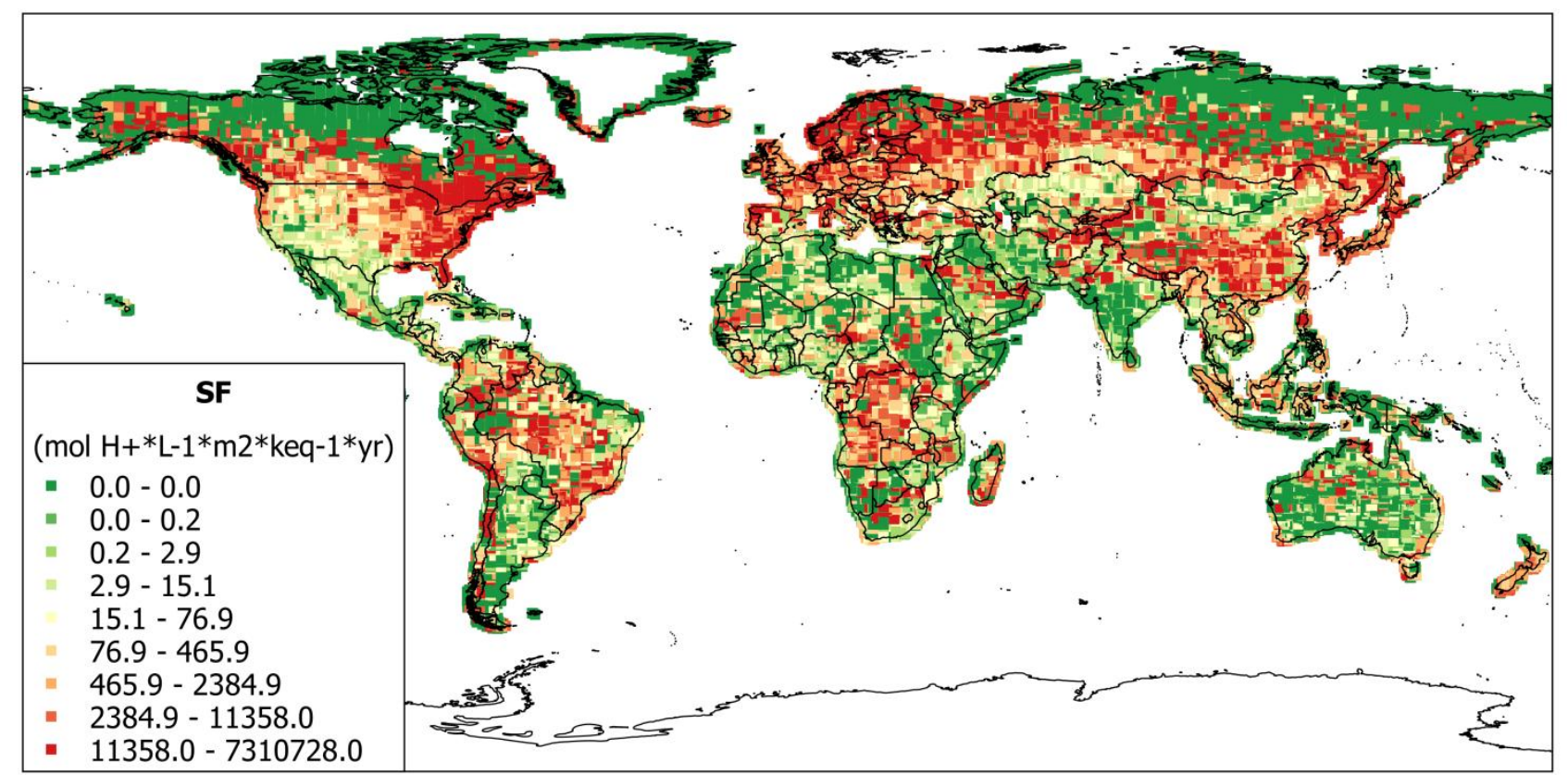

Figure S5.2: Soil sensitivity factors (SF) of Roy \& Desche (2012) for $\mathrm{NO}_{\mathrm{x}}$. 


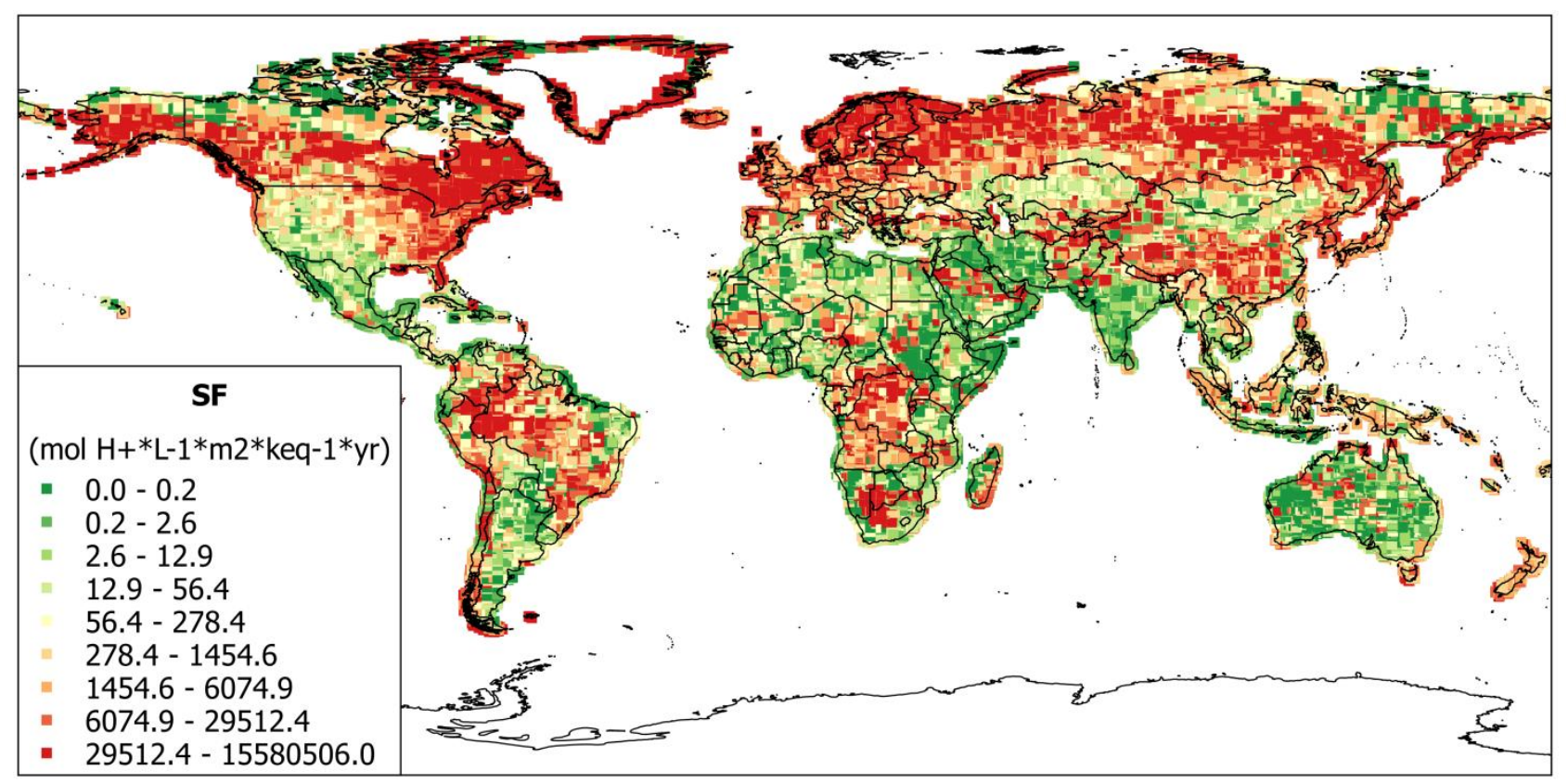

Figure S5.3: Soil sensitivity factors (SF) of Roy \& Desche (2012) for SO $_{x}$.

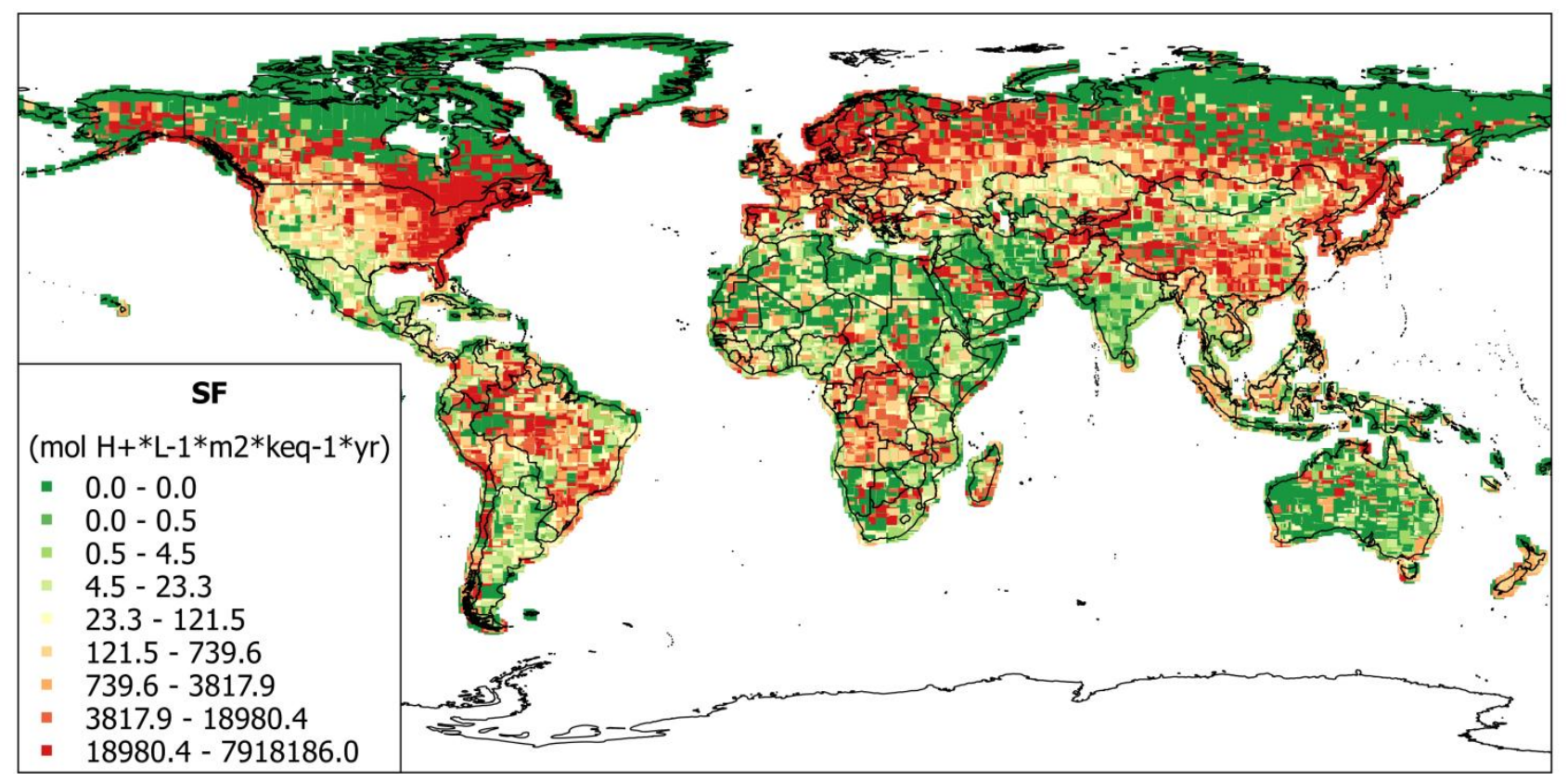

Figure S5.4: Soil sensitivity factors (SF) of Roy \& Desche (2012) for $\mathrm{NH}_{\mathrm{x}}$. 


\section{Characterisation factors}

See Excel sheet for CFs for $\mathrm{SO}_{x}, \mathrm{NO}_{\mathrm{x}}$ and $\mathrm{NH}_{\mathrm{x}}$. The GIS coordinates correspond to the lower left corner of grid cells. 


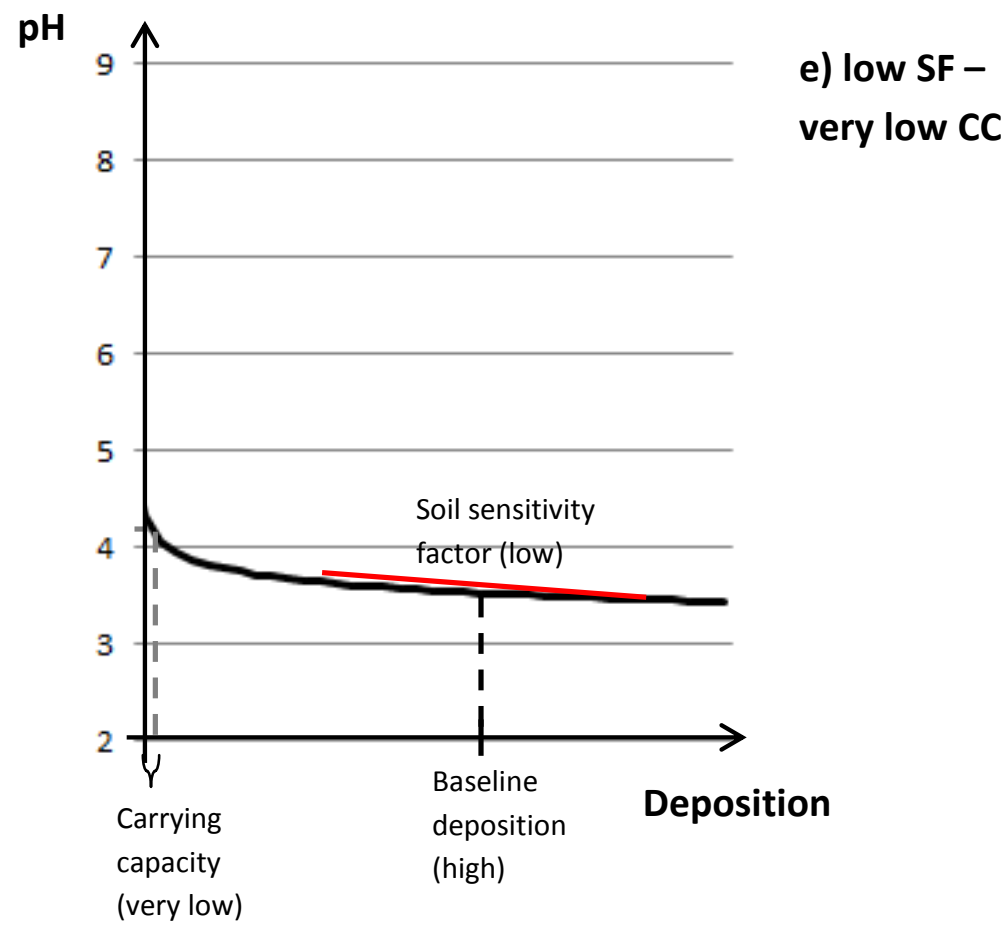

Figure S7. Response in $\mathrm{pH}$ to deposition for 5 cases combining values of natural pH and baseline depositions. Soil sensitivity factors (SF) and carrying capacities (CC) are categorized accordingly. 


\section{Key choices in the AESI for terrestrial acidification}

In our modification of the indicator of Roy et al. (2014) we chose two complementary threshold values based on the two points of the $\mathrm{pH}$ curve where the carbonate buffering system starts weakening and where the mobilisation of aluminium starts to occur. As environmental sustainability references other $\mathrm{pH}$ related threshold values could be applied, for example by taking the $\mathrm{pH}$ sensitivity of vegetation into account, as proposed in the critical loads concept (Spranger et al. 2004). We could also have applied a control variable more directly related to the sensitivities of ecosystems, such as "potentially disappeared fraction of species" (PDF), which is a common damage indicator in LCA. In this case a corresponding threshold value of a sustainable minimum level of species diversity should be chosen. The change in indicator score from changing choices of control variable and threshold value is important to quantify in the effort of managing and reducing overall uncertainties in indicator scores.

We furthermore calculated a substance generic carrying capacity from simulation of $\mathrm{pH}$ responses to increasing depositions of $\mathrm{SO}_{x}$. However depositions of similar quantities of $\mathrm{H}^{+}$equivalents can cause different responses in $\mathrm{pH}$ for nitrogen containing pollutants $\left(\mathrm{NO}_{\mathrm{x}}\right.$ and $\mathrm{NH}_{\mathrm{x}}$ ) than for $\mathrm{SO}_{\mathrm{x}}$ due to the effect of nitrogen uptake processes in vegetation across soils. To reduce the uncertainty introduced by calculating substance generic carrying capacity, simulations of $\mathrm{pH}$ response to stepwise increasing depositions of $\mathrm{NO}_{\mathrm{x}}$ and $\mathrm{NH}_{\mathrm{X}}$ should be carried out in the same manner as they were done for $\mathrm{SO}_{\mathrm{x}}$ here.

Thirdly, due to the approach of determining carrying capacities from simulated $\mathrm{pH}$ responses to stepwise increases of deposition, the range of carrying capacity values was in fact determined by the carrying capacity values assigned to grid cells for which threshold were crossed at the first deposition step and grid cells for which thresholds were not crossed at deposition step 9. In this study the former was assigned a value of $50 \mathrm{eq}^{*} \mathrm{ha}^{-1}{ }^{\text {year }}{ }^{-1}$ (the middle of the $0-100 \mathrm{eq}^{*} \mathrm{ha}^{-1} * \mathrm{year}^{-1}$ interval in which the actual carrying capacity lies according to PROFILE) and the latter an arbitrary value of 5000 eq $^{*}$ ha $^{-1} *$ year $^{-1}$ (the deposition at step 9 was 4000 eq $^{*}$ ha $^{-1} *$ year $^{-1}$ ). The sensitivity of CFs to the assignment of minimum and maximum carrying capacities could be easily tested. If large uncertainties should be reduced by obtaining more realistic minimum and maximum carrying capacity values from additional simulations in PROFILE. 


\section{References}

Bey, I., Jacob, D. J., Yantosca, R. M., Logan, J. A., Field, B. D., Fiore, A. M., ... Schultz, M. G.,2009. Global modeling of tropospheric chemistry with assimilated meteorology: Model description and evaluation.

Roy, P.-O., Deschênes, L., Margni, M., 2012. Life Cycle Impact Assessment of Terrestrial Acidification: Modeling Spatially Explicit Soil Sensitivity at the Global Scale. Environ. Sci. Technol. Environ. Sci. Technol 46, 8270-8278.

Roy, P.-O., Azevedo, L.B., Margni, M., van Zelm, R., Deschênes, L., Huijbregts, M. A.a J., 2014.

Characterization factors for terrestrial acidification at the global scale: A systematic analysis of spatial variability and uncertainty. Sci. Total Environ. 500-501C, 270-276.

Spranger, T., Lorenz, U., \& Gregor, H.-D. (2004). Manual on methodologies and criteria for Modelling and Mapping Critical Loads \& Levels and Air Pollution Effects, Risks and Trends (p. 266). Berlin.

Tegen, I., Fung, I., 1994. Modeling of mineral dust in the atmosphere: Sources, transport, and optical thicknessMODELING OF MINERAL DUST IN THE ATMOSPHERE - SOURCES, TRANSPORT, AND OPTICALTHICKNESS. J. Geophys. Res. 99, 22897-22914. 


\begin{tabular}{|c|c|c|c|}
\hline Longitude & Latitude & Nox & $\mathrm{NHx}$ \\
\hline-180 & -90 & 0 & 0 \\
\hline-177.5 & -90 & 0 & 0 \\
\hline-175 & -90 & 0 & 0 \\
\hline-172.5 & -90 & 0 & 0 \\
\hline-170 & -90 & 0 & 0 \\
\hline-167.5 & -90 & 0 & 0 \\
\hline-165 & -90 & 0 & 0 \\
\hline-162.5 & -90 & 0 & 0 \\
\hline-160 & -90 & 0 & 0 \\
\hline-157.5 & -90 & 0 & 0 \\
\hline-155 & -90 & 0 & 0 \\
\hline-152.5 & -90 & 0 & 0 \\
\hline-150 & -90 & 0 & 0 \\
\hline-147.5 & -90 & 0 & 0 \\
\hline-145 & -90 & 0 & 0 \\
\hline-142.5 & -90 & 0 & 0 \\
\hline-140 & -90 & 0 & 0 \\
\hline-137.5 & -90 & 0 & 0 \\
\hline-135 & -90 & 0 & 0 \\
\hline-132.5 & -90 & 0 & 0 \\
\hline-130 & -90 & 0 & 0 \\
\hline-127.5 & -90 & 0 & 0 \\
\hline-125 & -90 & 0 & 0 \\
\hline-122.5 & -90 & 0 & 0 \\
\hline-120 & -90 & 0 & 0 \\
\hline-117.5 & -90 & 0 & 0 \\
\hline-115 & -90 & 0 & 0 \\
\hline-112.5 & -90 & 0 & 0 \\
\hline-110 & -90 & 0 & 0 \\
\hline-107.5 & -90 & 0 & 0 \\
\hline-105 & -90 & 0 & 0 \\
\hline-102.5 & -90 & 0 & 0 \\
\hline-100 & -90 & 0 & 0 \\
\hline-97.5 & -90 & 0 & 0 \\
\hline-95 & -90 & 0 & 0 \\
\hline-92.5 & -90 & 0 & 0 \\
\hline-90 & -90 & 0 & 0 \\
\hline-87.5 & -90 & 0 & 0 \\
\hline-85 & -90 & 0 & 0 \\
\hline-82.5 & -90 & 0 & 0 \\
\hline-80 & -90 & 0 & 0 \\
\hline-77.5 & -90 & 0 & 0 \\
\hline-75 & -90 & 0 & 0 \\
\hline-72.5 & -90 & 0 & 0 \\
\hline-70 & -90 & 0 & 0 \\
\hline-67.5 & -90 & 0 & 0 \\
\hline
\end{tabular}

